(C) Copyright 2018

Allison Elizabeth Brown 


\title{
Conservation Communication and Photography: Conversations with Marine Conservation Photographers
}

\author{
Allison Elizabeth Brown \\ A thesis \\ submitted in partial fulfillment of the \\ requirements for the degree of \\ Master of Marine Affairs \\ University of Washington \\ 2018 \\ Committee: \\ Marc L. Miller \\ Edward Allison \\ P. Sean McDonald \\ Program Authorized to Offer Degree: \\ Marine and Environmental Affairs
}




\title{
University of Washington
}

\begin{abstract}
Conservation Communication and Photography:

Conversations with Marine Conservation Photographers
\end{abstract}

\author{
Allison Elizabeth Brown \\ Chair of the Supervisory Committee: \\ Marc L. Miller, Ph.D. \\ School of Marine and Environmental Affairs
}

This thesis announces the emergent field of marine conservation photography. A communications theory approach is used to discuss the conservation communication aspect of photography and a semi-structured interviewing approach is taken to record and interpret the thoughts and histories of marine conservation photographers. Key themes found in the words of eight of these artists and conservationists include money, love, work, education and positivity. Marine conservation photography can be considered an occupation, a hobby, an activity, and a purpose. The field of marine conservation photography itself is a strong tool for organizations to use for fundraising, education, awareness, and campaigning. The communication theory and semi-structured interviewing approach taken in this body of work could be extended to many other domains in marine and environmental affairs. 


\section{TABLE OF CONTENTS}

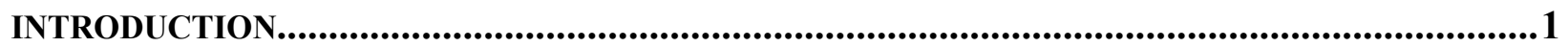

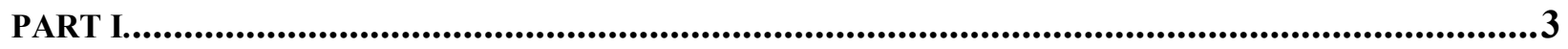

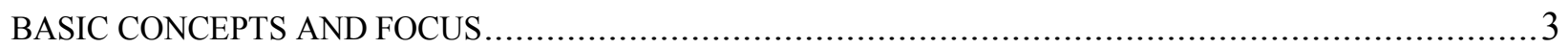

Chapter 1. Communication Perspectives and Conservation ............................................

Chapter 2. Marine ConSERVAtion Photography And Communication ....................................... 22

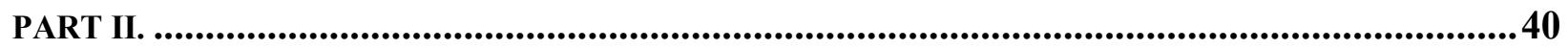

CONVERSATIONS WITH MARINE CONSERVATION PHOTOGRAPHERS ....................................... 40

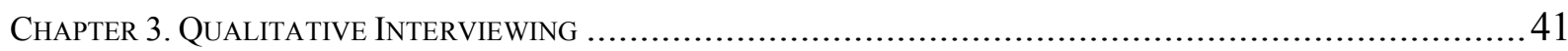

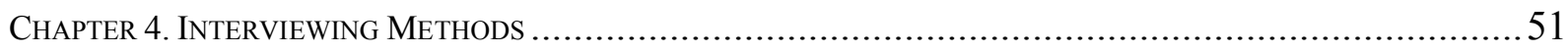

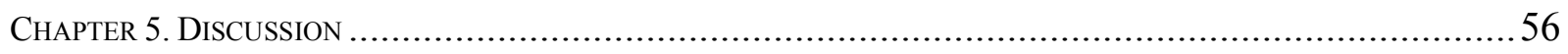

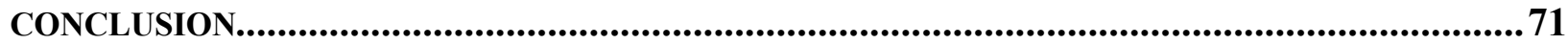

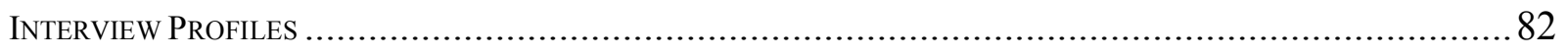




\section{ACKNOWLEDGEMENTS}

Many thanks to my advisor and thesis chair Marc L. Miller whose enthusiasm, imagination, guidance, and support of a thesis topic that is off the beaten path is a major reason all these pages are present. I would like to recognize my parents for attempting to calm me down when my plate got full of responsibilities and my cat, Loki, for succeeding. Thanks to Bryan Pelach, my co-advisee, who sat through many meetings where we talked solely about my thesis and not his and gamely offered his essential advice and opinions.

Finally, I want to express my appreciation to the eight kind and generous marine conservation photographers who agreed to an interview and took time out of their busy schedules to chat with me. 


\section{DEDICATION}

This thesis is dedicated to the incredible marine conservation photographers practicing their craft in challenging conditions and with limited resources. Because of your dedication to your work, so many people have been touched by the sea. 


\section{INTRODUCTION}

"When words become unclear, I shall focus with photographs. When images become inadequate, I shall be content with silence" (Ansel Adams).

The field of Marine and Environmental Affairs is diverse. It deals with issues of marine pollution policy and management, the blue-green economy, fisheries management, techniques for environmental monitoring, emerging patterns of economic and political development, governance of tourism and recreation, sustainability of coastal communities and livelihoods, benefits of marine protection, resilience in local ecosystems adaptation to ocean change, and issues of sustainable seafood and aquaculture. Many of these have to do with regulation, science, and policy, but the field must also involve communications. Communication is both a necessity and a tool for influencing others.

Communication is the reason the field of conservation photography exists. Conservation photography revolves around taking and using images for the purpose of inspiring conservation. To inspire conservation requires communication. Many of the photographs one sees that are labeled or assumed as conservation photography are terrestrial focused. All conservation issues on land do affect the ocean to some extent, but there are also conservation photos that primarily deal with marine issues and these photos fit into the emergent field of marine conservation photography.

This thesis delineates a field called marine conservation photography, as yet undefined, as a subset of the more generic field of conservation photography. The definition is informed by conversations with multiple marine conservation photographers. The goal is not to devalue conservation photography or to muddy the waters with an excessive number of terms and subdefinitions, but rather to register marine conservation photography in the academic literature as an occupation, hobby, activity and purpose. The field of marine conservation photography deserves recognition and attention in academic and occupational areas and providing it with a definition and a discussion is a first step in its establishment as a subject of study in the fields of marine conservation and marine affairs. 


\section{Plan of This Thesis}

This thesis consists of two parts. Part I deals with communication and photography concepts that orient a newcomer to this field. Chapter 1 discusses varying assessments of communication and models of communication. Assorted terms that are useful for discussing communication are introduced and conservation communication is defined. Chapter 2 examines photography and how it is categorized. Conservation photography, the power images hold, and a definition of marine conservation photography is incorporated. Lastly, there is a model portrayal of an example of how marine conservation photography communicates.

Part II contains a discussion of the semi-structured and elite interviewing used in this thesis as well as the research methods used in obtaining and presenting interviews that were conducted. Chapter 3 explains semi-structured and elite interviewing as well as general considerations for preparing for, conducting and presenting interviews. Chapter 4 details the methods of collecting interviews from Marine Conservation Photographers as well as methods for editing and presentation of the interviews. Chapter 5 identifies themes that appeared amongst the interviews conducted, provides an analysis of the answers to the posed research questions, and discusses limitations and challenges that occurred during the interview collection and processing period.

In the appendix there are edited interview transcripts from conversations with Marine Conservation Photographers. 
PART I.

BASIC CONCEPTS AND FOCUS 


\title{
CHAPTER 1. COMMUNiCATION PERSPeCtives AND CONSERVATION
}

This chapter discusses communication and a selection of the theory and models that make up the discipline. This chapter also includes an examination of environmental and conservation communication and explains why humans communicate.

\section{A. Perspectives on Communication}

\author{
"We are born into, and inhabit, a world without "meaning." That life becomes \\ intelligible to us - full of beauty or ugliness, hope or despair - is because it is \\ assigned that significance by the experiencing being” (Barnlund, 1962:457).
}

One cannot discuss conservation communication without first discussing communication itself. This is no easy feat, as communication does not have a single definition (Lewenstein, 1995; Littlejohn \& Foss, 2010). The many definitions of communication can be simple, such as: "Communication is the process of exchanging ideas and imparting information," or complex such as: "Communication can be understood as the practice of producing meanings, and the ways in which systems of meaning are negotiated by participants in a culture" (Jacobson, 2009; Schirato \& Yell, 2000). Another, more specific definition is: "Communication occurs when humans manipulate symbols to stimulate meaning in other humans" (Infante, Rancer, \& Womack, 2003).

The breadth of definitions for communication are wide and varied due to the multiple approaches to the study of communication as a field, the fact that it is an inexact science, and because it is complex, multifaceted, contextual, and culturally determined (Infante et al., 2003). Dr. Dominic A. Infante, who was a professor emeritus in the School of Communication Studies at Kent State University, discussed his view of the nature of communication and the characteristics it exhibits in the comprehensive and definitive work, Building Communication Theory (2003). Infante et al., believe communication is "a social, symbolic process that occurs in a context" (Infante et al., 2003:9). 
Infante draws on Cronkhite (1986) to discuss the characteristic that "communication is a symbolic process" (Cronkhite, 1986:9). Symbols are "deliberately created to represent something" and once a symbol, whether physical or non-physical, is agreed upon it can be used to cause others to think of the object, action, or idea represented. This does not always work as intended by the communicator because all individuals interpret symbols differently and it is our different interpretations that help create our individuality. Infante et al., postulate that the "communication discipline is the only one that focuses primarily on the activity of using symbols" (Infante et al., 2003:9).

"Symbolic action" is a term used by Kenneth Burke in the book Language as Symbolic Action (1968). In Burke's view the terminology and language we use are symbolic acts that are necessarily persuasive and make up our reality. In fact, Burke believes that symbolic action is what we see as reality, though it is only a subset of such. He states, "Even if any given terminology is a reflection of reality, by its very nature as a terminology it must be a selection of reality; and to this extent it must function also as a deflection of reality" (Burke, 1968). Burke urges us to "bring ourselves to realize just how overwhelmingly much of what we mean by 'reality' has been built up for us through nothing but our symbol systems." He suggests that without "our profound and inveterate involvement in symbol systems" much of our reality would not exist for us because a considerable amount of what we hear of or see is not immediate, but only reaches us through symbol systems that report on anything non-immediate to an individual.

The differing interpretation of symbols, is also touched on by Burke. He believes that the symbols we use are seen by others through many different lenses or "terministic screens" (Burke, 1968). Through these screens, we perceive the world. Burke gives the example of a man reporting a dream he had to multiple people who each belong to different schools of thought about dream meanings. He gives the example of a Freudian Analyst, a Jungian, and an Adlerian. In each case the dream the man had might be interpreted differently. Each of the people the dream is reported to see it through a different terministic screen and that screen is their school of thought or their field. The lexicon we use directs attention to one field or another, but that can be taken further to say that the observations we see are "implications of the particular terminology in terms of which the observations are made" (Burke, 1968). These screens affect what we see as reality, "in brief, much that we take as observations about 'reality' may be but the spinning out possibilities implicit in our particular choice of terms" (Burke, 1968:46). Burke uses terminology 
as the symbol in this philosophy, but this could reasonably be applied to any symbolic action including artistic genres such as photography and protests, where words are not necessarily used (J. R. Cox, 2012). How, where, and what is presented as well as who it is presented to and their preconceived notions will affect the observations about it, and therefore the perceived reality.

Infante et al., believe communication must be a social process, as in include both human beings and intention. They are narrowing down the nature of communication. Infante et al., say that communication is separate from cognition and that communication "does not necessarily occur whenever we perceive something," or whenever someone notices anything they would be communicating" (Infante et al., 2003:9). Infante et al., "limit the term communication to refer to the intentional exchange of symbols between human beings" and argue that communication is something that cannot be done by one person. They also note that this does not require verbal communication but does require "co-orientation" or "two individual's mutual awareness of each other" (Infante et al., 2003:10). Later I will posit that two individuals need not necessarily be in such mutual awareness of each other as to be in the same room for example, but may in fact communicate through symbols that have been distributed prior. For example, a photograph in a gallery.

Finally, Infante et al., assert that communication is contextual and occurs in different situations and places that give the communication different characteristics and can alter the meaning derived from a message. The generally agreed upon, non-mutually exclusive contexts for communication are interpersonal, small group, organizational, public, mass, intercultural, family, health, and political (Infante et al., 2003). These contexts are defined by Infante $e t$ al. (2003:12), below:

- Interpersonal-Communication between two people

- Small group-Communication involving several people

- Organizational - Communication within and between organizations

- Public - a speaker addressing a large audience

- Mass - communication mediated by electronic or print media

- Intercultural - communication between people of different cultures

- Family-Communication between family members

- Health-Communication involving health care providers and health care receivers 
- Political - Communication involving the governing part of our society

For the purposes of this thesis a new definition of communication can be formed. Communication will be defined as the social process of stimulating meanings and feedback in other humans via symbolic actions shared within a context. Further investigation into past communication models can shed light on how I arrived at this definition. I would like to acknowledge that this definition is limited to human-human communication and the fascinating ethological field incorporating human-animal, animal-animal, and even animal-human communication is avoided.

\section{B. Classic Communication Models}

Communication is a factor in every field of study and every interaction and, to reflect its ubiquitous nature, those who study it come from a wide range of backgrounds. With a background in the study of communications as the obvious, the fields that communication researchers, scholars, and teachers were raised in can vary from psychology (Christian A. Klöckner) to theatre arts (Robert Cox). Others come from the fields of anthropology (Edward T Hall), political science (Lance Bennett), journalism (Douglas Underwood), law (T. Barten Carter) and even resource ecology (Susan Jacobsen). The scholars and teachers from these differing backgrounds bring a variety of diverse perspectives to the study of communications. This diversity thus manifests itself in an assortment of communication models. What follows is a presentation and review of a selection of those models with the intent to develop an appropriate and pragmatic model for marine conservation photography. I present these models with the recognition that many more are not covered and there is a western oriented bias and gender oriented biases by both myself and the authors of the models. 


\begin{abstract}
Aristotle
Possibly the earliest model of communication was elaborated by the Greek philosopher Aristotle who explained the communication process before $300 \mathrm{BC}$. Many further models and theories in the western world are essentially elaborations on Aristotle's. Aristotle, in his work on rhetoric and with a focus on speech-giving, saw the act as consisting of three divisions "determined by the three classes of listeners to speeches. For of the three elements in speechmaking — speaker, subject, and person addressed - it is the last one, the hearer, that determines the speech's end and object" (Aristotle, 2000:226-227). After his rationalization of these, other scholars discussed his divisions and developed them into illustrations (Petersons \& Khalimzoda, 2016; Sveen, 2016) (Figure 1). Aristotle's model is simplistic and does not incorporate some important factors such as feedback, noise, or communication failure, which make an appearance in later models by other theorists.
\end{abstract}

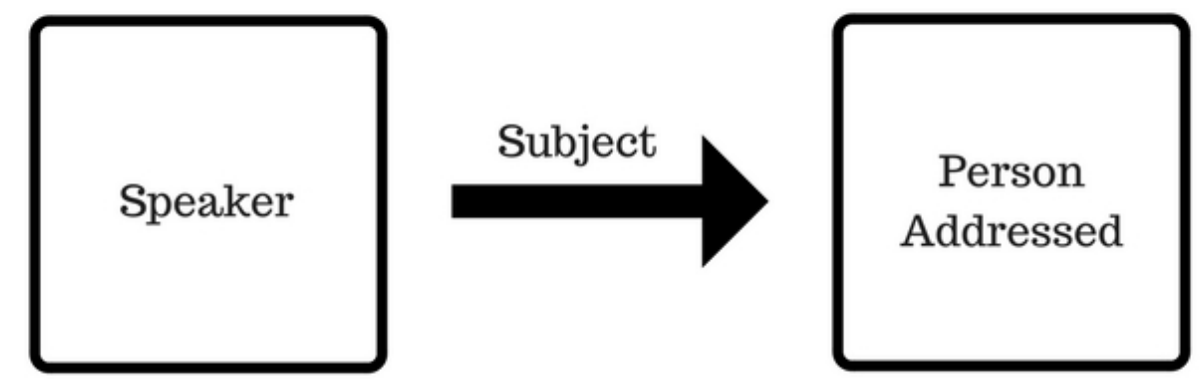

Figure 1. Recreation by author of Aristotle's simple communication model depicting three divisions of speaker, subject, and person addressed.

\title{
Lasswell
}

Harold Dwight Lasswell was an American political scientist and professor of law as well as a communications theorist. He had a bachelor's degree in philosophy and economics and was 
the director of war communications research at the Library of Congress during World War 2 (Encyclopædia Britannica, n.d.). He produced works on political psychology as well as propaganda and developed a linear model of communication in the 1930s based on a series of questions: Who? Says what? In which channel? To whom? With what effect? (Figure 2). This model is very similar to Aristotle's, which was likely used by the authors as a building block, but expanded to include communication occasions other than speeches.

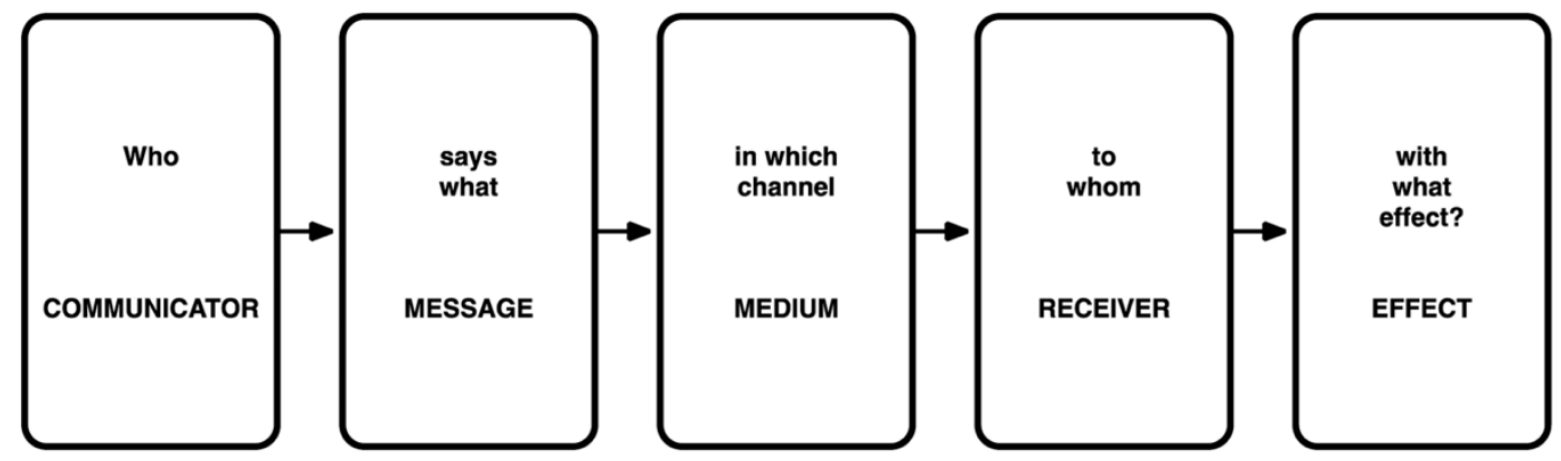

Figure 2. Representation of Harold Dwight Lasswell's communication model featuring five elements based on the sentence: Who says what in which channel to whom with what effect? (Sapienza, Iyer, \& Veenstra, 2015).

\section{Shannon-Weaver}

One of the conversations about communication models is on whether communication is linear, where information goes from a sender to a receiver via a medium, or transactional, where people are constantly influencing each other via their relationships. A continuation of the linear views that were presented by Aristotle and Laswell was proposed by Claude Shannon and Warren Weaver in 1949. Claude Shannon approached the model with a background in mathematics and electrical engineering as well as experience working in cryptography during World War 2, which largely influenced his communication theory. Warren Weaver, who had a background in civil engineering, contributed to the model by explaining in the book that Weaver 
wrote, The Mathematical Theory of Communication, why it had implications for a more general audience and not simply the technical audience Shannon had skewed it towards (Shannon \& Weaver, 1975). The model incorporates the notion of "noise" distorting or interfering with a message (Figure 3).

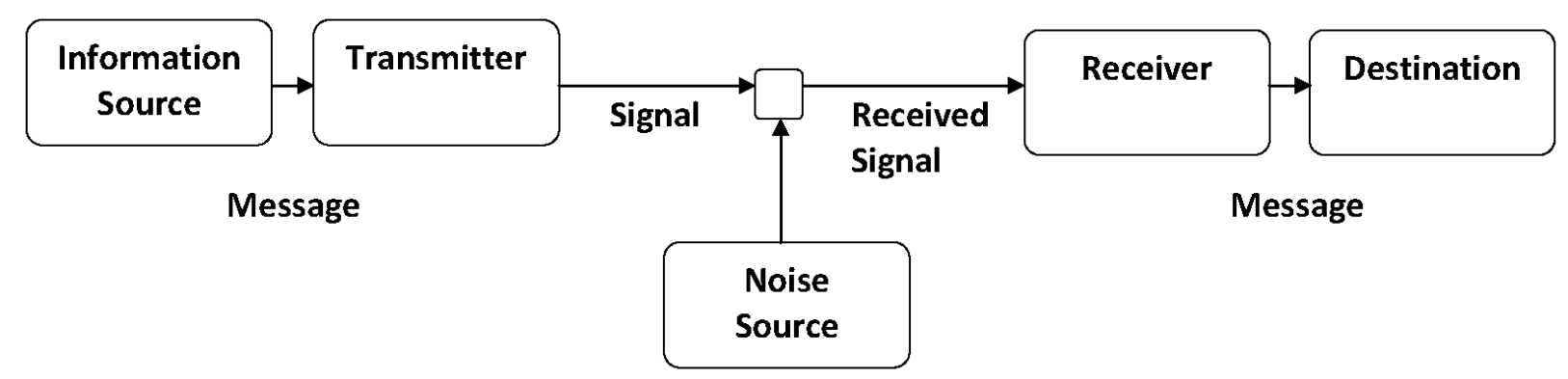

Figure 3. Representation of the Shannon-Weaver communication model which features the idea of noise affecting a message (Shannon \& Weaver, 1975).

This model, and the Lasswell and Aristotle models, are linear and do not account for meaning or the modes in which communication acts on our awareness (J. R. Cox, 2012; Shannon \& Weaver, 1975). In short, this model is too simplistic. The transactional version of communication grows from recognition that communication is planned and it has evolved from the linear view as the field of communication has progressed. Dean Barnlund, whose model is presented next, equated all linear models:

“(These) models reflect such conceptual kinship as clearly to have sprung from the same epistemological ancestry. They are alike in their basic elements, alike in their postulated relations, alike in their social implications. All employ a cosmology that emphasizes structure over function, object over relation, element over variable, linearity over circularity, additivity over non-additivity; all reify object, stimulus or message, and all presume behavior to be externally determined" (D. C. Barnlund, 1981:90). 


\section{Dean Barnlund}

A transactional view of communication assumes that "communication involves people sending each other messages that reflect the motivations of the participants" (Infante et al., 2003). This connects to a related view by Kenneth Burke, introduced in the beginning of this chapter, that even the most unemotional language and discourse is necessarily persuasive and all symbolic acts do something more than just transmit information (Burke, 1968). Communication includes the expectation of a response by the person receiving the message and that response provides more nuance to the communication situation. The transactional nature of communication theory is more detailed and allows for hidden or deeper meanings within a communication event. It evolves communication theory from the thought that communication is linear to the thought that communication is circular (D. C. Barnlund, 1962). Dean Barnlund incorporated the transactional aspect in his model which heavily concentrated on meaning creation.

Barnlund was an eclectic world traveler interested in art and architecture who harbored "personal preferences for honesty in design, precision, integrity of concept, and a vision of the whole" which show in his academic work and communication model (Bennett, 2012:781). Like Claude Shannon he worked in cryptography during World War 2. Barnlund had a doctorate from Northwestern University in The School of Speech and a meaning-centered perspective on communication rather than a message-centered perspective.

In a message-centered perspective the aim is simply to transmit information and "success hinges on mastery of the facts, effective arrangement of materials, and strength of expression" (Barnlund, 1962:455). Barnlund goes so far as to call this amoral as well as inadequate. The reasoning behind the inadequacy of the message-centered perspective is that the listener is neglected as an endpoint of the communication and there is a failure to explain how meaning occurs through communication (D. C. Barnlund, 1962). Barnlund's position goes beyond previous models and takes into account that "messages may be generated from the outside - by a speaker, a television screen, a scolding parent - but meanings are generated from within" 
(Barnlund, 1962:457). Barnlund's theory is nicely, though of course not comprehensively, summed up in one quote:

"What I am describing is a meaning-centered philosophy of communication. It admits that meaning in the sender, and the words of the messages are important, but regards as most critical the state of mind, the assumptive world and the needs of the listener or observer" (Barnlund, 1962:458).

Barnlund's theory also presents itself in the form of models, albeit seemingly complex ones. The models are simply more detailed than previous ones discussed in this paper and have the ability to show a more comprehensive roadmap of how a communication situation will play out (D. Barnlund, 1970). Barnlund believes communication is always happening, even when a person is alone, so he offers a model of one such situation (Figure 4), as well as a situation involving two people (Figure 5). These models are adaptable and easily modified to fit multiple communication situations.

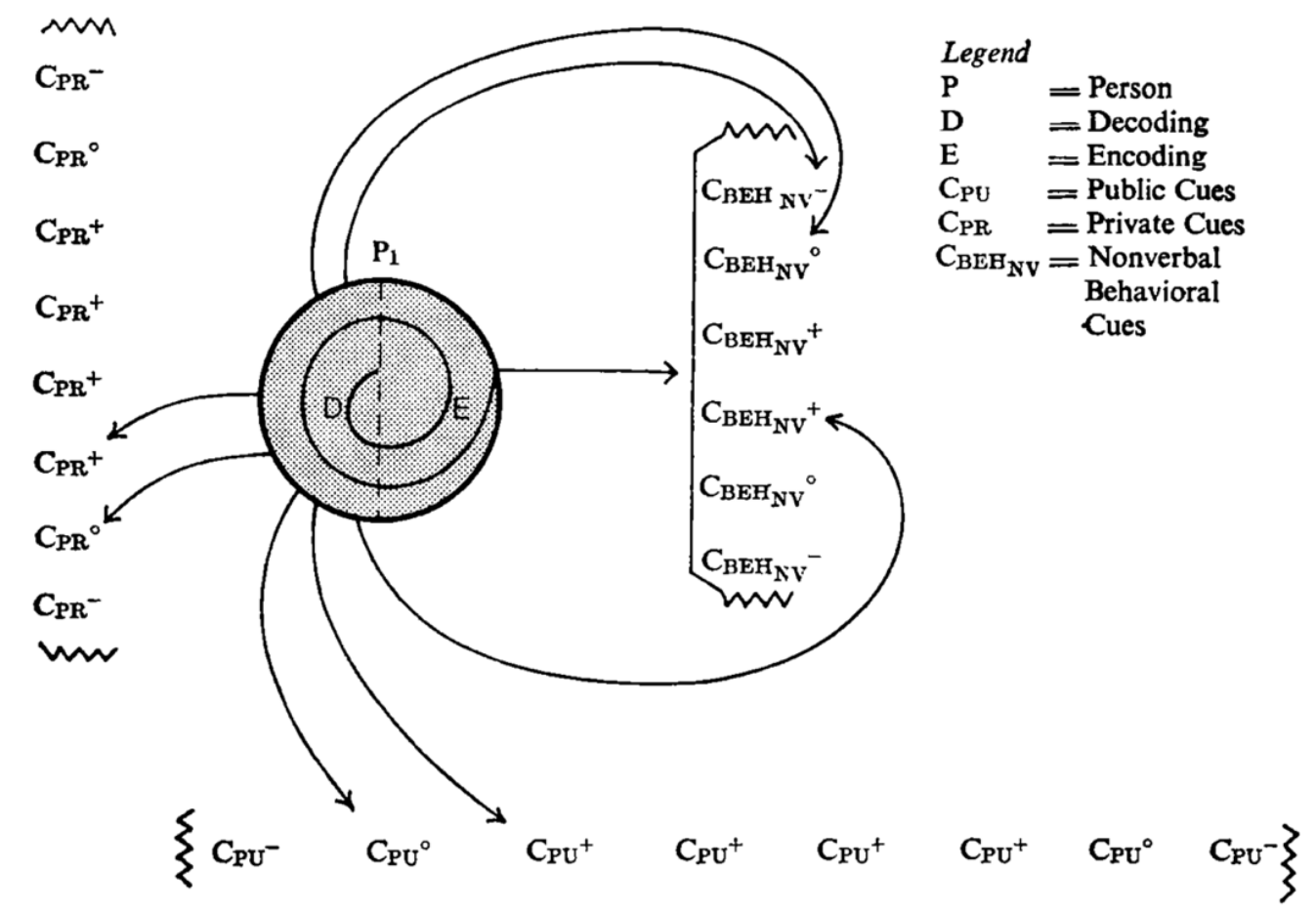

Figure 4: Dean Barnlund's intrapersonal model of communication (D. Barnlund, 1970). 


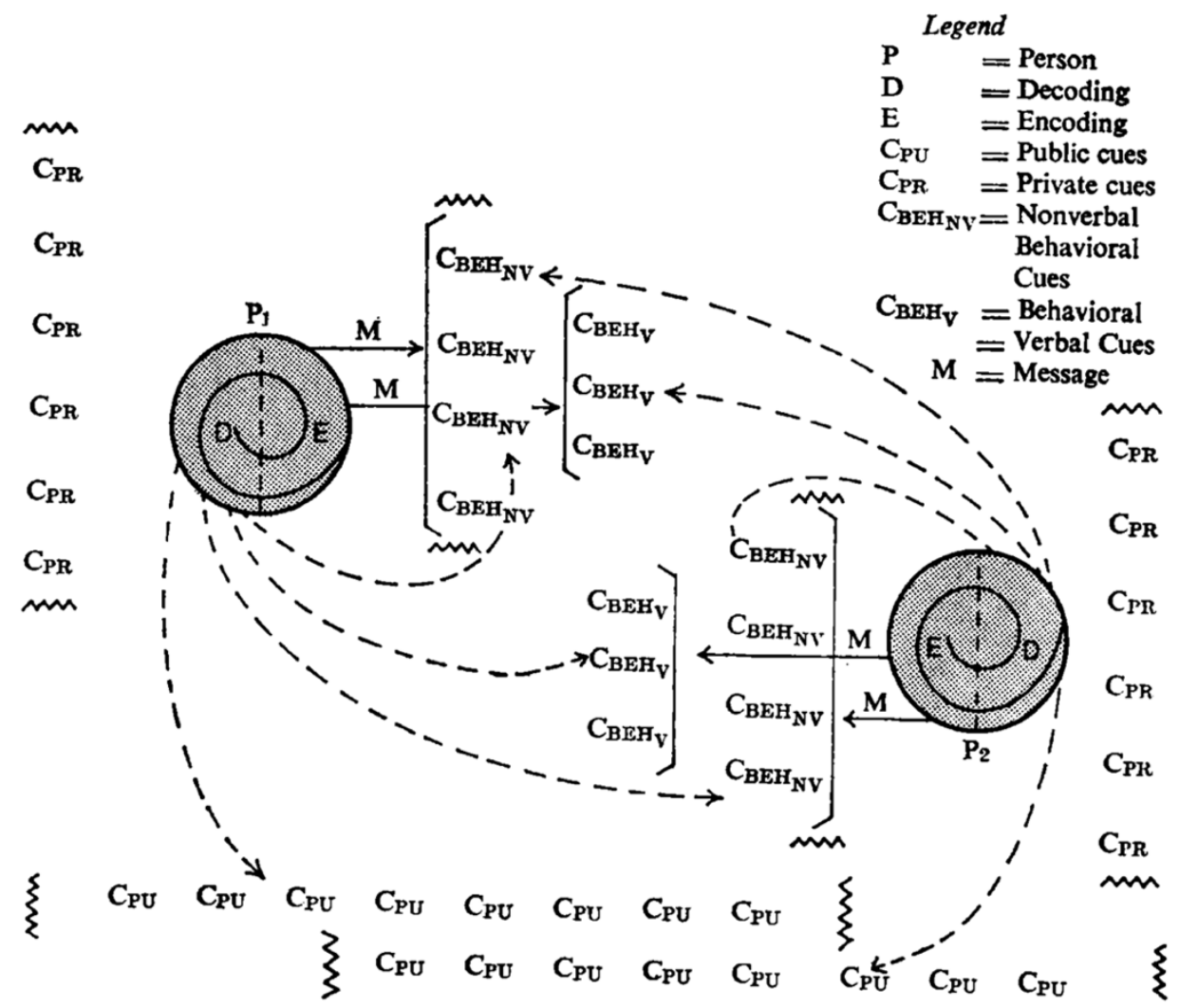

Figure 5: Dean Barnlund's interpersonal model of communication (D. Barnlund, 1970).

A brief explanation of these models is required to adapt them to a photography medium as will be done later. Figure 4 shows a person who is not communicating with another person and is alone. According to Barnlund, communication is still happening regardless and is called intrapersonal communication. I will be focusing on the intrapersonal model as that is the most relevant to this thesis' communication topic. In doing so, I am rejecting Infante et al's (2003), assertion that communication requires two individuals being in mutual awareness of each other. The label (P) indicates the person. The person decodes (D) and assigns meaning (E for encoding) to many cues in the environment. Those meanings are a result of what the person notices in the environment, which is what the arrows indicate. The arrows also indicate "that a single 'experience' may be a mosaic of many simultaneous perceptions" (D. Barnlund, 1970:54). The spiral line represents the "continuous, unrepeatable and irreversible nature of communication" (D. Barnlund, 1970:53). 
Continuing on, Barnlund identifies public cues, private cues, and nonverbal behavioral cues. Public cues $\left(\mathrm{C}_{\mathrm{PU}}\right)$ come from the environment itself and must fulfill the criteria of being available to the "perceptual field of all potential communicants" and of having been created prior to the communication event being analyzed and outside of the control of the communicant (D. Barnlund, 1970:54). These cues are potentially available to anyone, but the meaning assigned to each will be different for everyone. Within the heading of public cues are natural cues and artificial cues. These are best described by Barnlund himself:

"Natural cues, those supplied by the physical world without the intervention of man, include atmospheric conditions of temperature and humidity, the visual and tactual properties of minerals, the color and forms of vegetable life and climatic crises such as hurricanes and rainstorms. Artificial cues, those resulting from man's modification and manipulation of his environment, include the effects created by the processing and arranging of wood, steel and glass, the weaving and patterning of clothing, the control of climate through air or sound conditioning" (D. Barnlund, 1970:54).

Private cues $\left(\mathrm{C}_{\mathrm{PR}}\right)$ are similar to public cues in that they are not in the control of the communicants, but opposite in that they are not automatically available to everyone. They "might include the sounds heard through a pair of earphones, the sights visible through opera glasses, or the vast array of cues that have their origin in the taste buds or viscera of the interpreter" (D. Barnlund, 1970:54).

The last set of cues Barnlund proposes are behavioral, nonverbal cues $\left(\mathrm{C}_{\mathrm{BEHNV}}\right)$. These cues are generated by and under the control of the communicant and are made up of the deliberate articulation and movement of the communicant's body. For example, how the communicant holds a glass or changes position in a chair.

The other items of importance in these models is that the number of cues that could be assigned meaning is limitless (illustrated by the jagged lines in the models) and that these cues can carry a value to the communicant and therefore be ordered. 


\section{Terms for Discussing Communication}

Considering the transactional model of communication introduced under Dean Barnlund in this thesis, albeit a simplified one, there are several commonly used terms in the communication process. These are the source, encoding the message, the message, the context or medium, decoding, the receiver, and feedback (Jacobsen \& McDuff, 2008; Jacobson, 2009).

- The source or sender is who the communication message is coming from, whether that be an individual, a group, or an organization.

- Encoding the message is how that message is altered or added to by the source or whomever is sending the message to get the message ready for transmission.

- The message is the stimulus, whether verbal or nonverbal, that goes from the source to the receiver.

- The context or medium is how that message is carried to the audience such as by a blog, a conversation or a magazine.

- Decoding is how the receiver of the message perceives the message through their individual interpretation.

- The receiver is who the message reaches.

- Feedback is how the message was received and whether it was received as the source intended.

Barnlund does not agree with the use of the structural terms, such as sender or source, message, or receiver. He believes these static elements do not fit a process like communication and 'to erect such 'lines of demarcation' cannot help but obscure the circular character of communication (D. Barnlund, 1970:50). Barnlund prefers to focus on functional and operational terms, such as encoding and decoding (D. Barnlund, 1970). This is because Barnlund's model of 
communication is complex and takes into account situations not given as much attention by communication scholars. Some of these are:

"Symbolizing and interpreting may go on in a single person when he is alone; meanings may develop in two or more communicants simultaneously; messages, in the absence of either a source or receiver, may generate effects; meanings continue to flourish or deteriorate long after they are initiated, and so on (D. Barnlund, 1970:50).”

He also declares that "Communication seems more accurately described as a circular process in which the words 'sender' and 'receiver', when they have to be used at all, serve only to fix the point of view of the analyst who uses them (D. Barnlund, 1970:50)." The situations stated above make the process of describing communication extremely complex and while I agree with Barnlund's wariness of the structural terms I also believe that a fixed point of view can sometimes be helpful in allowing complex topics to be explained, albeit with caveats included. In order to describe marine conservation photography from a communications standpoint, I will use the terms described, source, message, decoding, etc., but I will also present a marine conservation photography example using Barnlund's model. Environmental and conservation communication are natural stepping stones to Conservation Photography and marine conservation photography and so must be discussed first.

\section{Environmental and Conservation Communication}

The International Environmental Communication Association describes environmental communication as "communication about environmental affairs. This includes all of the diverse forms of interpersonal, group, public, organizational, and mediated communication that make up the social debate about environmental issues and problems, and our relationship to the rest of nature (International Environmental Communication Association, 2015).” They label environmental communication as a lay activity that anyone can participate in, a field of 
professional practice for those who have made being an environmental communicator their job, and an interdisciplinary field of study with courses, research centers, scholarly journals and books on the field (International Environmental Communication Association, 2015).

The field of environmental communication boasts multiple related journals such as Applied Environmental Education and Communication, Environmental Communication, Journal of Science Communication, and Journal of Environmental Education and covers a wide range of topics (R. Cox, 2012). Robert Cox, the author of the book Environmental Communication and the Public Sphere and a Professor Emeritus in the Department of Communication Studies at the University of North Carolina at Chapel Hill has identified seven areas that environmental communication scholars study. These areas are (R. Cox, 2012):

- Environmental rhetoric and the social-symbolic "construction" of nature

- Public participation in environmental decision making

- Environmental collaboration and conflict resolution.

- Media and environmental journalism

- Representations of nature in corporate advertising and popular culture

- Advocacy campaigns and message construction

- Science and risk communication

Cox takes environmental communication to be "the pragmatic and constitutive vehicle for our understanding of the environment as well as our relationships to the natural world; it is the symbolic medium that we use in constructing environmental problems and in negotiating society's different responses to them" (Cox, 2012:19). The incorporation of pragmatic and constitutive in this definition asserts that there is a purpose for communication. I believe conservation communication is the attempt at narrowing down what that purpose is. However, it is difficult to find an established definition of conservation communication, so I will create my own.

Similarly to communication, conservation is hard to define. "Most definitions of conservation provided by conservationists reflect their authors' particular view of what conservation ought to be" (Sandbrook, 2015:1). Leader-Williams, Adams, \& Smith (2010) share the simple definition of "conservation comprises actions that directly enhance the chances of habitats and species persisting in the wild," however they acknowledge that this definition fails 
to answer the key questions of "why should we conserve; what should we conserve; how should we conserve; and, how much should we pay to conserve" (Leader-Williams et al., 2010:6)? Sandbrook, a political ecologist whose research focuses around the subject of biodiversity conservation and its association with society, took that definition and attempted to answer the questions raised by Leader-Williams et al., in a new definition. Sandbrook defines conservation as "actions that are intended to establish, improve or maintain good relations with nature" (Sandbrook, 2015:1).

"This definition highlights the idea of conservation as something that is active rather than passive (actions). It recognizes that some conservation actions create new relationships with nature (establish) whereas others build on existing relationships (improve or maintain). At the same time it recognizes that despite good intentions, not all conservation actions are successful (intended to). It captures the positive intentions of conservation towards nature (good relations), whilst leaving room for different perspectives on what these relations might entail. Finally, it allows for diverse understandings of the entity with which these relations are held (nature), which for some may include people and even non-living geodiversity" (Sandbrook, 2015:1).

Sandbrook's definition of conservation is broad enough that it is able to stretch to fit multiple situations that could arise within conservation. While individual conservationists may have definitions that fit their situations more specifically, Sandbrook seems to have created a definition that is enduring. For the purposes of this thesis, his definition of conservation will be used. To repeat: conservation is actions that are intended to establish, improve or maintain good relations with nature (Sandbrook, 2015).

The well-established field of environmental communication offers insights into conservation communication and the two are utterly intertwined. Environmental communication does not solely occur for promoting conservation of natural resources, rather someone who is arguing against ecological protections would still be participating in environmental communication (International Environmental Communication Association, 2015). Therefore, I 
define conservation communication more narrowly to be: communication solely for the

promotion of conservation actions. This gives conservation communication a place as a subset of environmental communication.

Conservation communication could be communication about what has been done or will be done within the conservation field, or communication leading to conservation actions. Conservation communication is not an established term on its own, however there are conservationists who communicate and it can reasonably follow that they are partaking in conservation communication (Jacobson, 2009).

As discussed with conservation communication, there is a purpose for communicating. If a source is forming a message with the expectation of feedback there is a reason they are communicating. In the case of humans, communication serves important social functions. Those functions are "to inform, persuade, educate, and alert others" and "to organize, argue, reconcile, and negotiate with each other" (International Environmental Communication Association, 2015). We also use communication to stimulate others to be more supportive of something they already approve of, or the reverse (Infante et al., 2003). This holds true in the case of Cox's (2012) definition of environmental communication with the inclusion of the word "pragmatic." We use environmental communication as a vehicle to educate, alert, and persuade with the end goal being to help solve environmental problems or in the case of conservation communication with the end goal being to conserve environments (R. Cox, 2012).

Communication serves to create meanings and shapes how we see and value what we come across (R. Cox, 2012; International Environmental Communication Association, 2015). Whenever we communicate as a receiver or source we are doing something and that communication is orienting us towards what we encounter (R. Cox, 2012). In essence, communication "provides us with a means of sense making about the world" (R. Cox, 2012). This is included in Cox's definition of environmental communication with the addition of the word "constitutive" and when this idea is placed in the context of environmental communication it means that "communication about nature also helps us construct or compose representations of nature and environmental problems as subjects for our understanding" (Cox, 2012:19). The language or images used in environmental communication are specifically used in an attempt to invite the receivers to see nature through a particular perspective, whether that perspective 
includes human involvement or not. In conservation communication's case this would be seeing nature as an important place to protect (R. Cox, 2012).

\begin{abstract}
"Central to environmental communication theory are these assumptions: The ways we communicate powerfully affect our perceptions of the living world; in turn, these perceptions help shape how we define our relations with and within nature and how we act toward nature" (Milstein, 2009:345).
\end{abstract}

Communication is also conducted by humans to pursue objectives. Clark \& Delia (1979), believe that there are three of these objectives that are present in every communication situation though in different amounts depending on the situation. Overtly instrumental objectives are to gain a response from the receiver related to a specific problem that is why the communication is taking place. An example would be influencing someone to donate money to a cause. Interpersonal objectives relate to establishing and maintaining relationships with the receiver. Lastly, identity objectives are concerned with presenting the desired self-image by the source with the intent being to have the receiver see them a certain way (Clark \& Delia, 1979; Infante et al., 2003). These objectives provide a more specific framework for the purposes of communication. Remember, however, Dean Barnlund's meaning-centered theory of communication and that each individual will generate their own meanings which may not align with what was intended (D. C. Barnlund, 1962).

\title{
Definitions of Importance
}

Communication: The social process of stimulating meanings and feedback in other humans via symbolic actions shared within a context.

Environmental communication: "The pragmatic and constitutive vehicle for our understanding of the environment as well as our relationships to the natural world; it is the symbolic medium that we use in constructing environmental problems and in negotiating society's different responses to them (R. Cox, 2012:19)." 
Conservation: "Actions that are intended to establish, improve or maintain good relations with nature (Sandbrook, 2015)."

Conservation communication: Communication solely for the promotion of conservation actions. 


\section{CHAPTER 2. MARINE CONSERVATION PHOTOGRAPHY AND COMMUNICATION}

"Contemporary forms of mass communication are saturated with images and stories that have the potential to influence people's perceptions. These help to communicate and simplify information, making messages memorable, condensing complex information, communicating concepts instantly, and providing a basis for personal thoughts and social interactions that contribute to people's memories, awareness, and opinions about particular issues" (O’Neill \& Nicholson-Cole, 2009:357).

This chapter provides a brief synopsis of photography and sub-categorizations that are included in photography and in photographs. Conservation photography as well as marine conservation photography is defined and discussed. Finally a marine conservation photography communication situation is modeled.

\section{A. Photography}

"Photography is a mirror with memory. It is an image-activated language that remains mute until released by command. Each photograph is a storage unit of reality and truth in the realm of remembrance. Photography can rise to the most sublime moments of humanity and transform the way we see ourselves and the world. The language of photography can be a weapon to expose or a means to comfort; it has provoked, inspired, and enlightened people"

(Khanfar, 2013: 29).

The first photograph of nature is said to have been taken in 1826 or 1827 of the view looking out a window. It took eight hours to expose (Rosenblum, Andy Grundberg, Beaumont Newhall, \& Robert Gernsheim, n.d.). Back then, and until fairly recently, heavy equipment, tripods and long exposures were required. Now we can take many images a second with a device smaller than our fist. The equipment used to take photos has become smaller, lighter, and cheaper and millions of people carry a camera with them wherever they go in the form of their 
cell phone. This is partially responsible for the abundance of picture taking in our culture today. We take snapshots of our lives and the world around us and every year the number of photos we take increases. One trend website estimates that in 2015 over one trillion photos were taken worldwide and believes that number will grow every year (Ed Lee, 2016).

So many photographs taken by so many people and images becoming such a large part of our daily lives encourages any number of categories that a photograph can fit into and a diversity of types of photographers. A simple Google search for 'photographer types' returns headlines such as 30 Types of Photographers Exposed, Top 15 Genres of Photography That you Need to

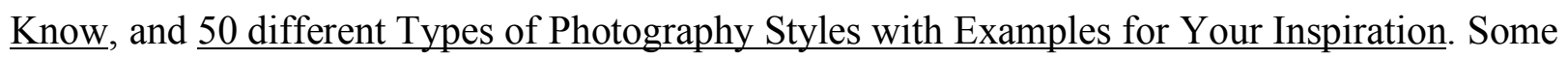
of the categories listed are fashion photography, landscape photography, portrait photography, sports photography, pet photography, travel photography, concert photography, wedding photography, dance photography, food photography, macro photography, documentary photography, wildlife photography, architectural photography, black and white photography, conceptual photography, underwater photography, rain photography, still life photography, film photography, the list goes on with categories broad and narrow.

The point is that a photographer who shoots one subject matter or who shoots in one presentation style, or with one type of equipment, will often identify into a category or into multiple categories since many are not mutually exclusive. For example, black and white architectural photographs on film. Some of these results depict types of photography and some depict types of photographers. Many can be taken either way. For example an aerial photograph can be taken by an aerial photographer. A fashion photograph can be taken by a fashion photographer.

I do not know if these categorizations are useful other than by personal experience. As a hobbyist photographer (which is its own category) with occasional paid work, I have dabbled in a number of photography categories. When I want to learn more or share my work, a category my work can fit into is extraordinarily useful. If I want to learn more about wildlife photography for instance I simply look up information under that title. Without categories these types of photographs and photography would be harder to find and harder to promote.

Classification by these standards is possibly endless and unlikely to be accepted by everyone. There is a compelling argument for a certain system that encompasses all photographs without need to extend the number of categories. Terry Barrett, a Professor Emeritus of Art 
Education, proposed a system of categorizing a photograph by its purpose (Barrett, 1986). Barrett proposes six types of photographs: Descriptive, Explanatory, Interpretive, Ethically Evaluative, Aesthetically Evaluative, and Theoretical. Barrett defines these as follows:

1. Descriptive photographs are made only to offer descriptive information. These are photos such as on an I.D. card or a medical X-Ray. These are "trusted, oftentimes naively, as mechanical and objective" (Barrett, 1986:41).

2. Explanatory photographs "are made to go beyond description in an attempt to provide answers to questions of a scientific nature." An example of this would be images of a fast moving object to determine how it moves (Barrett, 1986:41).

3. Interpretive photographs are made by photographers who "also offer information about the world, explaining phenomena, but from a personal, idiosyncratic, and nonscientific point of view." These "are fictive, poetic, and metaphoric, usually using actors, models, or situations directed by the photographer." These make claims that would be hard to prove scientifically (Barrett, 1986:42).

4. Ethically Evaluative photographs "make moral judgments, take political stances, promote social causes, and are often passionate pleas to right wrongs." These include photos promoting something good (Barrett, 1986:42).

5. Aesthetically Evaluative photographs present subjects as "inherently beautiful and worthy of aesthetic attention." Ansel Adams produced many Aesthetically Evaluative photographs. The category includes photos taken of something we may find unaesthetically pleasing, but are photographed in a way to make them appear aesthetically pleasing. This also includes the opposite, photographs that are made to show something as aesthetically displeasing (Barrett, 1986:43).

6. Theoretical photographs "are not so much about life as they are about art, functioning as visual art criticism, art about art, or photographs about photography" (Barrett, 1986:43).

Like the other categories listed that typify photographers and photographs, these categories by Barrett overlap and the placement of a photo into one or more of the categories is 
an action of interpretation. ${ }^{1}$ The photographer might have had a different intent from what viewer sees. A quote by Ansel Adams illustrates this: "There are always two people in every picture: the photographer and the viewer" (Ansel Adams, 1983). These categories are also fluid as the use of a photograph may change over time. "Often a photograph is made for one purpose and is later used for a different function: a NASA photograph of the earth made from space functions descriptively in a NASA file drawer, but when that same photograph appears in Time magazine with a Mobil Oil logo or a jar of Tang, it becomes a promotional photograph for the company, an advertisement, and is ethically evaluative" (Barrett, 1986:43). Furthermore, these categories help judge photographs. If a viewer is analyzing a photo by its purpose they can determine how effective it is at achieving that purpose.

Barrett's categories for analyzing a photograph are appealing because they are focused on the purpose of the photograph. The field of photography I am interested in, and in which I will sub-categorize marine conservation photography, is also focused on a purpose. Barrett's categories are helpful in that they provide a baseline for which to determine the effectiveness of the photos in the field and help determine if a photo should even be labeled into a field.

The particular field is Conservation Photography. Conservation Photography has a fairly well-documented past that was nicely laid out by Carlton Ward Jr. in his 2008 thesis titled Conservation Photography. Because his thesis is so comprehensive, I will strive to define and describe Conservation photography in the next section as briefly yet comprehensively as possible.

\section{B. Conservation Photography}

"The supreme images are autonomous and have strong bones to stand on their own without a footnote. They communicate; they have intellectual connection and emotional depth. They have clarity, impact, and a flawless sense of being timeless. Most of all, they have a reason to exist; they have a big heart that

\footnotetext{
${ }^{1}$ This references the generation of meanings from within each individual as discussed in Chapter 1 of this thesis.
} 


\section{pumps life all the way to the outer reaches of their body. They teach, inspire, and sometimes outrage" (Khanfar, 2013: 30).}

The first sentence of Carlton Ward's thesis is a definition of conservation photography. It states, "Conservation photography is simply: photography that empowers conservation" (Carlton Ward Jr., 2008:9). It is worth noting the similarities between my definition of conservation communication, "communication that leads to or attempts to lead to conservation", and this definition of conservation photography. Conservation photography is conservation communication. Ward takes it as a combination of documentary photography and nature photography (Carlton Ward Jr., 2008). Conservation photography is different from nature photography because it is done for a purpose (Cristina Mittermeier, 2005). That purpose is the most important part of what separates conservation photography from other photography.

Another description is given by a quote presented in Boyd Norton's Conservation Photography Handbook (2016). The quote is attributed to Alexandra Garcia who is a past executive director of the International League of Conservation Photographers. She says: "Conservation photography is about inspiring thoughtful action with the goal of achieving real and tangible conservation gains" (Norton, 2016:10). This quote also emphasizes a purpose. The purpose of conservation photography is to inspire action. A conservation photographer may use any of Barrett's photograph classifications to achieve that aim, but perhaps would most likely use ethically or aesthetically evaluative images.

Bruce Evan Farnsworth (2011), looked at conservation photography from an educational standpoint. He compared four photojournalists, two of whom were conservation photographers and two of whom were specialty photojournalists. His use of comparison identifies some of the differences between conservation photographers and non-conservation photographers. Using interviews and observations he teased out some salient differences between the two types of photographers. Farnsworth (2011), found that the conservation photographers he followed, in contrast to the photojournalists, were more attentive to the needs of their wild subjects before entering their habitats and would do research prior on their behaviors. Farnsworth determined that the conservation photographers were more sensitive and aware of ecology and also more likely to "address the complex socio-political ecologies of the natural environment" (Farnsworth, 2011:774). Another characteristic of the conservation photographers Farnsworth followed was 
that they were especially metacognitive while doing their work and very aware of the storytelling aspect of a photo. They also utilize and build large networks to inform and guide their work. Farnsworth builds upon prior definitions of conservation photography and proposes the following definition:

“...conservation photography is an inherently educational practice of communicating ecological messages visually, carried out by photographers with ecological understandings and collaborative skills who represent affected communities in the development of accurate and highly interpretive thematic photo essays, eliciting the critical stewardship and action orientation so needed in environmental education today" (Farnsworth, 2011:784).

Conservation photography has become an established field over the years. There are multiple organizations dedicated to or entirely based around conservation photography. Some of these include the Blue Earth Alliance, Braided River, ARKive, and likely many more. Perhaps most directly related to conservation photography is The International League of Conservation Photographers (iLCP). iLCP is a US based non-profit organization that hosts an annual symposium, supports conservation photography expeditions, offers mentorship opportunities, provides ethical rules for photographers involved, and curates a league of skilled conservation photographers along with much more. Their mission is "to further environmental and cultural conservation through ethical photography" ("International League of Conservation Photographers," n.d.). Multiple of the photographers interviewed for this thesis are fellows with the iLCP.

The creation of the iLCP was spearheaded by a photographer named Cristina Mittermeier, whose work to renew and continue the field of conservation photography in the present day has added immensely to the legacy of conservation photography and whose contributions are a new point in the long history of the field. This history is detailed extremely well in Finis Dunaway's book Natural Visions: The Power of Images in American 
Environmental Reform. ${ }^{2}$ I will not go into the history, in lieu of discussing an important aspect of Dunaway's book title. The title of Dunaway's book purports that images have power. This idea is an important building block for conservation photography. For how could a purpose be achieved without the tool having some power?

\section{Power of Images}

The power of photographic images is deeply rooted in emotion. As Iyengar and Kinder (1987), say in reference to another arena where photographic images have been influential:

\section{"It is one thing to understand that American boys are fighting and dying in Vietnam; quite another to watch them fight and die. In each case, so it is argued, the concrete visual details matter enormously" (Iyengar \& Kinder, 1989:35).}

I think that this argument can be viscerally and emotionally understood by anyone who has ever seen a news story featuring images of death and destruction. In my research, emotion is a word I often saw in association with images. The American Psychological Association defines emotion as "a complex pattern of changes, including physiological arousal, feelings, cognitive processes, and behavioral reactions, made in response to a situation perceived to be personally significant" (Frijda, N. H., 2000:208).

Using imaging to map brain areas while the brain is working on different tasks can show how an image might make a person feel based on which regions of the brain are stimulated. Nanda, Zhu, \& Jansen (2012), reviewed research that did just that, specifically in a hospital setting, and identified some interesting clues about the properties of an image that induce negative emotional reactions, such as fear, anxiety, and pain. Properties that may be useful for

\footnotetext{
${ }^{2}$ To read about the history of conservation photography please see the following selected works. For a short introduction see Norton, 2016. For a more detailed history that then focuses on present day conservation photography see Carlton Ward Jr., 2008. For an extremely detailed broad history of conservation photography that also includes the history of conservation videography see Dunaway, 2005.
} 
photographers when creating images with a goal of eliciting certain emotions. They found that images that stimulate negative emotional responses include "(1) fearful or angry faces; (2) ambiguous subject matter; (3) high novelty and unfamiliarity; (4) lack of realism; and (5) sharp contours:" (Nanda et al., 2012). Another study noted that fear response is greater (amygdala responsivity increases) $)^{3}$ when fear is seen in an image in the faces of members of the observer's own culture, relative to other cultures (Chiao et al., 2008). This is an interesting concept to note for photographers who may make conservation images of people in one country and show them in another. To further reinforce that emotions and images are connected, a database of images exists that is meant to be used for the study of emotion. Each image has a normatively rated emotional stimuli attached to it. The goal of the database is to "develop a large set of standardized, emotionally-evocative, internationally accessible, color photographs that includes contents across a wide range of semantic categories" (Lang, Bradley, \& Cuthbert, 2008).

Generation of emotion is not the only exhibit of power that images have. They also have been shown in a significant body of literature to be more quickly and easily recalled by adults compared to lexical words (Borges, Stepnowsky, \& Holt, 1977; Kaplan, Kaplan, \& Sampson, 1968; Paivio, Rogers, \& Smythe, 1968; Schirato \& Yell, 2000).

The power of an image is not necessarily constant. A message's ability to attract attention may decrease over time simply from overuse and oversaturation in the marketplace. An example where this may occur is the overuse of fear appeals or alarmist imagery (O'Neill \& NicholsonCole, 2009). In the environmental realm this could be a photograph of a stranded polar bear on an ice floe. Images such as this are extremely prevalent in the media. Images showing injured animals or humans because of a harmful practice or a climate change related disaster could also be considered alarmist. The extensive use of such images could lead to ineffectiveness or the tuning out of the message as time goes on. There is potentially a law of diminishing returns with the use of fear appeals (Hastings, Stead, \& Webb, 2004). Fear appeals may also lead to the unintended result of issue denial through the viewer's potential psychological response to control their inner fear. This response can create barriers to engagement (O’Neill \& Nicholson-Cole, 2009). Fear appeals may be "disempowering at a personal level," and "drive feelings of helplessness, remoteness, and lack of control” (O’Neill \& Nicholson-Cole, 2009:373). While

\footnotetext{
${ }^{3}$ The amygdala is a region within the brain that has been shown to have a role in emotion and memory (Salzman, n.d.).
} 
they may successfully capture attention, they do not stimulate personal engagement with the issue presented and may backfire and trigger barriers to engagement (O’Neill \& Nicholson-Cole, 2009).

The power that images have is complex. They can persuade people to think or feel a certain way, but how they are interpreted and acted upon relies upon the viewers pre-existing values and feelings (Domke, Perlmutter, \& Spratt, 2002). This is the major theme in the communication model Dean Barnlund subscribed to, as described in the first chapter of this thesis. As such, the persuasion someone is attempting with the presentation of an image, may in fact result in the opposite persuasion expected, leaving that image database I mentioned before possibly not as useful as anticipated (Domke et al., 2002). Most importantly, as Seppänen and Väliverronen argued, "photographs are crucial elements in the production of meanings" (Seppänen \& Väliverronen, 2003). In this way, they are an important aspect in how we as humans understand our environment and ourselves. Meanings, even the same meanings generated by a photograph, can be generated in text, but a photograph can make those meanings more intense, may give legitimacy, or may open up a new range of meanings that writing could not (Seppänen \& Väliverronen, 2003). Regardless of what meanings photographs generate in different people, they do produce meanings and that makes them an important tool in communication. My argument in this discussion of power and images is simply to say that, "just as all media are mixed media, images are more than just pictures" (Blewitt, 2011:721).

Power always has its downfalls. It is important to remember that, as Ansel Adams put it: "There are always two people in every picture: the photographer and the viewer." The photographer, as well as the editor who is publishing the image, is a present and affecting force that can alter an image's power. People, power lines, trash, all can be left out of a frame. Similarly only images of people in traditional cultural dress, rather than what they may normally wear in this time period, may form unrealistic perceptions of a community or culture in the minds of an audience. It is difficult to avoid changing the meaning of an image or purveying an alternate or wishful reality based on what is left in and out of a photograph when making visually appealing images, regardless of the appeal of the content (Foale \& Macintyre, 2005). These wishful realities can disempower communities, place externally imposed problems on communities, and can present a false view of nature that portrays it as void of humans (Foale $\&$ Macintyre, 2005). 
Aesthetically or visually appealing activities, animals, and nature are shown more often in imagery than those that are less visually appealing (Luis A. Vivanco, 2002). This phenomena is exemplified in the realm of endangered species. Some species are well known to the public due to their charisma. These species are called charismatic species and have been defined as some or all of the following: distinguishable from other species, detectable by naturalists and the public, functionally useful, having aesthetic properties whether that be due to the species' cuddly charisma or feral charisma, or inciting an emotional or intellectual response (Lorimer, 2006). Ducarme et al. (2012), believe that for conservation purposes, many charismatic species are large animals and vertebrates with attractive traits to humans (Ducarme, Luque, \& Courchamp, 2013). Charismatic species often serve as "symbols and rallying points to stimulate conservation awareness and action" (V.H. Heywood, 1995). Due to these animal's charisma, it is more likely to hear or see them in the media, in imagery, and even in zoos and aquariums. These animals are therefore more likely to be known by the public at the expense of less appealing animals who often hold fundamental roles in ecosystem health, for example phytoplankton, fungi, and insects (Foale \& Macintyre, 2005). The presentation of images of mostly charismatic species and a propensity to prefer images with visual appeal and anthropomorphized aspects results in biased reactions when it comes to protection or conservation of species.

In light of the power images hold, considering the human behind the camera and their choices is important to remember as a viewer who is generating meanings from an image. It is equally important as a photographer to recognize that what is included in an image may be just as important and affective as what is left out.

The harnessing of power for achieving conservation goals enables a simple tool, the camera, and its associated method, photography, to have a lasting and potent effect. Conservation photography is a fairly broad discipline in terms of subject matter and conservation focus. Yet humans crave categories. A quote by Quine puts this craving into perspective: "There is nothing more basic to thought and language than our sense of similarity; our sorting of things into kinds" (Quine, 1969:116). We categorize our clothes, our books, our art, our natural environment, everything. A semi-indistinct categorization many subscribe to is land and ocean. The soft and changing boundary between land and ocean, which I will call coastal areas makes the distinction difficult, but that does not mean there isn't a distinction. When thinking in terms of conservation photography that distinction still exists in our minds and should be recognized 
for what it is to enhance effectiveness of the messages by those photographers. There is a difference between conservation photography and marine conservation photography. Between land and ocean. Perhaps humans will feel more comfortable joining a field, utilizing a field, or supporting a field if that field is a distinctive, defined, and specialized subfield within conservation photography.

\section{Marine Conservation Photography}

"I make my living off of being a witness and trying to be that conduit for people to understand bigger issues and maybe to think beyond their borders and their personal bubbles. Because we are visual creatures I think imagery has a powerful role in that, especially for the marine environment which is so poorly understood and grasped by the general public" (Mac Stone, personal communication.)

The ocean is a complex, vast, and incredible system that covers a large part of our earth. It is also strange and foreign to many, if not most. This feeling and the difficulty in raising public concern as a result of it, is expressed well by environmental ethicist Clark Wolf:

"Most of us cannot regularly 'see' or 'feel' marine ecosystems. It is certain that we will never fully "understand" them in their full complexity. Surely is it easier for most of us to understand ourselves as 'plain citizens' of terrestrial ecosystems. When we enter a marine environment - often importing with us a compressed version of our own non-marine environment - we may feel instead like alien, foreign visitors. For this reason, it is easier to generate public concern about deforestation in the Rockies" (Clark Wolf quoted in Patton, 2006:6). 
Wolf was responding to wildlife ecologist and conservationist Aldo Leopold's opinion that "we can be ethical only in relation to something we see, feel, understand, love, or otherwise have faith in" ("Aldo Leopold," n.d.; Aldo Leopold, 1968). The unknown of the ocean and the limited access we have to it makes Leopold's belief particularly concerning for ocean conservation. Marine conservation communication and in particular marine conservation photography as a tool can help share the little we do know about the ocean.

In contrast to conservation photography, marine conservation photography is not yet a distinct field in academic literature or online. When searching for the term in Google, the only related result on the first page that uses the full term is in regard to a grant given by the Save Our Seas Foundation to support two budding marine conservation photographers with some money and an experiential expedition with a mentor. ${ }^{4}$ The grant was given in 2014 and in 2016.

Though marine conservation photography is little known as a field in and of itself, the products of those in the field are present in a plethora of books, magazines, online articles, films, social media, and marketing materials for organizations. Virtually every marine conservation organization utilizes photographs of the marine environment in some way to further their conservation message. Examples of this can be seen on the websites of organizations like Ocean Conservancy, Sea Shepherd Conservation Society, Oceanic Preservation Society, Oceana, Coral Reef Alliance, and Conservation International. These images not only provide an aesthetically pleasing and engaging look to a website or organizational materials, they also establish the organization's focus with potential supporters right away and help that organization inspire action towards their cause.

A prominent example of a marine conservation photography-based organization is called SeaLegacy. Founded by conservation photographers Paul Nicklen and Cristina Mittermeier, this nonprofit organization's tagline is "Turning the Tide for Our Oceans." This organization is solely focused on ocean issues and their technique to spur change is to gather teams of photographers and videographers to go to various locations and build visual stories. This media is used to launch campaigns for change and connect a community of people who together can work against some of the practices that harm our oceans. SeaLegacy also promotes the search for solutions to some of the more pressing ocean related problems with funding and publicity. SeaLegacy is a

\footnotetext{
${ }^{4}$ Read more about the Save our Seas marine conservation photography grant here: https://photogrant.saveourseas.com/2016/\#
} 
premier example of marine conservation photography being used directly to promote conservation action.

Even with the existence of prominent organizations like SeaLegacy, the prevalence of images used for marine conservation, and a monetary and experiential grant that uses the term "marine conservation photography" in its title, there is no definition to be found of the term. I present a definition here to assist in the scholarly establishment of this field as a legitimate career, activity, and passion.

Marine conservation photography can modestly be defined as marine environment focused conservation photography. This simplistic definition leaves many potential questions and not many answers. If a photograph is taken with a purpose for conservation, as is necessary for conservation photography, and it is not taken underwater, is it marine conservation photography? If a conservation photograph is taken upstream a river and depicts pollution of some sort that will flow into the ocean, is it marine conservation photography? Is videography part of marine conservation photography? I would be hard pressed to create a definition that clearly and uniformly answers all of these questions, but I will start with a more descriptive and comprehensive definition. This definition is informed by the interviews conducted for this thesis. Marine conservation photography is photography and videography of directly ocean associated subjects or in marine and coastal environments with the intent to inspire action for ocean conservation.

Analyzing this definition reveals some of the answers to the questions posed above. Photography and videography not taken underwater can be just as much marine conservation photography as that which is. A photograph taken inland far from any coast could be considered marine conservation photography if it is of a directly ocean associated subject or used specifically to inspire conservation of an oceanic or coastal habitat or species. A hypothetical example of this could be a photograph of the making of shark fin soup that is used to promote conservation of sharks and a decrease in shark finning.

Directly ocean associated subjects has fairly malleable meanings. Looking specifically at ocean conservation issues, it could be argued that nearly every conservation issue on land also affects ocean conservation to some extent. While this is certainly true, there are those issues on land that affect the ocean and raise ocean issues more immediately and directly than others. An example of this is the deforestation of inland forests. Deforestation releases stored carbon 
dioxide from the trees which contributes to climate change, atmospheric temperature rise, melting polar ice caps, and an increase in the amount of carbon dioxide absorbed in the ocean, eventually leading to ocean acidification (Doney, Fabry, Feely, \& Kleypas, 2009). The effect on the ocean, though incredibly large, is many steps down the line of events and is a little far away and abstract to consider images of inland deforestation marine conservation photography. That is, unless the photographs were taken with the intent to be used specifically for ocean conservation and raising awareness of ocean acidification and are captioned or juxtaposed with other images applicably.

Similarly, the overuse and improper disposal of plastic which is washed into rivers and then into the ocean, where it has many negative effects, is a slightly abstract and removed ocean issue (Derraik, 2002). Images of plastic waste on land or in landfills is not automatically marine conservation photography. However, if juxtaposed with images of plastic in the ocean, or with a caption explaining the impacts on the ocean, it could be considered marine conservation photography. The intent of ocean conservation must be present. This continuum is fuzzy and unrefined and comes down to personal judgement, the intent of the photographer, and what the photograph is ultimately used for and the text it is used with.

The most important prerequisite for determining if a photographer is partaking in marine conservation photography is the intent to inspire action for ocean conservation. If a photographer has that intent, then they are doing marine conservation photography. If a photograph is used to promote marine conservation and inspire marine conservation than it is a marine conservation photo. However it may not have been taken by a marine conservation photographer if that photographer did not have intent.

The term videography is used as well as photography in this definition because the two are becoming intertwined to the extent that they are often hard to differentiate. Videographers often use still photography in videos. Many of the marine conservation photographers that I interviewed or researched also do videography or are involved with video production in some way, whether that be including their still images in videos, being an interview subject in videos, or helping produce videos with content shot by others. Michele Westmorland, an interviewee for this thesis, believes videography is included in the definition of photography and is extraordinarily important for storytelling: 
"...if you look at the definition of photography, almost everybody thinks still photography. That's the area, but actually the definition of photography includes motion. It's still or motion. It's mixed media. It's the way it is and if you aren't inclusive of film or digital capture in still or in video than I don't think you have the skills to tell a full story because a still is that moment in time, the one that can really inspire, whereas the video can help you back that up with behaviors and emotion and it also visually attracts when you start blending the two. I'm just a real firm believer in it" (Michele Westmorland, personal communication).

If videography is a specialization inside photography, it is therefore photography and should not have to be listed separately. I do list it separately in this definition though, because in common vernacular it often is described and thought of as a separate field. Especially with the rise of videography and conservation videography in recent years, this clearly stated inclusion is important to streamline understanding. The inclusion also serves to provide a bridge to connect those who do solely still photography and those who do solely videography. The iLCP working together with Filmmakers for Conservation for example, an organization that is, "dedicated to inspiring filmmakers to use their films and media to conserve the natural world," could yield wonderful results.

Organizations, individuals, governments, and communities use conservation photographs to promote their message and reach others. That is the purpose conservation photographers are trying for when practicing conservation photography. These messages vary and some of them are very focused on the ocean and ocean issues. A few of the prominent organizations that do this are The Surfrider Foundation, Oceana, Ocean Conservancy, The 5 Gyres Institute and the Lonely Whale Foundation. More organizations have subsets of their mission that focus on the ocean, such as The Nature Conservancy and the Environmental Defense Fund. These organizations and so much more rely on marine focused photography. That is why in the next section I will discuss marine conservation specific communication and how photography comes to play in that context. 


\section{Communicating Marine Conservation Photography}

Putting marine conservation photography into a communication model can serve to establish how complex the communication situations can be. I will take a context-specific example of a person seeing a marine conservation photography image on display as an example. For this example I am directly relating the situation to a real-life example in reference to an experience had by one of the interviewees for this thesis. The interviewee was Keith Ellenbogen and the communication example for this model is a photography display at the United Nations: Our World Our Oceans conference in New York. A lot of thought goes into a display and a specific message is looking to be achieved, Keith says:

"Then we proposed the organization of the images and how it would be laid out. They suggested space and then when it changed or when we were able to do things, we suggested how people would move through it, what the flow would be. I spent a lot of time thinking about how images would be juxtaposed next to one another, the color palette, the things that are iconic, such as sharks, to things that are texture based and more artistic, such as delicate movements of an anemone or a scallop. I really wanted to take people into a place where when they were there, they were almost lost within not knowing it was New York, except really thrown through sort of a reinforced language of always the location stating New York. I think we got a lot of really positive comments and reviews so that was nice" (Keith Ellenbogen, personal communication).

For the purposes of keeping this hypothetical situation and its subsequent model as simple and understandable as possible I will first narrow the situation to be one individual seeing a photo with no one else around. Using the terms and definitions used by Jacobson (2009) in the book Communication Skills for Conservation Professionals, the situation can be outlined. In this scenario the message source is Keith Ellenbogen. In his process of choosing how to display the image, where to display it, and what to include with it, all with the United Nations mission and 
requirements in mind, the message was encoded. The message itself is the content of the photo he chose along with its caption and the intention of photographer and encoder. The medium is the exhibit itself or to make it even simpler, the wall the photo is hanging on. The message is decoded by the person viewing the photo when the person sees and interprets the photo according to their individuality. The receiver is the person seeing the photo. Feedback is whether that person got Keith Ellenbogen's message as Keith intended them to get it. Keith's intent was to raise awareness of the diversity of marine life in New York. So if the person who saw the photo walked away aware that New York has diverse marine life then the message was successful. The feedback would need to be measured to determine this. These aspects of the communication system can fit into any model presented in Chapter one of this thesis.

This communication situation can also be described more holistically via Dean Barnlund's communication model (D. Barnlund, 1970). Barnlund's model is described in chapter one of this thesis. In the representation in Figure 6, hypothetical cues were created that fit into each of Barnlund's cue types. In this model, the viewer is recognized as assigning meaning, whether consciously or unconsciously, to any number of cues in the environment and within themselves. The presentation of the model in Figure 6 in comparison to the terms described in the previous paragraph serve to establish that marine conservation photography communication situations are complex and highly variable. 


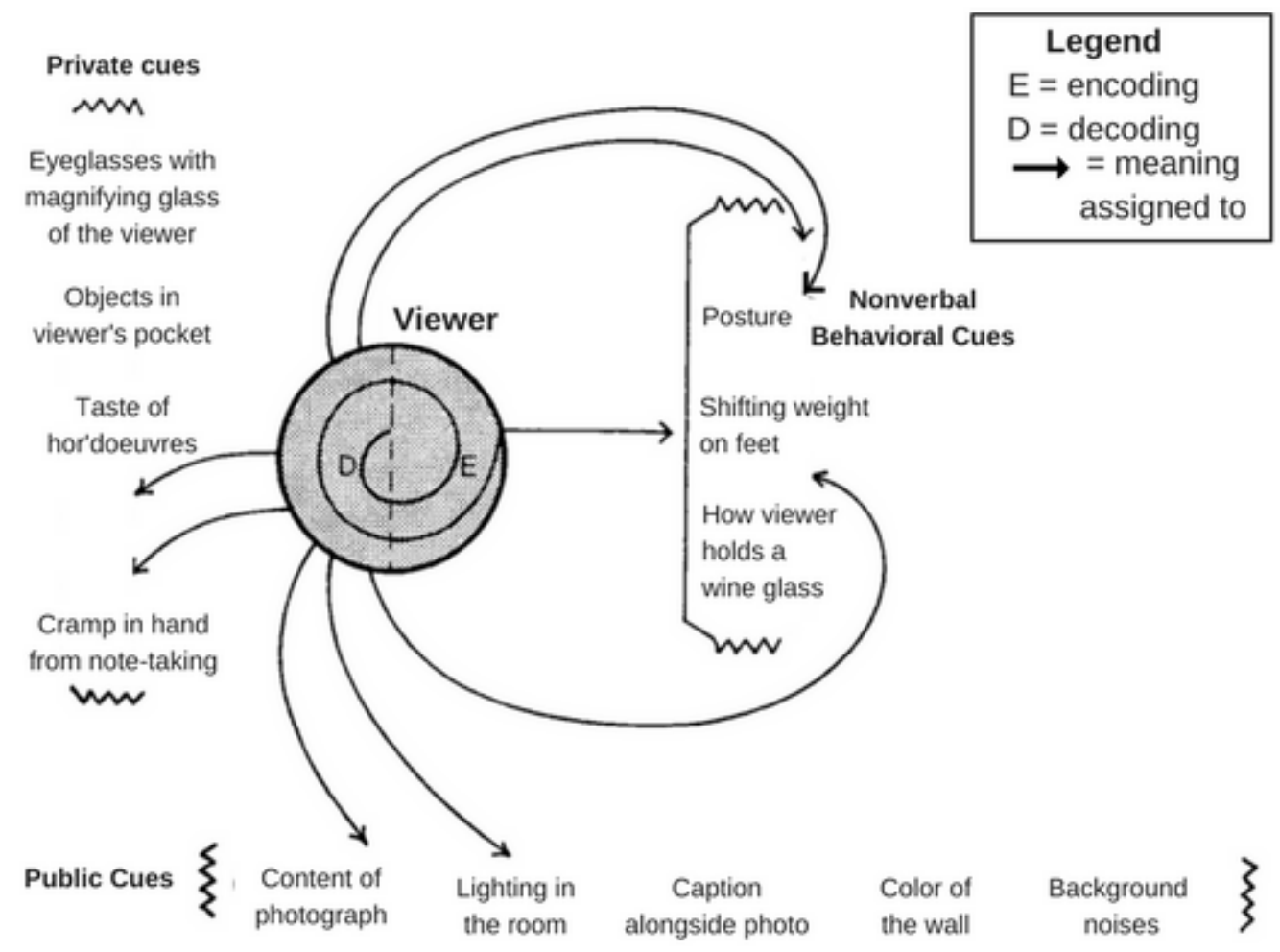

Figure 6: Adaptation of Dean Barnlund's communication model to fit a hypothetical marine conservation photography communication situation.

\section{Definitions of Importance}

- Conservation Photography: "Photography that empowers conservation (Carlton Ward Jr., 2008:9)."

- Marine conservation photography: Photography and videography of directly ocean associated subjects or in marine and coastal environments with the intent to inspire action for ocean conservation. 
PART II.

CONVERSATIONS WITH MARINE CONSERVATION PHOTOGRAPHERS 


\section{CHAPTER 3. QUALITATIVE INTERVIEWING}

Interviewing is a well-established method in qualitative research. There are many forms and purposes interviewing can take. Interviewing tradition exists in the social sciences and humanities as well as in reporting and journalism. Some divisions of interviewing are focus group interviewing, investigative interviewing, journalistic interviewing, group interviewing and participant observation interviewing. Interviewing is a form of qualitative research that should always be a last resort because it is "highly personal, expensive, and utterly political," however it is often the only way to gain information on the human experience and can be used to explore facts that are unquantifiable (Marc Miller PhD, 2017: personal communication). This chapter introduces two overlapping interviewing styles that I used in the data collection for this thesis, the semi-structured interview and elite interviewing.

For the purpose of this thesis, an interview is a strategic interaction with a person or people of interest, where the interviewer has a coercive motive to gather information from the interviewee(s) through observation or conversation. If one starts researching interviewing method one finds a deep field of advice, warnings, and reflections on the craft and the researcher quickly realizes that interviewing is not to be taken lightly. While the variations of interviewing are innumerable and vary based on who is being interviewed, where they are interviewed and why they are interviewed, there are three structures of interviews on a continuum that apply in almost any situation. Unstructured interviews have no predetermined questions or answer categories and solely rely on social interaction between the interviewee and the interviewer. "Structured interviews are similar to surveys except that they are administered orally rather than in writing" (Zhang \& Wildemuth, 2005:1). In between those two frameworks lie semi-structured interviewing, though an interviewing style could fit anywhere in between on the continuum (Figure 7).

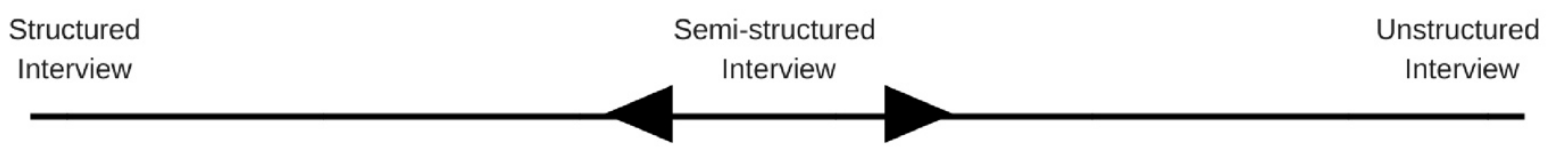

Figure 7: Interviewing format variation spectrum created by author. 
While this thesis uses a framework falling closest to semi-structured interviewing with perhaps a lean towards unstructured, the frameworks just introduced should be considered by any researcher when designing an interviewing project. The ultimate consideration is that regardless of how different the methods are, the interviewer must remember that he or she is "a "learner" in the conversation, trying to make sense of the interviewee's experiences from his or her point of view" (Zhang \& Wildemuth, 2006).

\section{A. The Semi-Structured Interview}

"I realized quite early in this adventure that interviews conventionally conducted, were meaningless. Conditioned clichés were certain to come...The talk was idiomatic rather than academic. In short, it was conversation. In time, the sluice gates of dammed up hurts and dreams were opened."(Terkel, 1997:XXV)

As said before, semi-structured interviews lie between structured and unstructured. "They offer a more flexible approach to the interview process. While they may use an interview schedule for predetermined topics, they allow for unanticipated responses and issues to emerge through the use of open-ended questioning" (Ryan et al., 2009:310). The key factor in semistructured interviewing is flexibility, however that flexibility does not extend so far as to not have set topics. Kvale (1996), a professor of educational psychology and director of the Centre of Qualitative Research, wrote that in semi-structured interviews "there is a sequence of themes to be covered, as well as suggested questions. Yet at the same time there is an openness to changes of sequence and forms of questions in order to follow up the answers given and stories told by the subjects" (Kvale, 1996:124).

So, while fully unstructured interviews include no set topics or questions and a fully structured interview includes a very rigid set of questions with no room for straying, a semistructured interview includes set topics and questions that are open for alteration during the 
interview. For the purposes of this thesis a semi-structured interview is a "conversation in which you know what you want to find out about- and so have a set of questions to ask and a good idea of what topics will be covered-but the conversation is free to vary, and is likely to change substantially between participants” (Miles \& Gilbert, 2005).

Participants in this study were interviewed once and for a short amount of time of one hour or less. This was due to the interviewees often having severe restrictions on their time in between field work or other responsibilities and the limited time for the interviewing to take place due to time restrictions for completing this thesis. These limitations made semi-structured interviewing a top choice, in comparison to other interview methods, as there was more opportunity for unexpected information to occur in a single interview.

\section{B. The Elite Interview}

"The most nearly universal rule for elite and specialized interviewing is that the best way to interview in a concrete situation depends upon the situation."

(Dexter, 2006:31)

An elite interview is one in which "any interviewee...who in terms of the current purposes of the interviewer is given special, nonstandardized treatment" and the "interviewer is willing, and often eager to let the interviewee teach him what the problem, the question, the situation is" (Dexter, 2006:18-19). Essentially an elite interview is not an interview of people considered elite in the traditional sense of the word. The interviewees are not always what many would consider superior to others in terms of career, appearance, personality, or intelligence. They simply know something that the interviewer wants and the interviewer is open and willing to learn from them. Oral historian and elite interviewer Studs Terkel said: "I'm celebrated for celebrating the uncelebrated" (Terkel quoted in Burkeman, 2002).

Most importantly, the elite, semi-structured interviews will stress the interviewees definition of the situation, encourage the interviewee to structure the account of the situation, and let "the interviewee introduce to a considerable extent... his notions of what he regards as relevant, instead of relying upon the investigator's notion of relevance" (Dexter, 2006:18). 
Elite interviewing cannot be done in the structured format as that would not allow the interviewee to guide the interviewer to what is relevant. It fits most ideally in the semi-structured or unstructured formats due to the flexibility allowed for the interviewee to guide the interviewer in those arrangements. In structured interviewing, the interviewee would not be given the chance to change or emphasize subjects. This research treats all those interviewed as elites due to their presumed knowledge of the field of MCP from participation in the field. Only very carefully are the views of the interviewees taken to represent a wider population.

\section{Considerations for Conducting the Interview}

"An interviewer can be likened to someone who attends a dinner party, and sits next to a stranger. He must keep the conversation going, without monopolizing it. The beginning interviewer, who is perhaps more comfortable with books than conversation, may feel that the social craft of interviewing is well beyond him. It isn't. It only requires an uncommon blend of common abilities - to overcome nervousness, draw the other person out, and be a good listener." (Brady, 1977:51)

What follows is a selection of techniques and contemplations that are helpful and important to consider when conducting interviewing as a research method. This list includes: Rapport and trust, aide memoir and interview structure, question design, listening and interpreting and recording and note taking.

\section{Rapport and Trust}

All the following techniques and considerations, when done correctly, help build rapport and trust with the interviewee. Rapport and trust are the building blocks of a good interview, and an interview in general, and take time to establish (Huggins, 2014). "Interviewing is the modest, immediate science of gaining trust, then gaining information" (Brady, 1977:68). To establish 
rapport is even more important. According to Jane Kramer as quoted in The New New Journalism, 5 "everything depends on the kind of rapport you have" (Boynton, 2005:195). Each interview subject will require different methods to establish rapport and "rapport can be instant or it can be impossible" (Brady, 1977:49). This all depends on the person being interviewed and their preconceptions and personalities.

\section{Aide memoir and Interview Structure}

An aide memoir, also called an agenda, conversational guide, or interview guide, is $\boldsymbol{a}$ list of questions or topics that is predetermined and helps ensure the gathering of reliable, and comparable data and overall encourages some consistency between different interview sessions (Bernard, 1988; Zhang \& Wildemuth, 2006:2). An aide memoir also "demonstrates that you are fully in control of what you want from an interview but leaves both you and your informant free to follow new leads. It shows you that you are prepared and competent, but that you are not trying to exercise excessive control over the informant" (Bernard, 1988:205). The aide memoir can therefore assist in establishing some power in the relationship with the interviewee and can help form an interviewee's confidence in the interviewer's abilities which itself may help establish rapport.

The aide memoir serves to give some structure to interview sessions regarding content and also allows for planning a structure concerning types of questions and when during an interview certain questions are asked. Due to the use of the semi-structured interview format in this research, this structure is flexible. It is, however, useful to have a structure prepared that can be referred to when necessary.

\section{"Spradley (1979) identified three main types of questions: descriptive questions, which allow interviewees to provide descriptions about their}

\footnotetext{
${ }^{5}$ The New New Journalism by Robert Boynton is a collection of question and answer conversations with nonfiction writers identified as New New Journalists. The writers profiled are incredible literary journalists who immerse themselves in their subjects and utilize methods and techniques that can inform and enlighten all those who use interviewing.
} 
activities; structural questions, which attempt to find out how interviewees organize their knowledge; and contrast questions, which allow interviewees to discuss the meanings of situations and make comparisons across different situations. Each type of question is used at different points in the interview to encourage interviewees to talk or to probe for more details. " (Zhang \&

Wildemuth, 2006:4)

The aide memoir created for this research includes some amount of all three types of questions that Spradley (1979), identified so all possibilities are covered when encouraging the interviewees to talk.

The questions themselves must then be sensibly structured, according to Brady (1942) a "good interview... begins with easy, rather mechanical questions; shifts to knottier, more thoughtful questions; moves back out with mechanical questions ... and closes with a query that offers a ring of finality (one effective question)" (Brady, 1977:72). While a similar structure in a semi-structured interview can easily fall to pieces, it is possible to place proposed questions in a comparable order within an aide memoir, allowing an interviewer to refer to this structure during the interview. In addition, it is feasible to follow one of two shapes of interview outlines, funnelshaped or inverted funnel-shaped. Funnel shaped interviews "open with generalities...then pin down the generalizations" (Brady, 1977: 73). Inverted funnel-shaped interviews open with "hard, fast, specific questions, then ascend to more general ground" (Brady, 1977: 73). This research takes advantage of the funnel-shaped interview outline and the aide memoir is thus organized.

\section{Question Design}

Developing questions is not an easy task and involves consideration of subject matter, wording, culture and possible elucidations.

"Nothing is more important for [the development of the questions and followup probes] than a good grasp of the subject matter... Other than paying close 
attention to the relationship between the questions asked and the content produced during the interviews, I also need to reflect on whether or not the questions are perceived by the interviewees as being respectful and culturally sensitive" (Rabionet, 2011:564).

Each question should be closely analyzed in light of who the question will be asked of. Knowing the background of the subject as well as having a good grasp of the topic will help devise questions that yield useful data. That research will also help the researcher discover what is or is not respectful with the individual being interviewed. While being disrespectful, nonculturally sensitive, or combative may benefit some interviews, as is often the case in Ariana Fallaci's work, this research will take care to avoid insulting or ostracizing the interview subjects because the information needed should not and will not require such extreme measures to gain.

Questions in this research shall be purposefully non-leading. Questions that impose interpretations will result in answers that will possibly not reflect truth. "Leading questions pressure interviewees to answer in a way that conforms with what the interviewer has suggested" (Barone \& Switzer, 1995:107). While some argue that leading questions may enhance the reliability of interviews, this research seeks to avoid them as much as possible (Kvale, 1996:158).

Even the wording of a question can affect the answers given, as Payne (2002) discusses in his book the Art of Questioning, however, "it is more than a mere matter of manipulation of words to produce surprising illusions. The most critical need for attention to wording is to make sure that the particular issue which the questioner has in mind is the particular issue on which the respondent gives, his answers" (Payne, 1951:9). In a face to face interview, rather than a survey or questionnaire as Payne was referring to, the interviewer can elaborate on the question and steer the interviewee back to the issue they desire. However, it is important to be clear with wording and aware of varying connotations of some words.

"When we see the three words-might, could and should-together, we realize that they have somewhat different connotations. Yet when it comes to stating questions, we may sometimes use these words as synonyms. The trouble with 
this assumption is that the public actually does see distinctions among these words changes its replies to fit" (Payne, 1951:9).

One particular point to remember when conducting a semi-structured interview, is to "follow up an open question with closed questions [such as] 'Could you give me an example of that?' [or] 'What do you mean by...?'”(Brady, 1977:75). When an interviewee is being quiet, this may serve to help gather more information.

\section{Listening and Interpreting}

Asking a question will hopefully lead to an answer by the interviewee and then comes the task of listening. "The good interviewer listens carefully - but not passively" (Brady, 1977:59). Brady's quote shows that even how an interviewer listens can encourage or discourage an interviewee's contribution. "The interviewer must perfect a style of "interested listening" that rewards the respondent's participation but does not evaluate the responses" (Fontana \& Frey, 1994:364). Most importantly perhaps, "Don't interrupt when the subject is talking" (Brady, 1977:59).

Interpreting what the interviewee is saying and then responding with appropriate followup questions, noises, and body and face motions is a challenge for the interviewer. Conversation can flow quickly and requires quick thinking all while keeping in mind the same considerations applied to pre-planned questions. For this stage, it is very important to be well-versed on the topic of the interview and the interview subject. It is also important to have practiced interviewing and be semi-comfortable in an interviewing situation.

\section{Recording and Note Taking}

Jon Krakauer always records his interviews in addition to taking notes because as he says "I don't want to miss anything" and "quotes not based on a taped interview often sound more like the writer than the interview subject" (Boynton, 2005:173). Taping an interview also helps 
when the aforementioned task of listening does not transpire well (Jon Krakauer in Boynton, 2005:174). It allows the unheard parts of an interviewees answers to be captured and reheard when transcribing the interview. It also allows for eye contact, which can be helpful when establishing rapport (Leon Dash in Boynton, 2005:63).

Recording takes care of most of what the interviewee is saying, leaving notetaking available to "capture [the subjects] spirit; the writer who gathers color in his notes can be agile and he is more likely to be true to his subject" (Brady, 1977:127).

"In fact, most of what I'm writing down are my observations: What the guys is wearing, the way his eyes dart, the nervous way he pulls at his earlobes. If I'm not using a tape recorder, I have to focus all my attention on writing down what the subject says, making it impossible for me to make these other crucial observations. I don't think anyone can do both things at once, no matter how fast they are at shorthand." (Jon Krakauer in Boynton, 2005:173)

While there are those who solely record, solely take notes, or do neither, this research employs both recording and note taking. Throughout the process, I utilized Fontana and Frey's (1994) advice to "(a) take notes regularly and promptly; (b) write everything down, no matter how unimportant it may seem at the time; (c) try to be as inconspicuous as possible in note taking; and (d) analyze one's notes frequently" (Fontana \& Frey, 1994:368).

As stated before, this discussion of the types of interviewing that were conducted during this research and some of the considerations and techniques to use prior to and during interviews is not exhaustive. These topics did, however, represent the foremost considerations in my mind while conducting this research and were applied during almost all aspects of the interviewing process. 


\section{Definitions of Importance}

- Interviewing: A strategic interaction with a person of people of interest, where the interviewer has a coercive motive to gather information from the interviewee(s) through observation or conversation.

- Semi-structured Interviewing: A "conversation in which you know what you want to find out about- and so have a set of questions to ask and a good idea of what topics will be covered- but the conversation is free to vary, and is likely to change substantially between participants" (Miles \& Gilbert, 2005).

- Elite Interview: One in which "any interviewee... who in terms of the current purposes of the interviewer is given special, nonstandardized treatment" and the "interviewer is willing, and often eager to let the interviewee teach him what the problem, the question, the situation is" (Dexter, 2006:5,19).

- Aide Memoir: a list of questions or topics that is predetermined and helps ensure the gathering of reliable, and comparable data and overall encourages some consistency between different interview sessions (Bernard, 1988; Zhang \& Wildemuth, 2006:2). 


\section{CHAPTER 4. INTERVIEWING METHODS}

This thesis intends to define the field of marine conservation photography (MCP) and therefore would be incomplete without the inclusion of perspectives from those in the field. As an outsider to the MCP world I can only guess at the reasons why some individuals make conservation photography and particularly MCP their career, hobby, or a major facet of their entire life.

A total of eight interviews were conducted for this thesis. To select the interviewees I made a simple Excel spreadsheet and collected a list of photographers whose online portfolio seemed to focus on marine environments. I found these photographers via internet searching, recommendations from friends and colleagues, and recommendations from the interviewees themselves in a loose procedure of snowball sampling. I associated gender and relative experience with the photographers as I wanted to obtain a diversity of perspectives and gain a semi-holistic view of the field. It is worth noting that while these photographers have portfolios featuring images from across the globe, they all primarily reside in North America and there is therefore a Western bias to this study. I then proceeded to email a majority of those photographers whom I could find contact information for. The photographers who were interviewed and their websites are as follows (presented in the order they were interviewed):

- David O. Brown - www.davidobrown.com

- Michele Westmorland - $\underline{\text { www.westmorlandimages.com }}$

- Mac Stone - www.macstonephoto.com

- Keith Ellenbogen - www.keithellenbogen.com

- Octavio Aburto - www.octavioaburto.com

- Chris Jordan - www.chrisjordan.com

- Bethany Augliere - www.bethanyaugliere.com

- Tanya Houppermans - www.blueelementsimaging.com 
I created an aide memoire that was on hand during all the interviews conducted. The questions were developed with an interest in the past, present, and future. The guiding research questions for the development of my aide memoire were:

1. How did the field of marine conservation photography look in the past?

2. How does the field of marine conservation photography look in the present?

3. How will the field of marine conservation photography look in the future?

Though these are already in the form of questions, I did not pose them so directly to the interviewees. Many of the questions that I developed were actually not in the form of questions, but rather in the form of requests. These were designed so as to reduce any limitations to how the interviewee might respond and to help the interviewee speak in story form. The posed questions were:

1. What is the story of how your career started?

2. What does the notion of conservation photography make you think about?

3. Tell me about the reactions to your work over time.

4. Tell me about marine conservation in your work.

5. Let's talk about one picture of yours [show picture in a publication]. How did this picture end up where it is and with the accompanying caption?

6. Tell me some of the challenges you face as a marine conservation photographer.

7. Do you consider yourself a marine conservation photographer?

Posed questions number 1 and 3 specifically related to research questions number 1 and 2. Posed questions number $2,4,5,6$, and 7 related to research question number 2 . Posed questions 3,6 , and 7 left openings for interviewees to speak on research question number 3 .

All interviewees were asked if I could record the conversation and if I could use their associated interview transcripts in the appendix of this thesis with quotes in the main body. All the interview subjects agreed to these terms as well as to being identified by name. I used both an application on my phone called Voice Recorder and an application on my computer called QuickTime Player to record the interviewees. 


\section{Editing and Presentation}

To transcribe the interview sessions I used an online service called Temi. Using Temi, I edited the transcripts for clarity, accuracy, and succinctness. My inspiration for how I edited the transcripts, which will henceforth be called profiles, was the oral historian Studs Terkel. Terkel wrote such books as Working: People Talk About What They Do All Day and How They Feel About What They Do, Hard Times: An Oral History of the Great Depression, and Will the Circle Be Unbroken: Reflections on Death, Rebirth and Hunger for a Faith (Terkel, 1970, 1997, 2001).

Terkel had a semi-structured interviewing style that leaned more towards the unstructured side of the spectrum. I quoted him earlier in this thesis as writing, "I realized quite early in this adventure that interviews conventionally conducted, were meaningless. Conditioned clichés were certain to come." Then reflecting on his own style he said, "The talk was idiomatic rather than academic. In short, it was conversation. In time, the sluice gates of dammed up hurts and dreams were opened" (Terkel, 1997:XXV). Terkel interviewed others by purposefully not presenting an academic air and encouraging conversation. Another quote by Terkel that helps describe his interviewing style is, "I'll ask him about his life and as he's talking I'm listening. I don't have written questions. It's a conversation, not an interview... sort of like you're having a cup of coffee or a drink, so it's informal and very easy. Out of that things are revealed" (Moser, 2011). This style is represented in his write up and interview editing, though he takes himself out of the picture. He presents the interviewees casually and with descriptions that help the reader feel like part of the conservation.

I used the book called Working: People Talk About What They Do All Day and How They Feel About What They Do and took select features of Terkel's interview presentation style from there. The aspects of Terkel's style that I incorporated were:

- A paragraph at the beginning of each transcript to present a descriptive view of the atmosphere and the feeling I got from each interviewee regardless of whether I interviewed them in person or over the internet

- The removal of any of my speaking contributions or questions.

- The location adjustment of some of the paragraphs to make the answers to my questions flow in as much of a story format as possible for easier reading. 
I removed some "ums", "uhs", "you knows", and repeated words. I did not move around any of the interviewee's words at a sentence or individual words level, but rather at a large paragraph or the full answer to a question level. I am unsure if Terkel adjusted sentence location, but I purposefully did not. Terkel italicized certain passages of his interviews to emphasize them, I did the same for passages and quotes I thought especially noteworthy or profound. This work resulted in the interviews seen in Appendix A.

The interviews presented in Appendix A are in one way stand-alone products providing a brief history of an individual person, life, and career. They are also the heart of this thesis, providing an extract of the individual minds of a subset of humanity. The interviews help to reveal that real humans are behind the beautiful or jarring photos that we see in magazines, exhibits and Instagram. Those real humans come with the wrinkles from an array of remarkable journeys that brought them in that moment to a conversation with me. Individual humans are amazingly distinctive in their thoughts, hopes, dreams, selves, but can surprise with their similarities at the same time. The interviews allowed for the emergence of common threads between the subjects.

An important reason for the identification of common threads, or themes, is presented in a paper by Gery W. Ryan and H.Russell Bernard (2003). They say: "Without thematic categories, investigators have nothing to describe, nothing to compare, and nothing to explain" (G. W. Ryan \& Bernard, 2003:86). They describe themes themselves as the "classification of more discrete concepts" and "abstract (and often fuzzy) constructs that link not only expressions found in texts but also expressions found in images, sounds, and objects" (G. W. Ryan \& Bernard, 2003:87). I identified these common threads, or themes, using a couple of the techniques Ryan and Bernard described in their paper, namely searching for repetitions and similarities and differences.

The process of identifying themes started simply by transcribing and reading over the interviews. The act of listening to the interviews again while proofreading the profiles was enough to identify some obvious commonalities immediately. After this, I worked through the texts again, looking for and separately highlighting topics that reoccurred over and over again. This search for repetitions is one of the easiest theme identification techniques (G. W. Ryan \& Bernard, 2003). Then I paired those repetition topics between interviews and looked for 
similarities and differences by comparing the units of data. The themes identified provide a glimpse into what is salient in a marine conservation photographer's life. 


\section{CHAPTER 5. DISCUSSION}

This discussion section will analyze the eight interviews conducted for this thesis. I will describe the themes I identified amongst the interviews and share the results of the research questions I acknowledged in the prior section. I will also share some of the limitations and challenges experienced through the course of this research.

\section{A. Prominent Themes}

In this section of the discussion I will remark on the five salient themes that occurred amongst the interviews. Some themes were more dominant and some less, though I did not rank them. The themes I identified are as follows:

1. Money

2. Work

3. Love

4. Education

5. Positivity

\section{Money}

Funding and monetary issues was the most prevalent theme between and within all interviews. Almost every interviewee commented on the struggles with money in their marine conservation photography careers whether they had been in the field for many years or only for a few. Several of the photographers interviewed, for example Michele Westmorland, and Octavio Aburto, rely on other jobs to pay their bills. Michele does commercial photography work and Octavio is a research scientist. Michele Westmorland and Tanya Houppermans were two of the interviewees who specifically delved into the monetary restrictions on new and current marine conservation photographers. 
"It's a challenge for people to survive, to be able to pay their bills. It breaks my heart because I mentor and teach a lot of young photographers who have a science background. Some of my college program students have Ph.D.'s for goodness sake and they really are also good photographers. For them to drop their science background or their way to earn a living and going into still photography to make a living is very, very difficult. I would say. 0.5 percent can even make a living at it" (Michelle Westmorland).

"So for those of us going out there and doing this, we need to earn money somehow. This is still a job. You know, I still have to pay my bills, I still have to maintain and upgrade my SCUBA equipment, my photography equipment. I think it's only going to get tougher and I don't see a lot of people being able to do this. Maybe on a part time basis, but full time not so much for specifically those of us who are videographers or photographers. Now conservation as a whole, I think there might be more opportunities, but if you're just talking about making the images and making the films, it's going to get tougher.

Which is a shame because we're the ones bringing these images of these animals to people in their homes and so you need people like us out there doing that. But we need to be able to buy food and pay our bills too. So it's just a sad fact that that's just how it is" (Tanya Houppermans).

Other interviewees commented on how they did not know how they were going to fund new projects (David O. Brown), they rely on creating photo stories near home because that is what they can afford (Bethany Augliere), and they have put themselves in great financial duress and risk to do their work full time while still following their ethical code, including being near bankruptcy multiple times (Chris Jordan). The frequency of monetary problems being brought up indicates that this is a consistent concern of marine conservation photographers.

\section{Work}

Monetary problems are not the only challenging aspect of being a marine conservation photographer. The work itself is physically and technically difficult and it includes tasks other than photography. The interviewees brought up sea sickness, the struggle to get close to their subjects, rough seas, low visibility, heavy equipment, and writing grants, articles, and emails. 
"When I think of conservation photography I think of long hours. I think of hard work" (Mac Stone).

"I have to now write all these grants and do all these other things that are a real pain in the ass. You have to do a lot of other work" (Keith Ellenbogen).

"...the shooting can be really hard. Like you're dealing with rough seas and animals underwater that you really need to get close to. It's not like I can put a telephoto on and shoot an elephant really far away. I have to be really close to my subjects. I also get sea sick which sucks as a marine biologist and as a photographer. I just have kinda learned to deal with it” (Bethany Augliere).

"You travel around the world and you get to go dive. OK, but they don't see all the days I'm sitting right here at my desk editing photos, or writing articles, or answering emails or, you know, everything that goes on behind the scenes, you know, they don't see the times that I've been rocking back and forth on a boat, I

do have a propensity to sea sickness. Horrible, horrible trait to have as an underwater photographer. Thank goodness for the patch or I could not do my job. They don't see me lugging 50 pounds of scuba gear, 50 pounds of photography gear, plus the rest of my luggage by myself through airports trying to get from point A to point B. It's stressful. It can be really, really stressful. So I guess there's a lot that goes on behind the scenes, but when you're in the water with the animals, you kind of forget about all that" (Tanya Houppermans).

The theme of 'work' may be broad, but it encompasses the interviewee's thoughts on the day-to-day aspects of their jobs. Those day-to-day aspects are an important portion of a job that people seem to glorify.

\section{Love}

While the work is hard, there is a reason the interviewees are all in the field of marine conservation photography. At the end of the last quote listed in the section above Tanya Houppermans says: “...but when you're in the water with the animals, you kind of forget about all that." She is expressing that the good parts of her job outweigh the bad. Other interviewees also expressed their love of what they do. 
"The medium doesn't matter. It's interesting to me that having come from, started in stills, worked in motion and then I left still photography for a long time because I couldn't make a living at it whereas I could make a living with the video and with the uplinks for that time. Even though I kept shooting stills cause I love them. I love that moment, but I couldn't, it was really, really tough to make a living at it" (David O. Brown).

"I think inherently people look for connections to others and I love connecting with people. I love hearing their stories and I like to share stories" (Mac Stone).

"I remember the cold, right as the snow was coming down. I got hypothermia on my very first dives, but I loved the feeling of being in the water, it was just something I really loved" (Keith Ellenbogen).

"I think the other thing that I would say, and this has continued to this day, is it's still the one thing that I love doing the most" (Keith Ellenbogen).

"When I met them, I slowly just began to feel this reverence for these beings and started to fall in love with them and then also the island they're on and the Pacific Ocean that they live in" (Chris Jordan).

"This whole time I'm exploring the fact that I really love storytelling in addition to science. I'm becoming obsessed with other National Geographic photographers, I'm watching documentaries and flipping through the pages of magazines and sort of discovering the field of what it means to be a photographer" (Bethany Augliere).

All the interviewees expressed some sort of love of their jobs. It seems that despite the long hours and the hard work there is a clear reason for why they do what they do: it would be hard to not do what they love.

\section{Education}

Marine conservation photography is not just about taking pretty pictures. Those pictures have to be disseminated, the places and animals they depict have to be advocated for, and interest in 
the ocean has to be raised. This speaks to both the pragmatic and constitutive aspects of communication presented by R. Cox (2012). The dissemination process came through thematically as education. All of the interviewees give talks, exhibit their work, donate their time, or lead tours.

"I donated a bunch of footage to a bunch of anti-fracking groups and did a lot of speaking out about that and we managed to keep it out of here for now"

(David O. Brown).

"I have a tour in May that is all cultural driven in Papua New Guinea. That has nothing to do with marine life, but when we are at Tufi on the coast, that's the chance for me, especially if they want to go just for a snorkel break or something, to talk to them about the marine life and the importance of the health of the ocean and what it means to these villagers, because they get to meet many of the villagers" (Michele Westmorland).

"At a very young age, about 15 years old I was giving presentations to local commissioners and city planners to try and advocate for some of the places that were, you know, I didn't know any better, they were just backyard places that I thought were special and didn't realize that they were up on the chopping block to be turned into apartment complexes" (Mac Stone).

"Today I'm sitting here working on a presentation and next week I'll be flying out to Singapore for ADEX, which is the Asia dive expo, and this year's ADEX is dedicated to everything sharks. So I'm giving two presentations and one is actually titled Making a Connection: Using the Power of Imagery to Inspire People to Care About Sharks. So how do we use these images to not only change minds, but then take it a step further to get people to actually do something about it" (Tanya Houppermans).

"I'll go and talk to schools and little kids and get them interested while they're young and that definitely helps too. So there are a lot of different platforms to use. There's no real one way, there's a lot of little ways that I do this and, you know, juggling a lot of balls in the air. But that's what you have to do. That's what you have to do. Just disseminate as much as possible" (Tanya Houppermans).

"So the picture, the photo, it's only one part of the conservation photography. You need to take that picture that you took with a lot of feelings, with a lot of knowledge, sometimes with a lot of risk, and take it to the arenas in order to match the image with the statements that you need to do" (Octavio Aburto) 
The interviewees indicated most strongly via the quotes above, that marine conservation photography as a career entails much more than photography and providing educational tools and advocacy is a major part of their jobs. That education in conjunction with their photography is truly the major way they use their work to change minds and inspire action for conservation.

\section{Positivity}

Working in a field with a purpose to promote conservation and protection of an ecosystem that is often not treated with the respect it deserves can be a sad affair. The emphasis of the problems the ocean faces, if overly negative, may lead to the opposite result of what is intended. The message may fail and "lead society into pessimism or the belief that the ocean is beyond restoration" (Duarte et al., 2015:130-131). This conundrum of when to show the positive and when to show the negative and what the impacts of that are, appeared as a theme in the interviews.

"Conservation photography makes me think about taking images that have a meaning, that inspire people to take action, positive action for the environment, or show people the plight of wildlife and ecosystems. So I think it's images that have an impact on conservation and inspire people to take action or tell a story about the environment that's going on, but I don't think it always has to be negative. Like I think we can get wrapped up in, they are important photos, but the shocking photos of the rhino without the horn. I think there's something to be said for images that are also just really stunning that make people interested in an animal, right" (Bethany Augliere)?

"When I think about conservation photography, I think about the complex relationship between the bad news and the good news, between horror and beauty, and on one hand it's easy to focus on the bad news and make images that look really bad and there are a lot of people doing that about plastic in the ocean and there are a lot of documentary films that are being made" (Chris Jordan).

"This is first, if you need to choose between what is the positive angle and what is the negative angle, or what is the human side in a positive way or a 
negative way, most of the time the stories that show the human side from a positive way are the ones that are receiving more attention" (Octavio Aburto).

"So I tried to, you know you're always looking for hopeful stuff in this business because it's really really easy to get down and out and it's really going to down out your audience to the point where they shut down and they're paralyzed. They feel like, oh well it's over. We'll kiss our asses goodbye and there's nothing we can do and so it's really, really important to find a lot of those stories. I tried to give it a positive spin" (David O. Brown).

"Sometimes you realize that there are more positive stories than what we thought because the media basically is in charge or telling us every day that this is world is... I mean of course it's happening, but maybe we can change that if rather than just show the bad things we also show the good things and sometimes the good things are more than the bad things. So again, I think for conservation photography, the human side and the positive outcomes, or the positive side of the stories, in my opinion are the ones that have had more impact when I share these stories with the audience" (Octavio Aburto).

The photographers interviewed here mostly seem swayed towards presenting positivity in their photography or at least juxtaposing beauty with destruction. Michele Westmorland calls images showing destruction the impact shot. In reference to a beautiful photograph of a turtle she said: "So it just, it allows me to take that one step forward. I wish that I had the hardcore impact shot to go alongside of it." The conundrum of what to show in their imagery to achieve their communication goals seems to be a prominent one in a marine conservation photographer's career and some aspire to show neutrality in their messaging.

Showing positivity or negativity is a result of photographer's choices and as such are no neutral. Indeed all photos, except perhaps truly descriptive and explanatory images, are not neutral. They are created by a human as a communication tool and the reality they present is the reality the photographer or the photographer's sponsor or employer intends to show (DeLuca \& Demo, 2000; Foale \& Macintyre, 2005). This is perhaps best described by Chris Jordan. Speaking on marine debris at Midway Island and the kind of conservation photographer he wants to be he says:

“... there's a little corner of the harbor when the wind blows at a certain angle, all the plastic that would otherwise wash up on the beach comes to the corner 
of the harbor. If that does that for a few days the corner of the harbor is a 20foot by 20 -foot floating mass of plastic junk. If you go with just the right lens and film the corner of the harbor, without showing that there's miles and miles and miles of clear open sea and even the whole rest of the harbor looks okay, if you film with just the right lens you can make it look like the Pacific Garbage Patch is a real disaster...As a conservation photographer, if I want to make the issue of ocean plastic pollution look really bad I can focus on that, leaving out all the good news and conversely you can do exactly the opposite. You can go to a city park and take a really beautiful picture of a cedar tree that carefully avoids the container facility that's right on the other side, or the power lines or whatever. Or you can go to a national park or go to a zoo and take a picture of a tiger that looks just like it was taken in the wild and conservation photographers do both of those things. My question is how to really authentically be a conservation photographer, how to not exaggerate in either direction. I have no idea what the answer to that is..."(Chris Jordan).

Chris Jordan is attempting to be neutral and as he says, he has no idea how to maintain a fully neutral aspect. I do not think there is any neutrality to be had. Any photograph cannot show the whole ocean and any photographer, perhaps especially not those creating images for a purpose, cannot fully eliminate their biases or conservation leanings. Indeed even how a photograph is presented after it leaves the photographers hands will influence how it is received, most likely in a non-neutral way (Seppänen \& Väliverronen, 2003).

\section{B. Communication Goals}

Marine conservation photographers are communicators. Communication is the main facet of their job. They individually vary based on personal goals and histories, but overall they want their work to promote conservation. Using the interviews and linking with communication theory it can be established that the marine conservation photographers interviewed here are communicating messages mostly of awareness, whether of the beauty of oceans and ocean life or

of the negative things happening to the ocean. They are communicating this through photographs and videos that are often accompanied by clarifying text or in-person presentations. 
Using terms defined by Jacobson (2009), ${ }^{6}$ the message source are the marine conservation photographers themselves. The audience that marine conservation photographers reach are the people who follow these photographers on social media, read the publications they or their images are featured in, see their films, or come to their talks and presentations. The audience is hugely varied and those who are already invested in the ocean are more likely to be reached than others. The most important and desired audience is decision makers who have the power to affect policy change.

The photographer's intended outcome, or the feedback they are hoping to see, is to raise awareness and love of the ocean. They also hope to get paid and have their images used by organizations or publications to reach larger audiences. Those publications, blogs, stories, or social media posts are all the context of the message. Once those organizations or publications use those images and encode the message, by placement choices and text and word choices for example, they may use the image to raise funds to achieve goals. The photographers also encode the message by choosing where to submit, what to include as a caption, and what other imagery they include.

In terms of the types of photography that Barrett (1986) defined, ${ }^{7}$ these photographers are making images that are purposefully ethically evaluative or aesthetically evaluative. These types of photographs in this field may also be able to function occasionally as descriptive photographs or explanatory photographs. For example, an image of a species of fish in an area could function as a tool to inform that that fish species or individual range includes that area. Similarly a video of a sea bird taking flight, such as in interviewee Chris Jordan's new film Albatross, ${ }^{8}$ could function as a tool for scientists studying bird flight. These images are therefore flexible within the photo categorizations, but the majority of the photos taken by the marine conservation photographers profiled in this thesis are ethically or aesthetically evaluative. Interpretive photographs within marine conservation photography do exist as well, though they are often very different from what is thought of as conservation photography. The image below shows an interpretive marine conservation photography photograph. This image was made for the purpose of inspiring ocean conservation and therefore is a marine conservation photograph.

\footnotetext{
${ }^{6}$ See page 15 of this thesis for a discussion of these terms.

${ }^{7}$ See page 24 of this thesis for definitions of these photograph types.

${ }^{8}$ More information on Chris Jordan's Albatross film can be found here: www.albatrossthefilm.com
} 


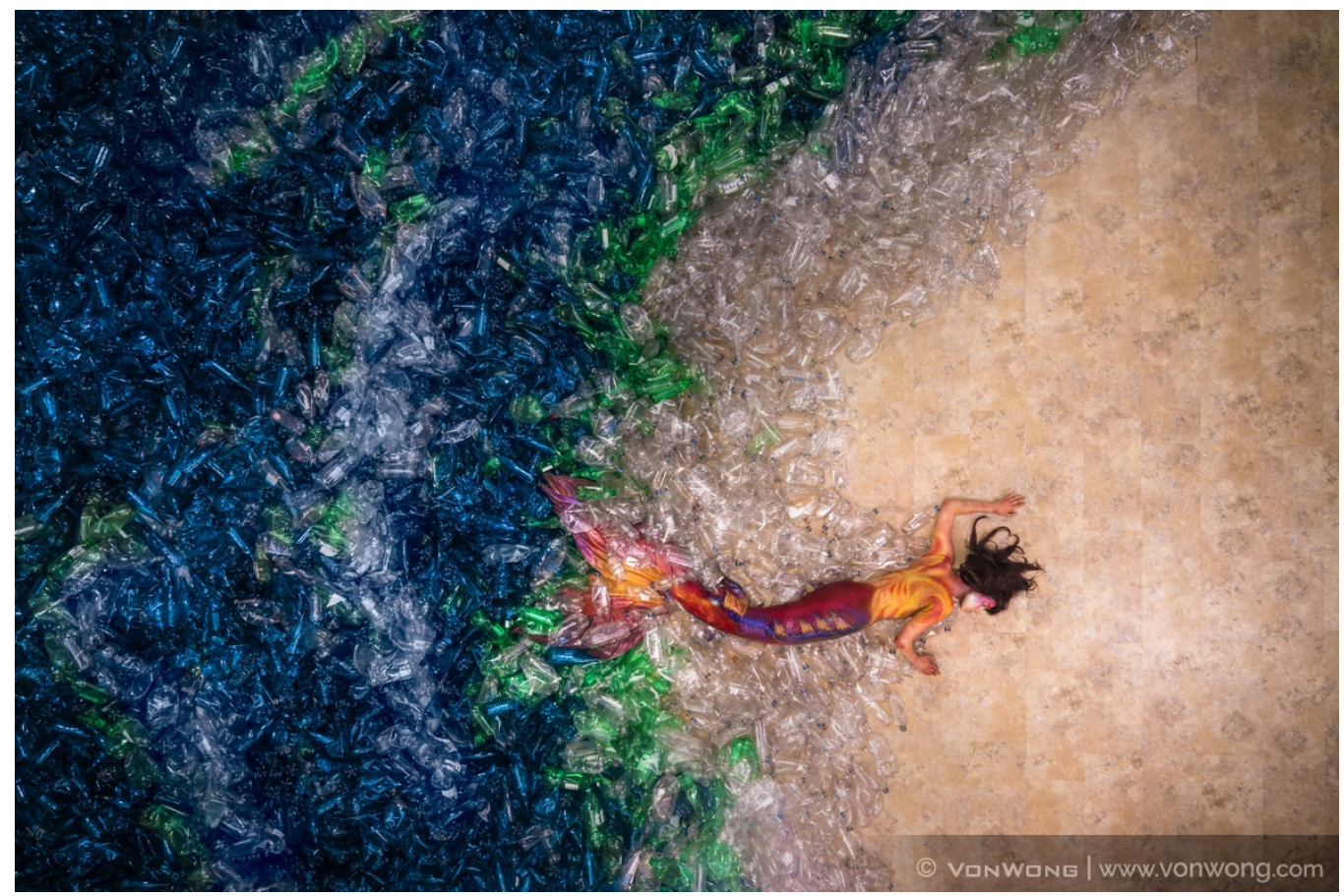

Credit: Von Wong

\section{Answering Research Questions}

The research questions that I used in developing the aide memoire for the interviewing process related to time and how marine conservation photography has changed, is at present, and will change. They were as follows:

1. How did the field of marine conservation photography look in the past?

2. How does the field of marine conservation photography look in the present?

3. How will the field of marine conservation photography look in the future?

The answer to research question one can be gleaned from some of the interviewees who have been in the field the longest. Answering question one also conveniently answers question two, because the past is often described in comparison to the present. One very noticeable way marine conservation photography looked differently in the past is the technology, largely thanks to the emergence of digital cameras. While camera gear is still fairly heavy and expensive, now 
better quality of capture can be gained from much less and lighter gear that is a fraction of the price. David O. Brown described the difference between now (in 2017) and only five or six years ago:

"Anyway, I had this rig and the whole rig cost, you know by the time you get the camera, the lens, the housing, all that crap, you get the hydrophones, put it all together, it was about 200 grand I was carrying into the water. And it weighed eighty pounds. I needed another human being with me just to get it down the side of the ice, the pack ice, to get to me, right. It was a major deal. I shot a polar bear hunting seals and above water, I'm humping 36 pounds of camera in through snow. Now I shoot four times that image and I'm using a rig that cost about 20 grand and I can pick it up with one hand and wave it around it over my head" (David O. Brown).

The change in gear availability and cost is definitely immense and makes underwater photography, and photography in general, much simpler. The barrier to enter any photography field is now much lower than in the past. Keith Ellenbogen describes this:

I think one big difference that's happened is the access to digital has changed people's ability to capture images and I think in a way, some of the craft of photography, the things that make photography so difficult are at the simplest level, much more easily accessible now and easily achievable with very little skill set. However, when looked in tandem, the art and the craft is still extraordinary, but the barrier is now much easier to be able to do. You know, when I first started you had film and you didn't know if it was right. You came back thinking every shot was fantastic and then all of a sudden you look at your film and you're like, "oy ay ay" not exactly what I was hoping for. If you had one good picture per ton, the learning was much slower. You had to keep meticulous notes. You would take the pictures and you didn't know. Now because you can learn instantly and see immediately, it's a quicker response and I think people's reactions are also quicker because they're bombarded much more frequently. So you have the two things that happened simultaneously. They see these things much more frequently, much more regularly, and people are able to achieve these things much more easily" (Keith Ellenbogen).

In the previous quote, Keith Ellenbogen also mentioned the more frequent bombardment of people with images. He may not have been remarking on the public's bombardment with images, but rather the photographers, but that is another way marine conservation photography 
was different in the past. More difficulty in taking images meant fewer images. Fewer images meant less dilution and more attention paid to the images that were disseminated. David O. Brown was one of the interviewees who commented on this:

"I'm always trying to think of how to have the most impact, right? How to actually effect change because when Cousteau came along and started doing the first underwater film making and there were only four channels on television or whatever and everybody was gathered around once a week to watch that was a tremendous audience and a tremendous impact and now anybody, any bozo with an iPhone can make a movie and there's so much crap out there that anything real gets diluted and it becomes the old needle in the haystack thing" (David O. Brown).

He also commented on how this has changed the effectiveness of conservation imaging from past to present.

"So I'm always wrestling with myself as to how to be most effective. How to be more effective. If anything I feel like there's been a lessening impact in the course of my career. I feel like conservation imaging is having less impact than it did, even though there's been a little bit of a resurgence with the March of the Penguins and Racing Extinction and Chasing Ice, etcetera" (David O. Brown).

While dilution of images in the marketplace might make effectively reaching an audience more difficult, Michele Westmorland has noticed a rise in interest and in attention among the audience that is reached.

"People lean forward now when you start talking ocean and environment and impacts. Because there's more communication about it. So I find them leaning forward as opposed to going snooze time. More interest. That's what I've seen as a big change, there's more interest" (Michele Westmorland).

"I think that the lexicon is certainly favorable now towards conservation photography and towards environmental awareness. I think it's heightened, it's so much more heightened now. People are willing to listen and they're willing to accept these kinds of testimonials from witnesses like photographers in the field who are seeing change and who are trying to work to bring about positive change" (Michele Westmorland). 
Based on the interviews I conducted, those were the major ways conservation photography has changed from the past to the present: an increase in access to photographic technology, an increase in ease of entry to photography, an increase in the number of images in the marketplace leading to decreasing effectiveness, and an increase in interest and attention by the audience that is actually reached.

Some of the photographers who spoke on these issues suggested that a selection of these changes will become more prevalent in the future. Equipment will get even cheaper and even easier to use. More and more images will pile up in the public sphere. It cannot be known whether audiences will become more or less interested as time moves along.

One specific way several photographers felt that marine conservation photography would be different in the future is in regard to money. Money as a theme was described starting on Page 56 , and excerpts from the quotes presented there show a pessimism about the ability to make a living in the future, as well as in the present, as a marine conservation photographer. Tanya Houppermans believes the monetary struggles will only get harder:

"So for those of us going out there and doing this, we need to earn money somehow. This is still a job. You know, I still have to pay my bills, I still have to maintain and upgrade my SCUBA equipment, my photography equipment. I think it's only going to get tougher and I don't see a lot of people being able to do this. Maybe on a part time basis, but full time not so much for specifically those of us who are videographers or photographers" (Tanya Houppermans).

From the accounts of these marine conservation photographers it is obvious that monetary struggles are and will continue to be a challenge in the marine conservation photography field.

\section{Limitations, Successes, and Challenges}

As I discussed in the Interviewing Methods section of this thesis, the aide memoire is a helpful document that provides some structure to an interview and demonstrates the competence of the interviewer (Bernard, 1988). The structure it provides is flexible in this type of interviewing and this flexibility was utilized in all the interviews I did. For example, my first interview required me only to ask the planned questions: What is the story of how your career 
started? And: Tell me about the reactions to your work over time, though during the interview this was adapted to: "Have you noticed any different reactions to your work over time?" Those two questions allowed the interviewee to tell the story of his career over the past and into the future. I had sent the interviewee a screenshot of one of his publications that I was planning on asking about and it was not necessary to ask my question regarding that image as he naturally came to that project while telling the story of his career. With the few questions I asked, some encouragement throughout, and a few small follow up questions during the interview, I was given answers to most of my unasked questions. This was not always the case. During other interviews I struggled to encourage the subject to tell me enough information and to think quickly enough to provide pertinent, non-repetitive follow up questions. There were multiple challenges I faced while conducting these interviews as well as some successes. I believe it is important to divulge those so others who may plan on using interviewing method can use my experience to guide their own. I will also discuss the limitations of this study.

Interviewing is not an exact science and learning by doing for adaptation is often a necessity. For example the question of: "Let's talk about one picture of yours [show picture in a publication]. How did this picture end up where it is and with the accompanying caption?" proved to be the least well received, the most confusing to interviewees, and gained the least information. Therefore it was cut out after the first few interviews. It seemed that I could often only find publications of photos by the photographers in articles about the photographers in question on the internet. This led to me relying on generalities such as: "How do the photos that you produce get to where they are and with the captions they are with or the text they are with? Walk me through that process." This was received with a need for clarification and provided non-relevant responses. I adapted to this by removing the question.

Another challenge I ran into for this research was the difficulty of obtaining in-person interviews or even video interviews. Most of the photographers I interviewed do not live in the Seattle area and most travel or are out in the field gathering images quite a bit. This left me with the problem of dealing with time zones and access. To remedy this, Skype was very helpful. Skype does freeze and lose connection occasionally though, interrupting the conversations in some cases. This was adapted to by making sure I at least had a good internet connection.

During the interviewing process I was aware that the extra practice would help my interviewing skills grow. While this is necessarily a good thing, it likely impacts my early 
interviews and places the early data retrieved at a relative disadvantage to the data I retrieved from later interviewees. This was nothing more than something to consider when going through and analyzing the data.

I found that the first question I asked everyone about how their careers in marine conservation photography started was a perfect introduction question that also yielded a lot of useful information and pushed the interviewees from the start to speak in a story format. This question was occasionally the only question I needed to ask to get answers to most of my further questions. Establishing and asking this introduction question was the single most helpful technique that I utilized during the interviewing process.

No research is without limitations. This research immediately is limited by a small sample size and irreproducibility of the exact data. My personal and locational biases in choosing participants is an immediate weakness. Interviewees were not randomly chosen from a master list of all marine conservation photographers in the world. In fact, as the field is not yet established as its own entity, there is difficulty in finding photographers who participate, as they likely do not identify as such publicly. The interviewees were selected based on my ability to find them. Thus, they all spoke English and were based in the United States, though most do their photographic work around the world. Two of the eight make their homes in Washington State near Seattle (Michele Westmorland and Chris Jordan) and were selected with the knowledge that I could do in person interviews. This small sample size that consists of only photographers living in the Unites States limits the scope of marine conservation photography that is covered. What marine conservation photography looked like in the past and looks like in the present and future is only identifiable for this limited subset of the participants.

This research is qualitative, which lends it both strength in one sense and weakness in another. If this study were designed to be quantitative the data would likely not be as rich and ethnographic. However it also means the study is irreproducible. The same exact questions were not asked of each interviewee as the conversation was adapted with and the individuals catered to. Some individuals were interviewed in their homes and others over Skype or over the phone, lending a different level of depth to each individual's stories. The variation throughout the data collection means the data is not as strong and definitive as it could be and the sample size not as large, though a quantitative research design using structured interviewing would not produce as vivid and deep ethnographic information. 
Future research that could vastly help the fields of marine conservation photography and conservation photography lies in the hard-to-measure realm of feedback and whether it is successful based on the message or not. What does marine conservation photography and conservation photography actually achieve? What conservation actions can be solely or partially attributed to conservation photography? How often is conservation photography translated into action? This conundrum presents a measurement difficulty, for how can the scale or impact of imagery be quantified to determine how much the imagery was responsible for the designation of a protected area for example? Determining a way to answer these questions, whether on a governmental or individual scale, would give further legitimacy to conservation photography or would indicate room for improvement and a need to push towards that.

\section{CONCLUSION}

In this thesis I introduced the field of marine conservation photography from a communications standpoint. I obtained and recorded a variety of conversations with marine conservation photographers. Major emergent themes included money, education, work, love, and positivity. Included is a discussion of marine conservation photography as it stood in the past and stands in the present and future.

The approach used applied an extension and adaptation of communication theory and data collection through semi-structured interview technique. The approach for data collection proved fruitful, and rich portraits of eight marine conservation photographers were obtained.

This thesis is not the final statement for the marine conservation photography field, this is simply a first chapter in what could be a long and detailed manuscript. In the future I hope to see others such as fine art scholars, historians, social scientists, and marine conservation photographers themselves producing works from their viewpoints on this field. I hope to see an expansion of this field, with more marine conservation photographers included in conservation photography conferences, trainings, or publications, as well as marine conservation photographers creating their own specialized events.

The field of marine conservation photography itself is a strong tool for organizations to use for fundraising, education, awareness, and campaigning. The approach taken in this body of 
work implementing communication theory and interviewing could be extended to many other domains in marine and environmental affairs such as oil and gas, fisheries, tourism, community resilience and more. In sum, this thesis serves to advocate for the further establishment of the field of marine conservation photography. 


\section{BIBLIOGRAPHY}

Aldo Leopold. (1968). A Sand County Almanac: With Other Essays on Conservation from Round River (Second Edition). Oxford, New York: Oxford University Press.

Aldo Leopold. (n.d.). Retrieved April 4, 2018, from https://www.aldoleopold.org/about/aldoleopold/

Ansel Adams. (1983, May). Playboy Interview: Ansel Adams [Playboy]. Retrieved from https://www.abebooks.com/first-edition/Playboy-Interview-Ansel-Adams-1983Chicago/2916474937/bd

Aristotle. (2000). Rhetoric. (W. Rhys Roberts, Trans.). Adelaide: The University of Adelaide Library. Retrieved from http://ebooks.adelaide.edu.au/a/aristotle/a8rh/

Barnlund, D. (1970). A Transactional Model of Communication. In J. Akin, A. Goldberg, G. Myers, \& J. Stewart (Eds.), Language Behavior: A Book of Readings in Communication (Reprint 2013, pp. 43-61). Berlin, Boston: De Gruyter Mouton. https://doi.org/10.1515/9783110878752

Barnlund, D. C. (1962). Toward a Meaning-Centered Philosophy of Communication. Journal of Communication, 12(4), 197-211. https://doi.org/10.1111/j.1460-2466.1962.tb01547.x

Barnlund, D. C. (1981). Rigor \& imagination: Essays from the legacy of Gregory Bateson. In C. Wilder-Mott \& J. H. Weakland (Eds.), Toward an Ecology of Communication (pp. 87126). New York, NY, USA: Praeger.

Barone, J. T., \& Switzer, J. Y. (1995). Interviewing: Art and Skill (1 edition). Boston: Pearson.

Barrett, T. (1986). Part III. Teaching about Photography: Types of Photographs. Art Education, 39(5), 41-44. https://doi.org/10.2307/3192925 
Bennett, J. M. (2012). The public and private Dean Barnlund. International Journal of Intercultural Relations, 36(6), 780-788. https://doi.org/10.1016/j.ijintrel.2012.08.007

Bernard, H. R. (1988). Research Methods in Cultural Anthropology (1 edition). Newbury Park, Calif: AltaMira Press.

Blewitt, J. (2011). The media, animal conservation and environmental education. Environmental Education Research, 17(6), 711-718. https://doi.org/10.1080/13504622.2011.625624

Borges, M. A., Stepnowsky, M. A., \& Holt, L. H. (1977). Recall and recognition of words and pictures by adults and children. Bulletin of the Psychonomic Society, 9(2), 113-114. https://doi.org/10.3758/BF03336946

Boynton, R. S. (2005). The New New Journalism: Conversations with America's Best Nonfiction Writers on Their Craft. New York: Vintage.

Brady, J. (1977). The Craft of Interviewing (1st THUS edition). New York: Vintage.

Burke, K. (1968). Language As Symbolic Action: Essays on Life, Literature, and Method. Berkeley: University of California Press.

Burkeman, O. (2002, March). Oliver Burkeman talks to Studs Terkel. Retrieved from http://www.theguardian.com/books/2002/mar/01/studsterkel

Carlton Ward Jr. (2008). Conservation Photography. University of Florida. Retrieved from http://etd.fcla.edu/UF/UFE0021860/ward_r.pdf

Chiao, J. Y., Lidaka, T., Gordon, H. L., Nogawa, J., Bar, M., Aminoff, E., ... Ambady, N. (2008). Cultural specificity in amygdala response to fear faces. Journal of Cognitive Neuroscience, 20(12), 2167-2174. https://doi.org/10.1162/jocn.2008.20151

Clark, R. A., \& Delia, J. G. (1979). Topoi and Rhetorical Competence. Quarterly Journal of Speech, 65(2), 187. 
Cox, R. (2012). Environmental Communication and the Public Sphere (Third). SAGE Publications.

Cristina Mittermeier. (2005). Conservation Photography: Art, Ethics, and Action. International Journal of Wilderness, 11(1), 8-13.

Cronkhite, G. (1986). On the focus, scope, and coherence of the study of human symbolic activity. Quarterly Journal of Speech, 72(3), 231-246.

https://doi.org/10.1080/00335638609383771

DeLuca, K. M., \& Demo, A. T. (2000). Imaging nature: Watkins, Yosemite, and the birth of environmentalism. Critical Studies in Media Communication, 17(3), 241-260. https://doi.org/10.1080/15295030009388395

Derraik, J. G. B. (2002). The pollution of the marine environment by plastic debris: a review. Marine Pollution Bulletin, 44(9), 842-852. https://doi.org/10.1016/S0025$326 \mathrm{X}(02) 00220-5$

Dexter, L. A. (2006). Elite and Specialized Interviewing. ECPR Press.

Domke, D., Perlmutter, D., \& Spratt, M. (2002). The primes of our times?: An examination of the 'power' of visual images. Journalism, 3(2), 131-159. https://doi.org/10.1177/146488490200300211

Doney, S. C., Fabry, V. J., Feely, R. A., \& Kleypas, J. A. (2009). Ocean Acidification: The Other CO2 Problem. Annual Review of Marine Science, 1(1), 169-192. https://doi.org/10.1146/annurev.marine.010908.163834 
Duarte, C. M., Fulweiler, R. W., Lovelock, C. E., Martinetto, P., Saunders, M. I., Pandolfi, J. M., ... Nixon, S. W. (2015). Reconsidering Ocean Calamities. BioScience, 65(2), 130-139. https://doi.org/10.1093/biosci/biu198

Ducarme, F., Luque, G., \& Courchamp, F. (2013). What are “charismatic species” for conservation biologists? BioSciences Master Reviews, 1, 1-8.

Dunaway, F. (2005). Natural Visions. University of Chicago Press. Retrieved from http://www.press.uchicago.edu/ucp/books/book/chicago/N/bo3630546.html

Ed Lee. (2016). Fun Facts About the Photography Market via InfoTrends. Retrieved February 18, 2018, from http://blog.infotrends.com/?p=21310

Encyclopædia Britannica. (n.d.). Harold Lasswell | American political scientist. Retrieved November 30, 2017, from https://www.britannica.com/biography/Harold-Lasswell Farnsworth, B. (2011). Conservation photography as environmental education: focus on the pedagogues. Environmental Education Research, 17(6), 769-787. https://doi.org/10.1080/13504622.2011.618627

Foale, S., \& Macintyre, M. (2005). Green fantasies: Photographic representations of biodiversity and ecotourism in the Western Pacific. Journal of Political Ecology: Case Studies in History and Society. Retrieved from https://openresearchrepository.anu.edu.au/handle/1885/80019

Fontana, A., \& Frey, J. H. (1994). Interviewing: The Art of Science. Thousand Oaks: Sage Publications.

Frijda, N. H. (2000). Emotions. In K. Pawlik \& M. R. Rosenzweig, International handbook of psychology (pp. 207-222). London, United Kingdom: Sage Publications. 
Hastings, G., Stead, M., \& Webb, J. (2004). Fear appeals in social marketing: Strategic and ethical reasons for concern. Psychology \& Marketing, 21(11), 961-986. https://doi.org/10.1002/mar.20043

Huggins, C. (2014). Arranging and Conducting Elite Interviews: Practical Considerations. Infante, D. A., Rancer, A. S., \& Womack, D. F. (2003). Building Communication Theory. Waveland Press.

International Environmental Communication Association. (2015). Environmental Communication: What it is and Why it Matters | The IECA. Retrieved October 19, 2017, from https://theieca.org/resources/environmental-communication-what-it-and-why-itmatters

International League of Conservation Photographers. (n.d.). Retrieved April 1, 2018, from https://conservationphotographers.org/about-us/

Iyengar, S., \& Kinder, D. R. (1989). News That Matters: Television and American Opinion (Reprint edition). Chicago: University Of Chicago Press.

Jacobsen, S. K., \& McDuff, M. D. (2008). Communication as an Effective Management Strategy in a Diverse World. In M. J. Manfredo, J. J. Vaske, P. J. Brown, D. J. Decker, \& E. A. Duke (Eds.), Wildlife and Society: The Science of Human Dimensions (1 edition, pp. 301-314). Washington, DC: Island Press.

Jacobson, S. K. (2009). Communication Skills for Conservation Professionals. Island Press.

Kaplan, S., Kaplan, R., \& Sampson, J. R. (1968). Encoding and arousal factors in free recall of verbal and visual material. Psychonomic Science, 12(2), 73-74. https://doi.org/10.3758/BF03331199 
Khanfar, Y. (2013). Photography: The Language of Light. World Literature Today, 87(2), 2831. https://doi.org/10.7588/worllitetoda.87.2.0028

Kvale, S. (1996). InterViews: An Introduction to Qualitative Research Interviewing (1 edition). Thousand Oaks, Calif: SAGE Publications, Inc.

Lang, P. J., Bradley, M. M., \& Cuthbert, B. N. (2008). International Affective Picture System (IAPS): Technical Manual and Affective Ratings. Technical Report A-8.

Leader-Williams, N., Adams, W. M., \& Smith, R. J. (2010). Deciding What to Save: Trade-Offs in Conservation. In L.-W. Nigel, W. M. Adams, \& R. J. S. Fellow (Eds.), Trade-Offs in Conservation (pp. 1-13). Wiley-Blackwell. https://doi.org/10.1002/9781444324907.ch1

Lewenstein, B. V. (1995). From Fax to Facts: Communication in the Cold Fusion Saga. Social Studies of Science, 25(3), 403-436. https://doi.org/10.1177/030631295025003001

Littlejohn, S. W., \& Foss, K. A. (2010). Theories of Human Communication: Tenth Edition. Waveland Press.

Lorimer, J. (2006). Non-human charisma: Which species trigger our emotions and why? ECOS, 27(1), 20-27.

Luis A. Vivanco. (2002). Seeing Green: Knowing and Saving the Environment on Film. American Anthropologist, 104(4), 1195-1204.

Miles, J., \& Gilbert, P. (Eds.). (2005). A Handbook of Research Methods for Clinical and Health Psychology (1 edition). New York: Oxford University Press.

Milstein, T. (2009). Environmental Communication Theories. In Stephen W. Littlejohn \& Karen A. Foss, Encyclopedia of Communication Theory (Vol. 1, pp. 344-348). SAGE Publications. Retrieved from http://www.academia.edu/2221482/Environmental_Communication_Theories 
Moser, W. (2011, August 1). Studs Terkel on How to Interview Someone. Retrieved April 1, 2018, from http://www.chicagomag.com/Chicago-Magazine/The-312/July-2011/StudsTerkel-on-How-to-Interview-Someone/

Nanda, U., Zhu, X., \& Jansen, B. H. (2012). Image and Emotion: From Outcomes to Brain Behavior. HERD : Health Environments Research \& Design Journal; London, 5(4), 4059.

Norton, B. (2016). Conservation Photography Handbook: How to Save the World One Photo at a Time. Buffalo, NY: Amherst Media.

O’Neill, S., \& Nicholson-Cole, S. (2009). "Fear Won’t Do It": Promoting Positive Engagement With Climate Change Through Visual and Iconic Representations. Science Communication, 30(3), 355-379. https://doi.org/10.1177/1075547008329201

Paivio, A., Rogers, T. B., \& Smythe, P. C. (1968). Why are pictures easier to recall than words? Psychonomic Science, 11(4), 137-138. https://doi.org/10.3758/BF03331011

Patton, K. (2006). The Sea Can Wash Away All Evils: Modern Marine Pollution and the Ancient Cathartic Ocean. New York, UNITED STATES: Columbia University Press. Retrieved from http://ebookcentral.proquest.com/lib/washington/detail.action?docID=908538

Payne, S. L. B. (1951). The Art of Asking Questions: Studies in Public Opinion, 3. Princeton, New Jersey: Princeton University Press.

Petersons, A., \& Khalimzoda, I. (2016). Communication Models and Common Basis for Multicultural Communication in Latvia. SOCIETY. INTEGRATION. EDUCATION. Proceedings of the International Scientific Conference, 4, 423. https://doi.org/10.17770/sie2016vol4.1555 
Quine, W. V. (1969). Ontological Relativity \& Other Essays. New York: Columbia University Press.

Rabionet, S. (2011). How I Learned to Design and Conduct Semi-structured Interviews: An Ongoing and Continuous Journey. The Qualitative Report, 16(2), 563-566.

Rosenblum, N., Andy Grundberg, Beaumont Newhall, \& Robert Gernsheim. (n.d.). history of photography | Inventions \& Events. Retrieved April 26, 2018, from https://www.britannica.com/technology/photography

Ryan, F., Coughlan, M., \& Cronin, P. (2009). Interviewing in qualitative research: The one-toone interview. International Journal of Therapy and Rehabilitation, 16(6), 309-314. https://doi.org/10.12968/ijtr.2009.16.6.42433

Ryan, G. W., \& Bernard, H. R. (2003). Techniques to Identify Themes. Field Methods, 15(1), 85-109. https://doi.org/10.1177/1525822X02239569

Salzman, C. D. (n.d.). Amygdala | anatomy. Retrieved May 7, 2018, from https://www.britannica.com/science/amygdala

Sandbrook, C. (2015). What is conservation? Oryx, 49(4), 565-566. https://doi.org/10.1017/S0030605315000952

Sapienza, Z. S., Iyer, N., \& Veenstra, A. S. (2015). Reading Lasswell's Model of Communication Backward: Three Scholarly Misconceptions. Mass Communication and Society, 18(5), 599-622. https://doi.org/10.1080/15205436.2015.1063666

Schirato, T., \& Yell, S. (2000). Communication and Culture: An Introduction. SAGE.

Seppänen, J., \& Väliverronen, E. (2003). Visualizing Biodiversity: The Role of Photographs in Environmental Discourse. Science as Culture, 12(1), 59-85. https://doi.org/10.1080/0950543032000062263 
Shannon, C. E., \& Weaver, W. (1975). The Mathematical Theory of Communication (First Edition). Urbana: The University of Illinois Press.

Sveen, K. (2016). Leverage efficiency with optimised information security communication. 118. Retrieved from https://brage.bibsys.no/xmlui/handle/11250/2403085

Terkel, S. (1970). Hard Times: An Oral History of the Great Depression (1st edition). Pantheon Books.

Terkel, S. (1997). Working: People Talk About What They Do All Day and How They Feel About What They Do. New York: The New Press.

Terkel, S. (2001). Will the Circle Be Unbroken?: Reflections on Death, Rebirth, and Hunger for a Faith by Terkel, Studs. The New Press.

V.H. Heywood. (1995). Global Biodiversity Assessment (Published for United Nations Environment Programme). Cambridge, UK: Cambridge University Press.

Zhang, Y., \& Wildemuth, B. M. (2006). Unstructured Interviews. Retrieved from http://hsmi.psu.ac.th/upload/forum/Unstructured_interviews.pdf 


\section{APPENDIX}

\section{INTERVIEW PROFILES}

Table of Contents

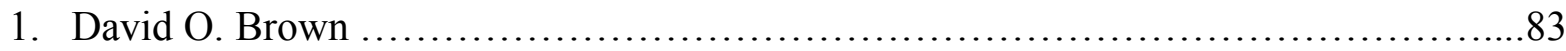

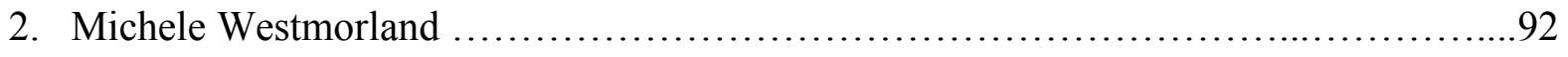

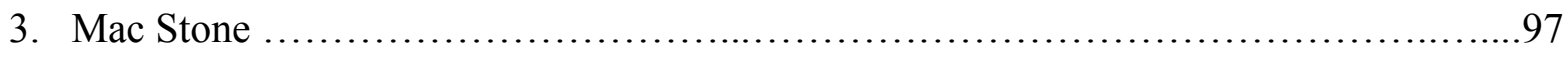

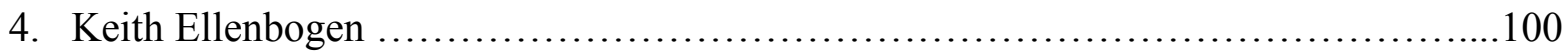

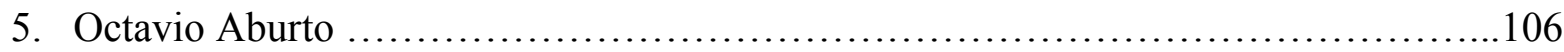

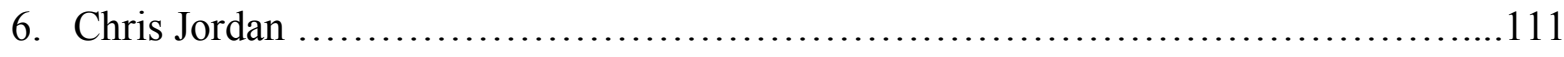

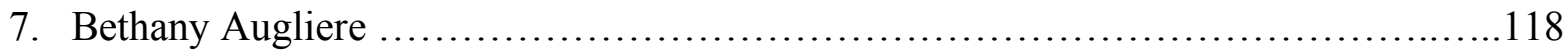

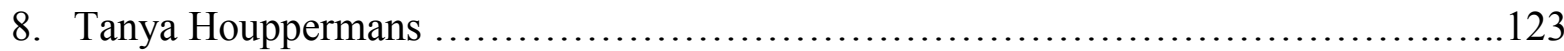


David has had a long career as an underwater photographer and ocean communicator. His resume includes such feats as being the first person to broadcast to the internet from under the ocean, documenting the search and finding of a lost submarine, working with the Cousteau's and filmmaking. He is currently based in Ithaca, New York.

\section{Website: davidobrown.com}

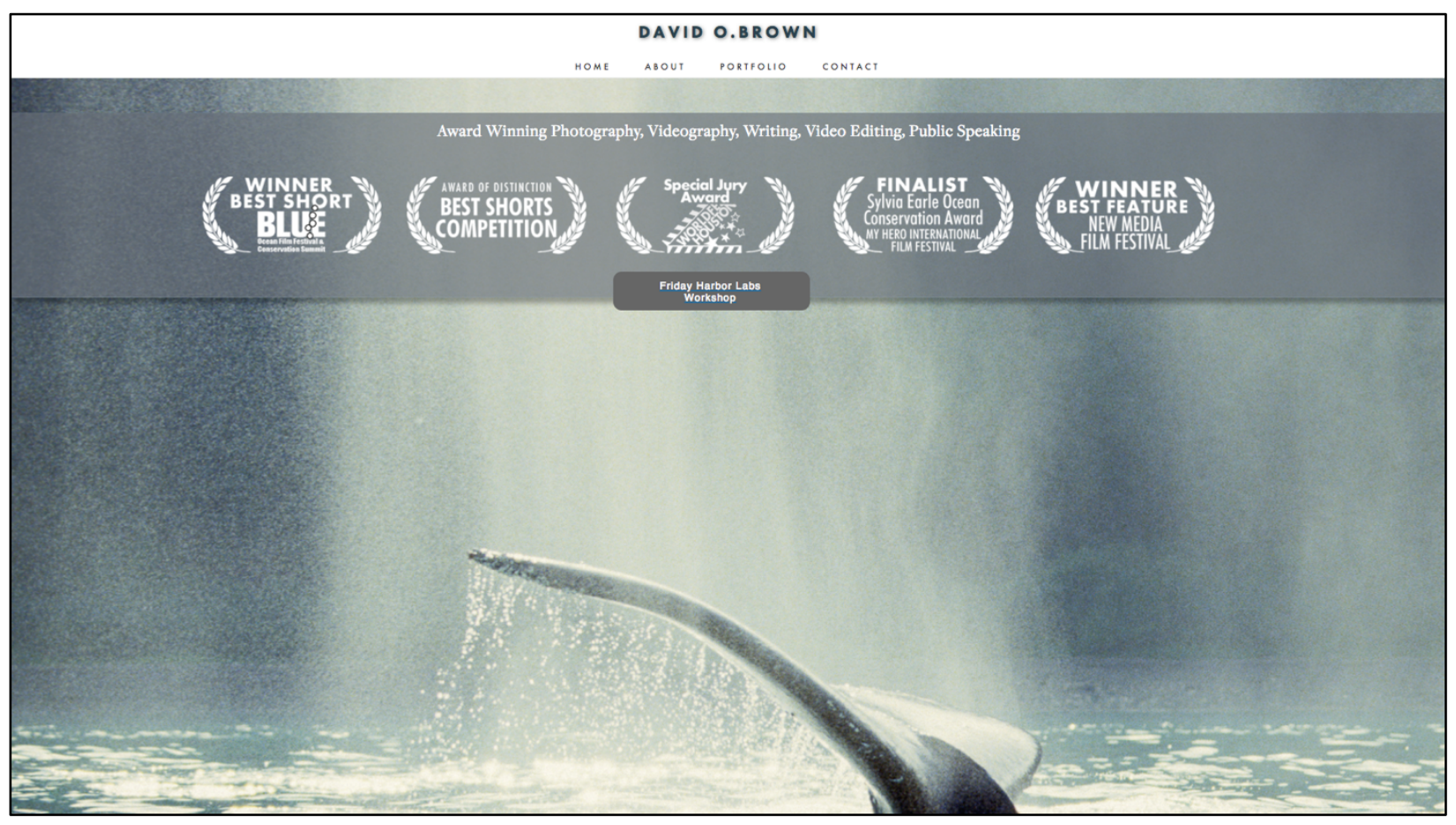

I can hear the distinct sound of traffic in the background as David and I speak over the phone. With a friendly voice, he tells me about his long history in the conservation photography world and his passion for past and future projects is evident in every word.

When I was an undergrad at Cornell University I got a summer job working as a naturalist and researcher for whale watches out of Gloucester, Massachusetts. I found that I enjoyed working with the public. I enjoyed interpreting the natural events that I was seeing on the whale watches for them. I enjoyed the research and part of the research was to take fluke shots. We needed to get the underside of the tail of the animal when we found it for identification purposes. That was all shot on Tri-X, which was black and white film that we could soup ourselves. We would buy it in bulk and roll it through our cameras. The pattern on the underside of whale tail, of a humpback tail anyways, is black and white, and so it could be in black and white. It was a cost-effective way to do it and we would soup it ourselves, we'd do all the processing ourselves, and then we've got a catalog of fluke shots. 
So a big part of the job was to get fast with the camera on the water, on a moving craft. All the time we're standing on the wheelhouse of a whale watching boat bouncing around. Get fast because the animal sounds and it takes three seconds for it to disappear. You've got to be positioned and you've got to get the shot and all that stuff. I'd do that and then we would get our IDs and every now and again I'd sneak a little color in there because we would have something spectacular going on, an animal breaching or a flipper slapping or whatever it was doing, and lobtailing and so I'd shoot some of that and lo and behold, I could sell that I realized. So here I was making 50 bucks in whale research, but I could make a hundred and fifty bucks selling a shot at the time. So I sold to Ranger Rick and some of the other magazines that wanted shots of whales.

I had thought I was going to be a biologist because I've always been an animal crazy. And I thought in particular I wanted to be marine biologist because I love the ocean, always have. But I didn't care for the necessity to mess with the critters in a major way to get a lot of biology done and so once I realized I could actually make money of sorts shooting wildlife photography, I thought hey, maybe this is a good way to have a good excuse to get close to the animals and be in their space, but not do any damage and not really interfere. You know, the whole idea is to be as close as you can be and get the best behavior you can get and document it, but you don't have to mess with them and I enjoyed that. I understand there's a really important reason to put in taggers and trackers and I've shot a lot of tagging and tracking operations and that's really key work. But from my personal way of interacting with critters, I like to just be in their environment, share their space and ideally not interfere with them. So that really got me started and I went from there.

My last semester at Cornell was with the Sea Semester at Woods Hole. It was the maiden program and it's just really incredible for undergrads from anywhere. You get on a sailing research vessel and go to sea. You learn basic marine biology, oceanography, maritime history, celestial navigation, all that stuff on shore for six weeks and then you go to sea for six weeks and I'm shooting while I was doing that. That was my last semester as an undergrad and I loved it and I jumped off the ship in St Thomas a free man. I was a graduate. So I started my big plan. I was kind of, I guess that I was kind of a Bohemian in my thought at the time. I thought, I like shooting pictures. I like to write, and I love the ocean so maybe I'll sail my way around the world, you know, crewing and just photograph the whole thing and write about it! It sounded like a great idea.

I was in Miami, Florida, on a ship for the yard period and got offered a job as a whale trainer at the Miami Seaquarium. I'd never seen a whale in captivity. I'd never seen a whale show. I went to see one and ended up talking to the trainer and he persuaded me that I should at least try it even though I had reservations with the practice. He said, well I need another trainer. There's two of us, we lost one, we need three and it could be you or it could be someone who doesn't care about animals, so give it a try. So I said I'll give it a try, I don't particularly think it's a great idea to put a killer whale in a swimming pool, but I'll try. Sure enough I hated it, I lasted about four months. I was working with an Orca and a white sided dolphin. It was wonderful to be close to them, but the Orca in particular was so mentally damaged that it just wasn't a real authentic experience of the creature.

So I quit, and I was all set to go on a yacht, going trans-Atlantic coast, and I was going to start my big voyage and I got word that the Cousteau's were going to be represented at the Miami Ocean Fest. So I said, "Oh, I'll go talk to them and see if maybe there's some possibilities there," and sure enough there was! I ended up talking to the guy who's in charge of that for them and he 
said, "Well, I think you might be exactly what we need because we're looking for someone who has some field skills, but who could also go out and represent us on the road in the universities and colleges, trade associations, and all that about the Marine Environment and you strike me as reasonably eloquent." So I said, "Great. Well what do you want me to do." He said, "Well, set up something where I can see it, set up an event and present and you can make it about anything you want that's ocean related and I'll come see it and if I like it then we'll take the next step." So I got off the phone with him, I went home, I went to the apartment I was about to leave and told my roommates, they already knew I was leaving to go on the yacht. I called the captain of the yacht, I said "Hey somethings come up, I got this opportunity and I want to try to see this through." So I got in, you know, got in a drive away car, or I hitchhiked, I can't even remember, but I got to New York, which is where I'm from and I stayed with some friends in the city and I started calling around and one of the first calls was the American Museum of Natural History and they... is this too much information? Do you want me to cut to the chase? You can tell there ain't no formula, it's not a formulaic approach. I was just following my heart and it ended up working out okay.

So anyway, I called the American Museum of Natural History and on the way up I decided I would talk about the human relationship to cetaceans in the wild versus captivity. Because by then I'd worked for the natural whale watches in the wild. So with the people having an authentic experience with the animals, and I'd worked in captivity where they were watching, you know, a deranged whale do tricks for them. So I had some pretty strong opinions about it and I had a lot

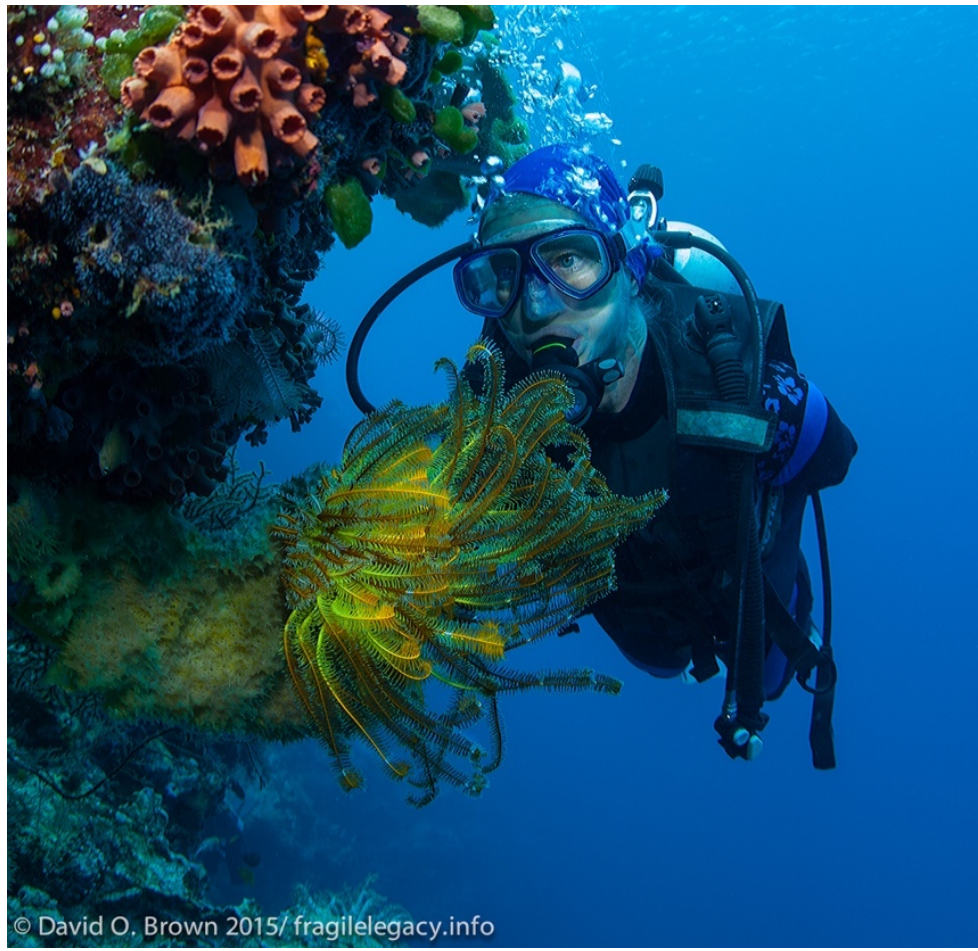

Credit: David O. Brown of slides to illustrate the whole thing. So I called up the museum and they said, "Well, talk to the American Cetacean Society because they meet here every month and could be interested." So I called them up and said, you know, "Would you'd be interested in a talk, a discussion of humans relating to whales in the wild versus captivity?" They said, "Yeah! It's timely, come on, come on, do it." I said, "When you want to do it?" They said, "next month" and I go, "okay..." and I get off the phone.

This is like two or three days after I'd left Miami right. I mean it just happened really fast and I pick up the phone and I call the guy who had been setting up the Cousteau event in Miami, and I said, "Hey this is David, what are you doing on, you know, such and such a day and can you come to the American Museum of Natural History and see a presentation?" There is this dead silence on the other end of the phone. He hadn't expected it that fast. He said, "Yeah, I'll be there." So he showed up and I gave my talk and it was well received and he liked it and he said, 
"OK, great. Now you've got to talk to the Cousteau's." I said, "Great, let me at them, where are they?" And he said, "Well I don't know. They are somewhere in the world right now. We're not quite sure where. But I'll set up an interview." So I said, "All right, well just let me know."

So I went back to Gloucester where I had been doing the whale watching and I figured I'd cover my ass because I didn't know if I was going to get the job. So I went back to Gloucester and I needed just a little bit more sea time to be able to sit for my coast guard license, for my hundred-ton operator's license. So I went back and I signed on as a mate on old whale watches that I'd worked on and said, "OK, I just need sea time. I need to be able to work some hours." And every week I called this guy in New York saying, "Where are they? Where are they? Where are they?" And he's like, "Well..." He set it up three or four times. They were really, you know, they were all over the place so it was really hard to schedule them and every time it got canceled or postponed. Finally in September, that was in June that I went up to Gloucester, and it's September. Seasons up and I've sat for my Coast Guard license, all that stuff. Phone rang and he says, "Can you be in New York tomorrow? The Cousteau's are both going to be here JeanMichelle and Captain Cousteau." And I said, "Sure!" So I showed up and actually I was told I had walking pneumonia. I froze my tail off on the whale watches! Anyway, so I spoke to both of them and they were very, uh, very, well Jean-Michelle was very challenging. He would throw out these weighty philosophical questions to try to get out how I viewed the world, but his dad, Captain Cousteau was very friendly and very supportive and looked at my photos and all that and that night they offered me the job and I ended up doing that for seven years.

So I was a still photographer in the field for them and then a production diver in the field and then I'd represent them on shore. So every fall and every spring I'd do a lecture circuit and I'd take my images. I was work for hire, so they owned everything that I shot, but I would take images and I had access to the whole Cousteau archive going back to the forties, which was pretty cool, to build these multimedia presentations. So I did that and loved it and I got to go on some pretty cool expeditions. Stopped that in the early nineties, 91. I'd been there seven years and I just was kind of burned out because the last year there I was on four expeditions. I had lectured at, I don't know, 45, 50 colleges, universities and trade associations and, I'd just been gone. I didn't have a home the whole seven years, just go wherever they put me basically, so I was kind of burned out and I'd had this idea of doing uplinks, which at the time no one had ever heard of. Basically doing live broadcasts from underwater to various venues, and so I wanted to pursue that! Neither of the Cousteau's were really interested in that because they didn't like the quality of video at the time and it had to be video, obviously, couldn't do it on film. It was real time. But I really felt strongly that the immediacy of the experience would compensate for any loss of quality in the imaging and such. It wasn't about the quality of the imaging as much as it was about the experience and it was a way to reach people who wouldn't otherwise pay attention to what's going on underwater. So they both said uhhhh ahhhhh, we don't really want to do that. So I said alright I'm going to do it, I'm going to start a company. So I did and had a company out of Santa Barbara for about 10 years doing that and did it all over the world.

At one time, I had three teams of three divers, you know, working at any given moment anywhere in the world. We did the first internet broadcast ever in '97 from Fiji. People loved it! It really dug in and it was really, really cool. Really hard to make money doing. Really hard to support a family on and I had gotten married, I don't know, when did I get married? I got married a while ago. It was in August because that's when our anniversaries happen, but I don't have any idea what the year was. Anyway, so we had a kid and my old family back here in Ithaca, New York had difficulties. My Dad had died, my mom had a stroke and she was in a nursing home 
here. We couldn't really move her to Santa Barbara, she was too damaged. And, you know, here I was an independent marine cinematographer, photographer, whatever. It seemed like a very strange move on some levels because Ithaca is not exactly a maritime city, but at the same time it's a quality place on a lot of other levels because there's a really interesting blend of culture and nature here because we've got gorges coming all the way through town and I grew up swimming in the streams and lakes and all that stuff. So we decided, my wife was a web designer at the time and a Pilates instructor in Santa Barbara and, and so she was independent, I was independent. We said, OK, we'll try it. We'll come back to Ithaca as long as we are needed here, we will stick around and then we'll come back to the ocean. That was, my kid is now 17 so that was a while ago. He was one and a half when we moved back here.

So I've been doing a lot of travel for my ocean work still, but I've also been doing a lot of freshwater underwater work. I just finished, in fact it was just posted up, a hellbender film. It's an aquatic salamander that occurs around here that's endangered or it's in trouble. I've designed a few, an executed a few museum exhibits that go from inland to ocean and really count watershed health and all that. When I moved back here, I was shocked to find out that there was a possibility of hydrofracking here. What a stupid thing to do! You've got incredible freshwater resources here. I'm in the Finger Lakes region. We've got just incredible freshwater resources and they were ready to trade that for, you know, natural gas. So anyway, I donated a bunch of footage to a bunch of anti-fracking groups and did a lot of speaking out about that and we managed to keep it out of here for now. God knows what's going to happen with the powers that be on a national level now, but so far the state's holding, and we still like it here. I still trip out for the ocean stuff.

The photo you sent from The Times was from a Fragile Legacy project. That project came about honestly enough. I was walking through the Johnston Art Museum, which is Cornell's art museum, and I looked down. I was going past a showcase and I looked down and there was a squid, and a nudibranch, and a flatworm and they all looked like the real deal. They looked like they were just plopped there and I got really excited for obvious reasons and very surprised. I looked at the caption on it and turned out they were made by Rudolph and Leopold Glaschka who were turn of the century naturalist artisans. Glass masters at the turn of the last century who produced perfect glass replicas of over 600 species of marine invertebrates. Because at the time that was the way that people could experience the animals. Most people couldn't get under water obviously, and they produced these things and sold them all over the world and Cornell's president at the time authorized purchases of a collection here and we have the largest collection at Cornell that was used for teaching marine biology,

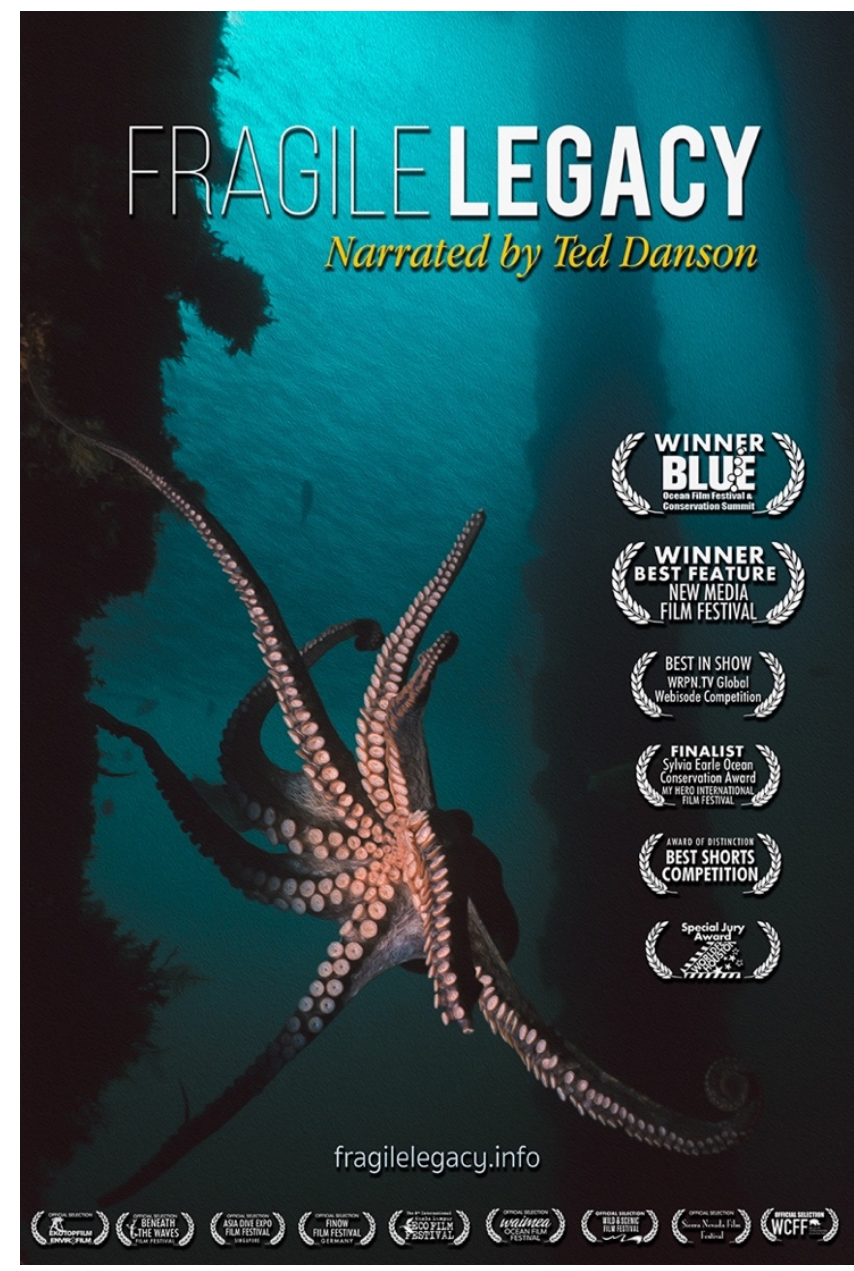


because they're perfect. They are perfect replicas of these creatures.

I saw that and I got really excited about it and I went to see a presentation by the curator of that collection, who also happens to be one of the preeminent marine biologists in the world, Drew Harvell. She's a coral reef ecologist and I was sitting in the audience, you know, watching and getting more and more excited and I happened to be sitting with a guy named Chuck Green, who's an oceanographer, climate change scientist who I'd filmed in Hawaii years before that. So we're hanging out and I'm getting more and more excited. I'm like, Chuck, this is incredible. I've got to make film about this. He says well, let's go talk to Drew. Well turns out he's married to Drew. So we went up and waded through throngs of admirers and I got up to her. I said, "This is an incredible story, I've got to make a film. It's just too good not to make a film." She said, "OK."

So then it was a matter of piecing together enough resources and we never quite got enough. But we did manage to get some grants from a variety of sources, mini grants, and I pieced together a very small budget to produce the film and it was supposed to produce kind of a sales demo to be able to sell it to Nature or Nova or whomever and get a real budget to execute. I ended up getting really carried away because the story is amazing. These guys were working just as the industrial revolution was rolling into full steam. Leopold, the father, was on an ocean voyage in the 1860 s, traveling from Europe to the Americas by sail, because at the time hardly anyone was traveling by steam yet, and they were becalmed off the Azores. They were becalmed for two weeks. He went out on deck and most of the guys were probably playing poker below decks, and he was up on the rail looking over and he saw a jellyfish pulsing by and said, "those are amazing they look like glass I'm going to make them" because he was from a long line of, an ancient lineage of glass masters. So he went back to Europe and did it. Then his son came into the business. They were, of course, the precursor to what I do now, which is trying to capture accurately the marine environment and any other wild thing I come across and try to convey how wonderful it is to the public. So it's kind of a neat thing because had he been traveling even 10 years later, he probably would've been under power and they would have powered right through. They would have left a bunch of chewed up jellyfish in their way. And the fact that he was traveling by sail not by fossil fuel power, at the time fossil fuel was the great hope, right? It transformed everything and we didn't know, no one knew, humanity didn't understand that it was going to really screw things up.

So the premise of my film is that we are an incredibly creative, capable, creature obviously and if we can just think our way through the problems we've created for ourselves we'll be all right. So, I tried to, you know you're always looking for hopeful stuff in this business because it's really really easy to get down and out and it's really going to down out your audience to the point where they shut down and they're paralyzed. They feel like, oh well it's over. We'll kiss our asses goodbye and there's nothing we can do and so it's really, really important to find a lot of those stories. I tried to give it a positive spin. The films far from perfect. I jammed a twoand-a-half-hour film into a 30-minute deal because that's all I had budget to execute. I hope to God someday before I die I'll be able to find enough money to be able to stretch it and make something and make it properly. But it's done really well. It won a bunch of awards in the international community as an independent and it resounds with people. People seem to really like the message of the film. So that's good.

The speed of change is what's so hard to convey to people because of the shifting baseline. Everything's accelerated to the point where, when I started diving in the Caribbean in the early eighties, it was all staghorn and Elkhorn coral. That's almost extinct there now. When I 
was growing up here in Ithaca I'd never heard of something called a zebra mussel. It's now in the substrate from the Finger Lakes through the Great Lakes, through the St Lawrence Seaway, which is how they got in here, and it's an invasive and it's completely shifted everything. There's a ton of species of Gobi, a round Gobi, that somehow got here in someone's ballast water or whatever and I was the first to document them in the North end of Kayuta Lake, which is the longest of the Finger lakes, 38 miles long, and we see in a year and a half they managed to completely take over the bottom throughout the entire 38-mile stretch. It's crazy how fast things change and it's really, really critical, doing what we do, critical that we somehow convey to people that it's happened really, really fast and there isn't time to dither about and play politics and think short term because it's changing so damn fast. Now of course, the climate, oh that little thing! That's bringing about a few changes as well.

You know, it's really interesting because I'm always fighting with myself. Or I'm always trying to think of how to have the most impact, right? How to actually effect change because when Cousteau came along and started doing the first underwater film making and there were only four channels on television or whatever and everybody was gathered around once a week to watch that was a tremendous audience and a tremendous impact and now anybody, any bozo with an iPhone can make a movie and there's so much crap out there

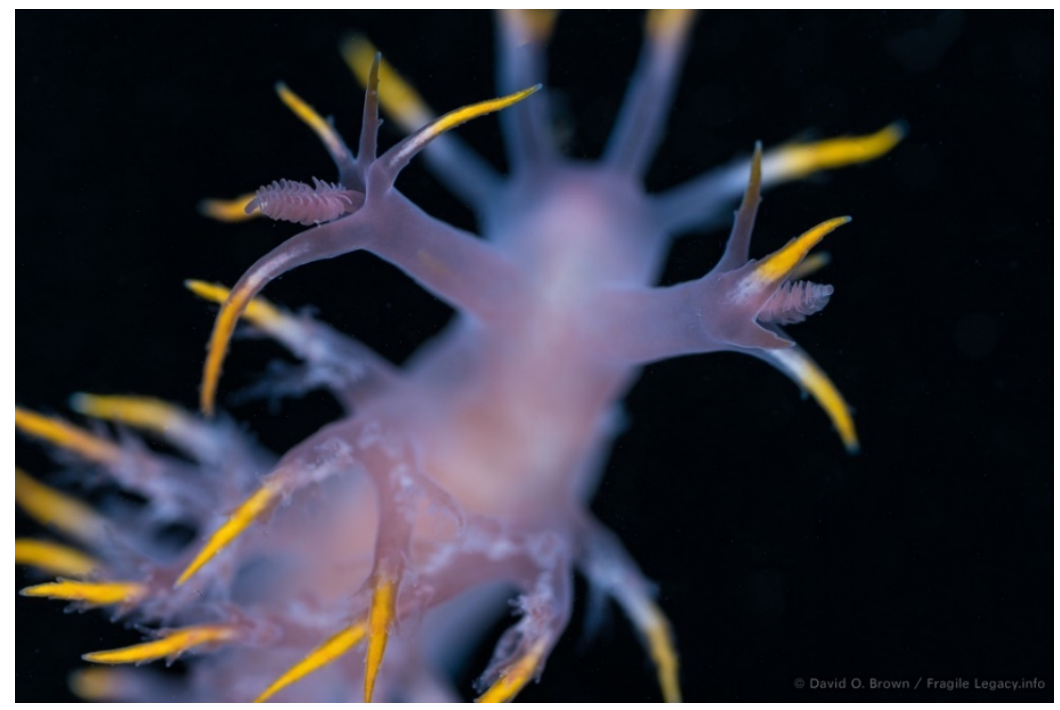

Credit: David O. Brown that anything real gets diluted and it becomes the old needle in the haystack thing. So, I'm always wrestling with myself as to how to be most effective. How to be more effective. If anything, I feel like there's been a lessening impact in the course of my career. I feel like conservation imaging is having less impact than it did, even though there's been a little bit of a resurgence with the March of the Penguins and Racing Extinction and Chasing Ice, etcetera. I'm still not convinced that spending millions and millions of dollars and years and years of time to reach, trying to reach masses of people, I'm not convinced that's the answer anymore because I'm just not convinced that it has the impact. I worry about the amount of fossil fuel I burn zipping around to various places.

You know, I was in the arctic a few years ago and the expedition cost tens of thousands of dollars. I was there to film narwhals. I burn fossil fuel to get there. I burn fossil fuel to get back. I'm just not convinced that it had the impact it needs to have and so what I am working on now, and I'm trying to find appropriate partners for it and I've got some good leads and a lot of good connections at Cornell who I'm working with, what I want to do is create highly targeted media that speaks to very particular stakeholders on a given issue. So, for example, for part of the film The Fragile Legacy, one location was Indonesia because Drew happened to be working there and it's a biodiversity hotspot. So, we went to Wakatobe, which is the heart of the coral triangle. It's the peak biodiversity of our coral reef. And I had done a lot of work in Indonesia in 
the nineties for Passage Productions from my old company and I've been in and out a couple of times since, but it had been years between trips. I get to Wakatobe, I had arranged, I don't know, 18 dives or so. Half the dives were blown to pieces by dynamite fishers. Half the dives. And I hadn't seen dynamite fishing, I dove all through the Indonesia chain extensively, repeatedly in the nineties and I hadn't seen dynamite fishing there. I've seen it in the Philippines. I've seen it in Malaysia. I hadn't seen it there. And half the dives are blown up and I started saying, "OK, there's got to be a better way". I could go back and try to raise some money, make a multimillion dollar feature film about dynamite fishing and blast fishing and how destructive it is, but in the end how much reef is going to be lost?

So why not instead, get with people, find a network on the ground of people who are trying to manage the fishery in Indonesia. Manage to create a sustainable fishery or maintain a sustainable fishery and people who know these people. Not another white guy like me, but the people who live there and know the cultural nuances and know what speaks to those fishers and then make a film, a little tiny film, like a two-minute-long film. Go to the location, come away with the footage and then make a version of the film that is designed to speak to the very, very poor people who are actually doing the blast fishing and it will be designed to be hand carried on a telephone, which wasn't possible just a little while ago but now everybody has telephones, carried on a telephone by a ranger or by another fisherman or by whomever we can get who feels that this is an important issue. Go into the villages and say, look, this is what it looks like after you've blown up a reef and this is how long it's going to take to come back, etcetera, etcetera. But put it in their terms, in their language. Not for mass consumption. And then make another version that's targeting the middle-class people who go to the fish market to buy their fresh fish and it shows them, OK, here's the difference between a fish that's been blown up and here's the fish that's been taken sustainably, line caught, and here's the fish that's been blasted, right. You can tell! It's pretty obvious. Then make another one that speaks to policy makers in Indonesia. So, take that same location and make it work over and over and over. Make these versions where you're speaking directly to stakeholders and you're trying to find a common ground in ways which matter to them, you know, put it in their terms. So that's what I'm working on now. That's what I'm trying to get going. And its, I don't know yet how I'm funding it. I don't know how I'm doing any of it. I never seem to know that until I'm actually doing it. But I think it's really important because it could have real time effect and that's what's needed now. It has to happen in real time. We are just out of time.

The medium doesn't matter. It's interesting to me that having come from, started in stills, worked in motion and then I left still photography for a long time because I couldn't make a living at it whereas I could make a living with the video and with the uplinks for that time. Even though I kept shooting stills cause I love them. I love that moment, but I couldn't, it was really, really tough to make a living at it. So, the motion was a way to augment that, but now the technologies have converged to the point where I'm shooting $4 \mathrm{k}$ video on the same camera I'm shooting 42-megapixel stills. So, hooray. The means of production obviously have gotten less and less expensive. I mean when I was doing narwhals, that was probably five, six years ago, I had a Sony camera, shoulder mount video camera to shoot high definition because at the time was still considered bleeding edge, right. I had a typical housing for it. So, by the time I got the camera in the housing, it was about three feet long. I also had hydrophones on it because I wanted to get time and sound in sync because the sound is so spectacular underwater. We were actually working on a film about that, it was called Sea of Sound. It was about ocean sounds and how important it is and how anthropogenic noise is problematic. Anyway, I had this rig and the 
whole rig cost, you know by the time you get the camera, the lens, the housing, all that crap, you get the hydrophones, put it all together, it was about 200 grand I was carrying into the water. And it weighed eighty pounds. I needed another human being with me just to get it down the side of the ice, the pack ice, to get to me, right. It was a major deal. I shot a polar bear hunting seals and above water, I'm humping 36 pounds of camera in through snow. Now I shoot four times that image and I'm using a rig that cost about 20 grand and I can pick it up with one hand and wave it around it over my head. So, I'm shooting stuff that is so tiny, is so compact and I am shooting stuff that I couldn't get otherwise. A lot of the freshwater stuff, I couldn't even fit that rig into the water. I'm shooting a lot of streams and so I'm shooting in three feet of water sometimes. So, there's a real revolution in that and that's the hopeful thing as long as it's used well, you know, and again it comes down to things like anything else, you can have really solid use of the tool or you could just make a bunch of crap. It's kind of nice to stick with the good stuff if you can.

It's a very, very rewarding, experientially rewarding field, but it's really hard to make a living. Like a lot of other conservation work. It's more important now that scientists and conservationists be able to tell their stories effectively. It's more important than it's ever been for obvious reasons. When they're trying open up the entire, all of our coasts to offshore drilling and everything else they're doing. We've got to get really effective and really fast. 
Michele Westmorland is a highly accomplished commercial photographer and conservation photographer. She is a proud member of the iLCP and the Women Divers Hall of Fame among many others. She makes her home in Redmond, Washington but her current focus and passion is the culture of Melanesia.

\section{Website: www.westmorlandimages.com}

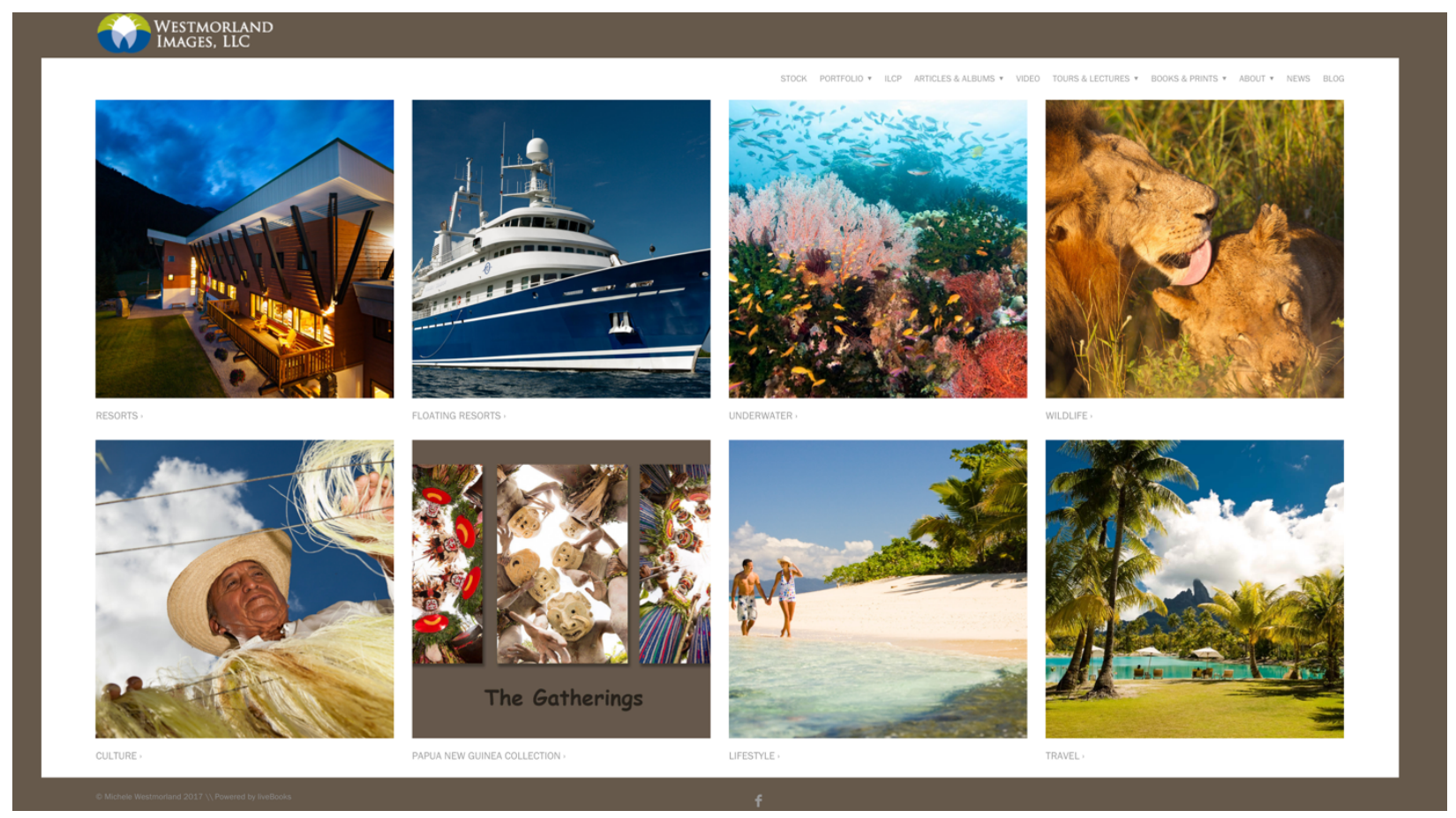

The house is filled to the brim with interesting art from Melanesia. One corner holds computer monitors and a large desk. After showing me her collection of artifacts, Michele offers me tea from some far corner of the world to sip on while we chat.

I've always done photography as a hobbyist, but the first half of my career life I spent in commercial real estate, corporate real estate, totally, totally opposite. I was recruited by Burger King Corporation back in 1984. I lived in California, grew up in California. Recruited by BK, and their headquarters are in Miami. So, I moved to Miami. I thought well, I can't snow ski here, so what am I going to do? So, I took up SCUBA diving, obviously in my back yard and then I said I gotta try photography. That was it. That was it. I was absolutely obsessed.

It was a slow process. There were a lot of things 30 years ago that, you know, it was all about taking pretty pictures and not really being able to observe what's really going on. And sometimes I'm very sad about that because of course when I started diving in 1984 in Miami and throughout the Caribbean, what I saw then versus when I go back now, today, it just startles me. So again, it was all about pretty pictures. The good news about having a business background is 
that I knew I didn't want to read hundred-page lease documents the rest of my life. So, I put a business plan together so that I could transition, and it took quite a few years. It's not an easy step. At least to build up enough that background, get articles published, and become known, especially in the dive community. So, I was very fortunate I had those chances to do that.

My very first trip to Papua Guinea was '91, '92, but about the fourth or fifth trip there, I started connecting. I started seeing. The marine biodiversity in that part of the world, in the IndoPacific region of course, there's no other place on the planet that can beat anywhere around that significant area. I really started focusing on the people who are living on the shorelines and fishing and the connection was too strong. I love both and the diversity in Melanesia, the cultural diversity, is just way over the top. That's when I started to see. These people are depending on health of the ocean and more and more conversation was going on about ocean health and that was like 20, 25 years ago. It was really starting to creep in into my vocabulary.

So instead of always taking pretty pictures, I started to try and note things that were different and that were changing. In Papua New Guinea and that part of the Pacific from the Great Barrier Reef, of course the reef runs all the way up into Papua New Guinea and all that area, 1998 was the last big temperature spike and so I saw in Kimbe Bay a lot of the diving areas with absolutely stunning reefs, I saw them completely bleached out and that was really an eye opener for me. Yeah, just blew me away. So again, those are the little steps, those are the little personal impacts that kind of drive you from I just want pretty pictures and why do I care, to fully caring.

That image [refers to large photograph on canvas on the wall] ${ }^{9}$ that's a signature image of mine. All I did was remove a couple sensor specks on the image and that's turned out to be one of my signature shots. It's an over/under shot. Taken in Bora Bora in a marine conservation area that focuses on sea turtles. Not everybody knows that these creatures are endangered. So, when I captured that image, and you know as a photographer, you know exactly when you press that shutter. Even though I took probably 15 or 20 shots, you know the one. As soon as you press the button it's like yeah, this is really good. That image captures people's attention, it's the beauty shot, but then it allows me to speak to the variety of species of sea turtles out there and how endangered they are. I can bring in some of the social aspects, the indigenous tribes who used to hunt sea turtles. That's been reduced significantly and now they're moving into a lot of little spots where they collect the eggs, incubate the eggs, release the young turtles as opposed to hunting them for food. Tribally there are still areas that do, you have to have a source of protein. So, you can't go shame, shame, shame. And that's the agreement in some territories, that on the conservation side you might have a little tiny island, you have a little area that's a sea turtle conservation area where they incubate, they watch the beds, they watch for all the activity and egg laying and stuff, but on the other side of the island that particular village is allowed to collect $\mathrm{X}$ number for food. So, you have to work with the community. But that one gets attention all the time so that allows me to go ahead and discuss. I can talk about how turtles are caught in nets from the big fishing companies that travel through these waters. Which is getting bigger and bigger especially in the endo-pacific region which really has me concerned especially around Papua New Guinea and all of the islands that are included and Indonesia. So, it just, it allows me to take that one step forward. I wish that I had the hardcore impact shot to go alongside of it. One that shows maybe one of the markets in an area that might have turtle meat for sale, the shells for sale. Next time I'm over there I may, if nothing else, go ahead and set up some shots of tortoise

\footnotetext{
${ }^{9}$ This image is fairly similar to the one on page 94, though not the same.
} 
shell jewelry, a whole slew of them so that I can discuss with people, remind them please do not buy tortoise shell objects.

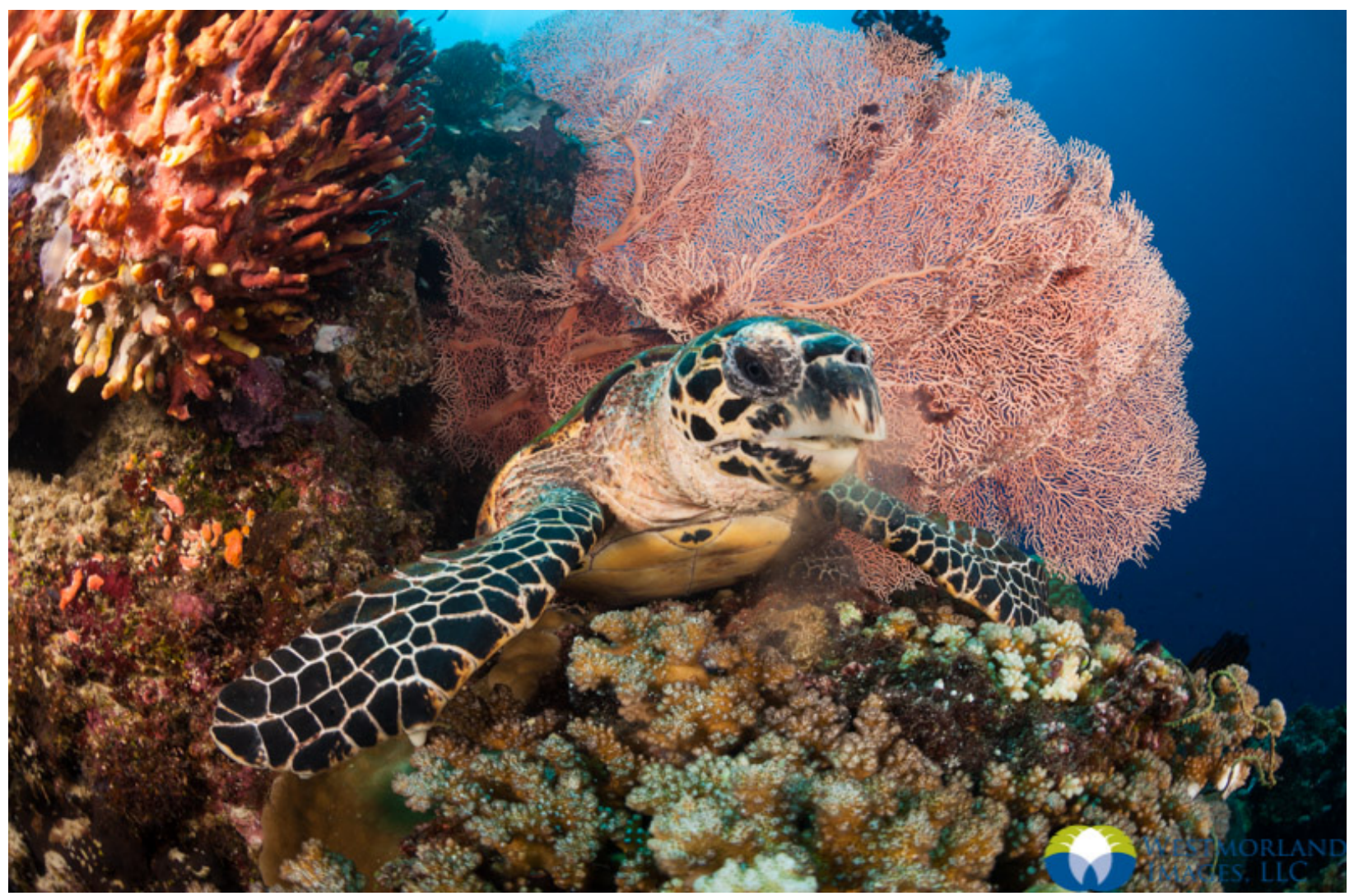

Kimbe Bay, Papua New Guinea; Credit: Michele Westmorland

When I think of conservation photography respect is at the top of that list. Respect of the ocean is way at the top. Education. We have to educate ourselves and we have to educate the communities around us and I find that having visual content, even the beauty pictures at that point, are what you want to use to all of a sudden get an audience who's never been 60 feet deep, to capture their attention and then be able to show them what some of the impacts can be because then, now it starts connecting.

I think the audiences have changed. When I give lectures or presentations. In fact, I'm coleading a tour with Visionary Wild. I'm going to be the marine photography person on board, no diving, it's all snorkeling. But it's still the chance for me to take a non-diving group of photographers and say, "You see this beautiful boat we're on" and show them what's underneath. People lean forward now when you start talking ocean and environment and impacts. Because there's more communication about it. So, I find them leaning forward as opposed to going snooze time. More interest. That's what I've seen as a big change, there's more interest.

Visionary Wild is a company that Justin Black started and almost all the photographers that are involved in any of the tours that he set up, a good portion of them are iLCP fellows. There are some pretty big names in there. I'm thinking of some of the others that are just, Jack 
Dykinga who won a Pulitzer Prize. We talk about ideas and Justin comes up with variety of locations and then he asks full time pros to come who have specialties in that particular area. So, I'm the marine person in the group. That's why I'm going to Hawaii. Brad Lewis is the volcano man. One of the most famous photographers who's captured incredible images on the big island of the volcanoes. Then Justin is an impeccable landscape photographer. So, it just depends on the location and what Justin thinks up. I have a tour in May that is all cultural driven in Papua New Guinea. That has nothing to do with marine life, but when we are at Tufi on the coast, that's the chance for me especially if they want to go just for a snorkel break or something to talk to them about the marine life and the importance of the health of the ocean and what it means to these villagers, because they get to meet many of the villagers. We go in, and it's a small group I don't like big groups, because I think it's pretty invasive to the villagers.

And so we spend time with them and I've even been out photographing them in the water doing their traditional fishing. So I know and I understand- they know when they can fish, they know how much to take to provide food for their village, but yet leave the reef healthy enough so the fish population comes back again. So those kinds of cultural tours are really important to me and then next December I have a dive trip back to Papua New Guinea. I don't really sell my own personal tours that much, I usually go as part of a company because I don't want to get into the travel business.

This photography period, today, is a challenge. It's a challenge for people to survive, to be able to pay their bills. It breaks my heart because I mentor and teach a lot of young photographers who have a science background. Some of my college program students have Ph.D.'s for goodness sake and they really are also good photographers. For them to drop their science background or their way to earn a living and going into still photography to make a living is very, very difficult. I would say. 0.5 percent can even make a living at it. And that makes me feel sad, because as communicators, you know we're just not out there on vacation. You know they're out there to collect information and imagery is the story teller. So I think that's the hardest thing for me to watch these days is the decline of value of important content. I also do commercial type shooting. The commercial type shooting is what paid my bills and has allowed me to get out, I still shoot the Aggressor Boats, but it gets me to parts of the world that I wouldn't be able to and see the changes and the differences. So how lucky am I to get paid to do a job and also more recently the past few years I've been able to also photograph things that disturb me. You know, the change. So, I just want the people and the young people that I mentor to be able to source a living.

It's the dilution in the marketplace. The technology is improving so much that anybody can snap a picture. But what constitutes a good image? Only a few people, you know, you have to have eye. Right. I don't care how much training you get; how much you know about post processing to fix an image or whatever. If you don't have an eye for it and a real heart for it, then it's not going to be compelling. One thing I like about iLCP and that we're very, very strict about is truth in captioning. There are so many people out there that might go, for topside and wildlife, might go and photograph game farms which have wolves and animals that are staged for you and then they don't caption properly. They don't say this is a captive animal, it was shot at blah, blah, blah. It really is important to have truth in captioning so iLCP very hardcore about that. People are even thinking of ideas of shooting home aquariums for God's sake. You can do set ups in aquariums. It's because there's so much available to us now. It really is important to make sure that that image has the right story to it. Also, even if you get a decent shot in the wild, post processing can tell a lie as well. I will only do things like color correction, I'll remove sensor 
spots or some backscatter that shows up in the image. It's a learning process, there were days when I would move a stationary animal. I won't do that now. We use a little stick that's noninvasive. I pay more attention now. If I'm capturing photos for example of a pygmy seahorse. They're very shy and they're very, very tiny and very hard to photograph. Any members of the seahorse family can get blasted to death by a lineup of photographers with heavy strobes. In the past, I didn't pay attention to that, so it's been a learning process for me. Now, if I have the opportunity to photograph any kind of seahorse or an animal that's disturbed by strobes I will not push it. If I don't get the shot that I think, and the animal is now starting to look disturbed, especially like in cephalopods, if they are starting to really flash at you and get upset, I back off. I still see a lot of people, a lot of underwater photographers who are just really not caring enough that will want to push the animals to a stress level. Or, you know, especially if it's out free swimming, can they get it to ink.

We have over a hundred photographers who are fellows in the iLCP and it's not a club, it's not a membership, you're vetted, they want to see your work, they want to see your conservation attitudes and stories. So, I'm really honored, hugely honored to be a part of iLCP.

For iLCP we're redeveloping some strategic planning right now and finessing some of the language because if you look at the definition of photography, almost everybody thinks still photography. That's the area, but actually the definition of photography includes motion. It's still or motion. It's mixed media. It's the way it is and if you aren't inclusive of film or digital capture in still or in video than I don't think you have the skills to tell a full story because a still is that moment in time, the one that can really inspire, whereas the video can help you back that up with behaviors and emotion and it also visually attracts when you start blending the two. I'm just a real firm believer in it. Now, do I shoot video underwater? No. Not because I don't want to, but because it's two different ways of composing and capturing a particular scene and I'm older now and for me to be able to go in, unlike the younger emerging league in iLCP and the younger people who are so used to switching over, I'm finding that people who switch back and forth, for example on one dive, they take a few stills and then switch over and run video. It separates the brain on how you compose, capture, and tell the story. So usually when I'm with students, I tell them, try and get your mindset that if you're gonna make a particular dive, choose your weapon. Because then you're focused on how do I compose for the still or what story do I want to tell? And especially if they get to do repetitive dives in one location, I think it's better capture instead of a mish-mosh. 
Mac Stone is Florida native and resident with a photographic focus on its wetlands. He is a winner of the Save Our Seas Marine Conservation Photography Grant, intentional in his shooting, and skilled both above and below the water.

Website: www.macstonephoto.com

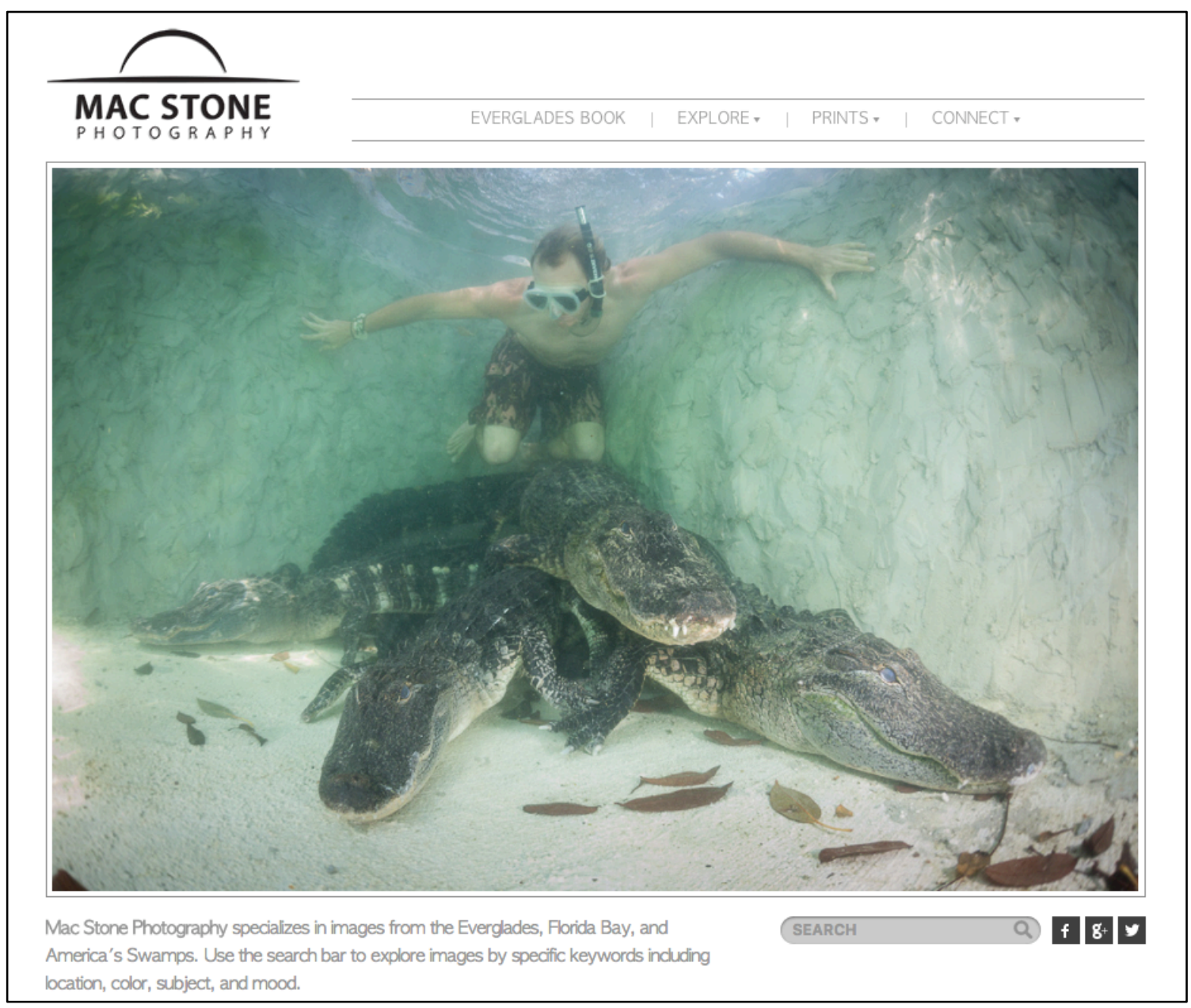

Mac is fitting an interview in right before he goes off into the field for three weeks. With confidence, he speaks eloquently about conservation photography and his career, easily proving that he has studied and lived in this arena from a young age.

I'm originally from Florida, and I just started with shooting photos of my backyard, my surroundings and beginning to understand the rhythms of my state and the local ecology. That started having some appeal especially to city planners and policy makers in and around my hometown, because we were able to put those images to action in a way. Florida, as you know, has exploded in the last 30 years with population in terms of development. It's losing land at exorbitant rates. So the photos were put to good use in trying to explain some of the unique 
natural heritage that we had there. At a very young age, about 15 years old I was giving presentations to local commissioners and city planners to try and advocate for some of the places that were, you know, I didn't know any better, they were just backyard places that I thought were special and didn't realize that they were up on the chopping block to be turned into apartment complexes. I started realizing the power of photography to persuade and to bring people to places that they haven't been and to try and use images as a way to bridge that emotional gap. Then it kind of went on hold when I was in college. I went up to Virginia Tech and my heart wasn't really in the mountains, my heart was in the low country and the flooded forests and the coasts. After school is when I started really going after it. I went down to Honduras and worked and I've lived and worked in many places since.

A lot of my work revolves around wetlands and much of it is actually fresh water wetland areas, so interior bottom lands or riverine systems. A lot of the issues facing these systems are the same ones that end up facing the coast, the marine environment. So at the confluence of fresh and saltwater is where we often see the result of some of these negative effects, whether it's poor $\mathrm{b}$ and p's for farming or dumping, or overfishing in these estuaries, in these coastal regions. Displaced peoples, rising sea levels. So oftentimes I find myself starting a story on the interior and then find that the real impact of the story actually happens in the marine realm. You know, we as people get very few glimpses of marine environments. We go to the beach and maybe swim, but we don't necessarily go deeper than 20 feet or 10 feet in most areas. So some of these issues and some of these narratives are out of reach and out of mind for people. We don't go personally fishing for tuna. We don't personally go out and swim around sharks as a general rule with people. So I think it's part of our job as photographers to bring these areas to light and to show these narratives. For me, the marine photography started coming about, I would say about seven years ago. So a little later in my career is when I started piecing the stories together, whether lobster fisheries or shark conservation in South Africa, or coastal estuaries around the Everglades. I really started understanding the marine environment and photographing it.

When I think of conservation photography I think of long hours. I think of hard work. I think of mission driven. I think of advocacy and I think of journalism as well. Those things to me are what define conservation photography. It's one thing if it's a hobby of going out and documenting what's around you just to, just because it's a fun pastime. Conservation photography to me has much more of a purpose, an end goal in mind. Now that could just be something as nebulous as awareness, or it could be something as specific as trying to protect this 500-acre property or trying to designate this area as a marine sanctuary. So a lot of the times it's not one pretty picture that's doing it, it's a series of images, it's a portfolio, it's a body of work that you develop, try to develop journalistically into a story that you can then disseminate and partner with organizations or news agencies to get this out and to affect change

I think inherently people look for connections to others and I love connecting with people. I love hearing their stories and I like to share stories. Ultimately, I think that the real change occurs when you partner with other organizations or State agencies or federal agencies that have either a larger network or more at stake to where they can give your images legs and meaning. Magazines like Nature Conservancy or Audubon, or World Wildlife Federation or National Geographic, all these are great vehicles to affect that change. So you're trying to find those connections and say, how can we leverage both of our interests to make this happen? That's just how work gets done, but there's no straight line to any of it. A lot of these things take years to happen. If you're talking about true conservation, again like I said, the nebulous thing of awareness is really good because that's what creates this undercurrent and these grassroots 
movements to get people thinking and caring and then ultimately we'll get those policy makers to act.

I think that the lexicon is certainly favorable now towards conservation photography and towards environmental awareness. I think it's heightened, it's so much more heightened now. People are willing to listen and they're willing to accept these kinds of testimonials from witnesses like photographers in the field who are seeing change and who are trying to work to bring about positive change. So I think you have a much more receptive audience now, however, at the same time many of these issues have been politicized where people are now starting to firmly plant themselves into certain camps. So the messaging is, and this is especially true in the southeast where I'm from, there are certain audiences that just don't, they don't want to hear about climate change and rising sea levels, they just turn off. So you have to message it a little differently, you have to word it a little differently, or approach it in a way that can be more democratic I suppose. But all in all I think that the people are certainly open to it, but I've never had an instance where people just shut down entirely and it's probably because of my age. I was coming up in a time when you know, these have always been issues and really all your providing is photographic evidence and experiential anecdotes and it's hard to argue against those and that's somewhat the power of photography.

I make my living off of being a witness and trying to be that conduit for people to understand bigger issues and maybe to think beyond their borders and their personal bubbles. Because we are visual creatures I think imagery has a powerful role in that, especially for the marine environment which is so poorly understood and grasped by the general public. We're just trying to bring some of the science that is being done, some of the advocacy that is underway and put visuals to it so people can digest it and then they can choose to act on it. 
Keith is currently based in Brooklyn, New York and his recent work aims to raise awareness of the amazing marine creatures in his neighborhood. Though his latest photography is close to home, he has traveled all over the world to take images to promote ocean conservation. He is a senior fellow with the International League of Conservation Photography and a part of multiple other organizations.

Website: www.keithellenbogen.com

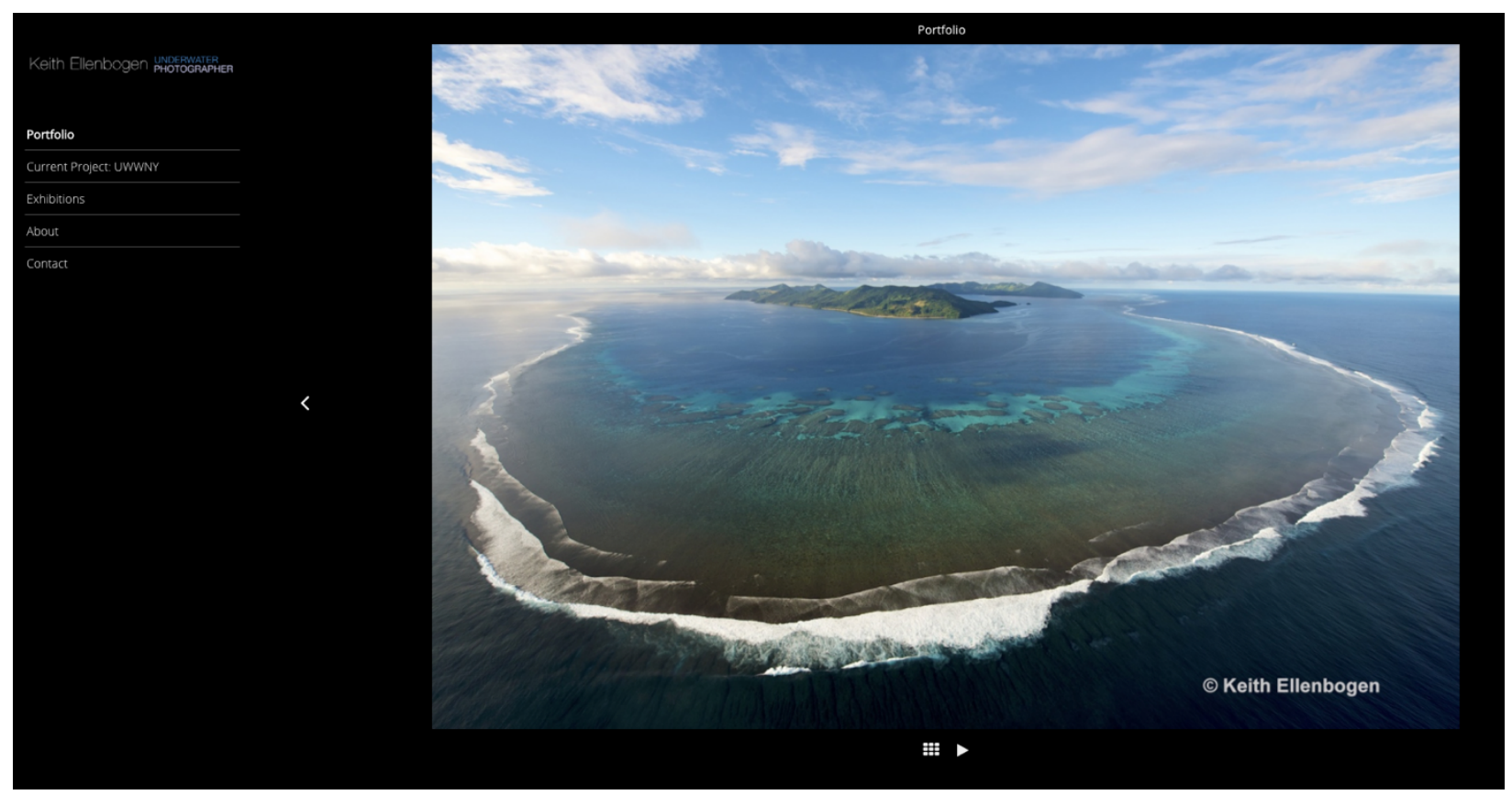

Keith has greyish curly hair the same color as his flannel. His office is slightly dark as it is night where he is skyping in from and his tired-looking eyes bely the fact that he has been traveling extensively. Regardless of his fatigue, he happily makes time for this project.

I grew up in Boston and I started diving when I was 16 . I was actually a volunteer at the New England Aquarium in Boston and what happened was they were doing a collecting trip that went to the Bahamas to capture fish to bring back to the aquarium. I was in high school and my boss at the time was like, "Hey, if you get certified you can come on this trip." So I got certified in November. I remember the cold, right as the snow was coming down. I got hypothermia on my very first dives, but I loved the feeling of being in the water, it was just something I really loved.

So then after being certified, I went down to the Bahamas and they were doing a collecting trip. Unbeknownst to me at that time, there was this show called, I think it was called Capture the Future. It was like a chronicle TV show. I'd have to get the exact title of it. It was ages ago. Anyway, they were doing a bunch of filming at the aquarium. Nothing to do with me, 
but I was in high school and I was one other high school student who was selected and they came down and they're like, "oh, there's some high school kids" and as you would imagine, it makes for an interesting part of the story. So they filmed us a little bit and I saw these guys doing underwater videography and I was totally inspired like, "Wow, that's really cool. I realize now that there can be cameras under there." My grandfather was an amateur photographer and so when I got back he got me my first camera, which was a Nikonus-V. Shortly after that I just began diving and taking pictures mostly because I loved it. I didn't really have a set path at that time and it wasn't for many, many years later that that really did happen. But it was something that I grew into with just a true love for seeing the animals under there and for the art of, and the challenge of like - how do you take picture and what does that mean? So the two sort of grew simultaneously together.

So then fast forward many years later one goes to college and I'm in the art world, you know, fairly indecisive and can't decide what to do. It wasn't until I did my masters, and I did a masters at Parsons School of Design. In the end, as most graduate students do, you do something you love to do. So I chose my thesis on underwater photography and I began to really realize that was an area that I thought I would like to re-explore. At this point, I think my photography was getting reasonable to competent. Then as soon as I graduated I received a Fulbright Fellowship to do a year of underwater conservation photography in Malaysia and that was fantastic. I would describe the Fulbright program as, first of all it was one of the best years I've ever had of my life, I thought it was extraordinary because they provided an opportunity to really dedicate a year of my life towards just a craft in a way that I never had been able to dedicate myself before. I think my photography went from what I would say was competent, I obviously got accepted, to where I thought it moved to a level where I was beginning to find my own art. I was sort of separating it out and I felt confident in my own skills moving forward from there. That year really developing the craft, learning how to tell a story, selecting the images and being repetitive over and over again, was extraordinary and I'm always eternally grateful for the Fulbright Program for that.

Once the Fulbright ended, I got my first really lucky break in that I got selected for an assignment on the endangered Atlantic Bluefin tuna. I spent three months in the Mediterranean Sea with Oceana and we started in Spain and we went into Malta, Italy, France, and then Greece and it was incredible! It was the first time I'd ever seen tuna. We were following fishing stories and so it was a great conservation story about an unbelievable animal and it really was the first story in which I felt the power of photography. It could really make a change instantly and things were happening in real time. To give you an example, the season is open for a month. The very first day they had caught the whole months' worth of the quota. Incredible. And it's not like they were illegally fishing or terribly fishing. It's just they're efficient at it.

One of the great challenges is how do you deal with multi-cultural, multi-countries in a region, some are part of the EU and follow the EU, some aren't and it's an incredibly complicated fish in that it's extraordinarily valuable. If one country doesn't fish for it and the other does, why is that fair? How do you manage their populations and how do you appeal to the world? So the photographs were really documenting and weren't doing anything that was causing any troubles, and the pictures immediately were making newspapers and all of those photos were on the surface. Then I managed to get a few very strong underwater photographs of tuna and I think that that helped in, at least for me in my career, helped set the stage of a very charismatic and powerful animal that had immediate impact. And those images have gone through on movies like End of the Line, they were used by IUCN to represent the species, they were used on the nomination of the fish for when they nominated it to be an endangered species. Even though it 
didn't get voted on properly, for me those were really proud moments and I realized that, I already was realizing this, but you know, we don't typically see fish in a live environment that look living. Our image of them is always one that's on ice and dead. So I think that a lot of what I was trying to show and try to show are the animals that have some sort of quality that exemplifies them as an animal or at least my perception of them and, you know, it gives a life to them that we can have a human connection to and feel some sort of, "Here's a living animal that maybe we should be considerate for."

So that really was the first assignment that was able to go there and it was a unique one because a lot of people, the very first thing they think of are coral reefs and all those kinds of things, but there are lots of pictures of coral reefs so it's hard to separate oneself out in that area. The tuna are particularly difficult because you really need a lot of time there. And it was incredible, I mean these fish would swim by you and you can feel the power go through your chest and it's really extraordinary. I think some of the images echo those kinds of feelings and they were few and far between, but I was able to get them and that really is how my career moved from doing something that I loved, to getting a formal education on it, to getting a grant that began to question how do you deal with international relations, how do you convey global issues that are impacting everyone? Because Fulbright really focused a lot on the national relationships between the United States and in this case Malaysia, but how does this work in a global context as well as local and within in our home country. So it forced me think of those things and then, a first assignment that began to deal with that in a very international way. So that was really the beginning. Then from there I was able to get other assignments and stuff like that. I think the other thing that I would say, and this has continued to this day, is it's still the one thing that I love doing the most. I mean, I have to now write all these grants and do all these other things that are a real pain in the ass. You have to do a lot of other work. But the thing I like the most is being in the field and taking the pictures and photographing these animals. I find that still very rewarding.

I think some of the biggest challenges are the conditions often are difficult in places and I think that difficult conditions are wonderful because they're challenging. They're also difficult. So for instance, I've been doing a project in New York on trying to create awareness about New York's marine life, but the visibility in New York is often very difficult. It's not like being in the Caribbean, you can't see all of the things, the weather is... at best half the time you can get out to sea, and the animals aren't predictable. You don't know where they're going to be. So it doesn't match your perception of what you think of is healthy in terms of like this beautiful tropical reef.

The conditions and the environment are changing and the animals are having to adapt, but you can't always be there to show those things. The scale of things is very difficult in the ocean, for example if you were on the surface for instance, we can see there are so many cattle on a farm, we can see the landscaping change, you can see the ice melting, you can see the forest being deforested. In the coral you can't really see that, there's just no way to image it. Even at best, in a dense reef, in most places it doesn't look really dense. I mean the image gives a perception of it, but it's not like you're surrounded constantly. I mean that's the power of photography. So I think that it can often be a trouble to capture the larger issue of what's really occurring under here, and people's perceptions are often very different to what reality is, or their perceptions are very localized to what the realities might be and those are what make things complicated. So for example, if people are fishing in Area A and there's lots of fish, it doesn't mean that there aren't a lot of fish in Area A, but relative to A through Z, maybe all the fish are in Zone A and their numbers are low, but you don't see those kinds of things. So I think this is 
where photography and science and conservation and policy work well together because it's not always what one sees is happening as what is happening in totality. The underwater world is so hidden and it's so large that it's often challenging to capture the enormity of the ocean relative to the scale of a human and I think that that is one of the big challenges ahead for people.

It's not that it's too big of an ocean it's that the things are sprawled out, and the images can only capture really close. One of the other challenges in photography is you have to be close to your subject so you have to be able to create these wonderful, wonderful intimate moments with the animals you're photographing. So they need to react to you in the same way that you need to react to them and that is just one more element of it, which means when they swim they are there perhaps, but maybe they're out of sight or maybe they're further away or whatnot. There's a challenge in that.

For the New York project in particular, the UN was hosting Our World of the Oceans in New York and it seemed crazy to me that Our World of the Oceans would highlight all other parts of the world and exclude the one place where we are. Now I had self-interest, I've been working on this for three or four years, but I had lots of partners in this one and I think that we together felt that this was a great opportunity to highlight what was spectacular about New York and to really showcase it. There's a lot of places in the world and no one associates New York with this kind of marine life, but it's really extraordinary marine life, and so could we put this on a stage and get it in there. So we wrote a proposal that suggested that we would like to highlight the work, that we would like to showcase New York and put it on the stage of a world forum to say like, look, these animals are migrating through from Point A to Point B. They're coming through New York. We have not only an amazing city, but amazing marine wildlife.

So then they go through a vetting process in which they look at the images and sort of decide is this appropriate for them, is it the right message and does it convey both a local and a global aspect. Because the UN is very cognizant of not promoting any one country, one thing, or one of anything because this is a conference that had a lot to it. So one of our things that we were trying to show is that here on a world stage, one, not only does New York have these things, but these things are migrating through and coming through from other places and so there's a nice global presence. Then in tandem we wrote this with the other scientists who were part of the project and we wrote the captions, we wrote the text, and in the case of the United Nations, they vet this fairly intensively. They weren't micromanaging the way we wrote it, as much as a massaging to make sure that it fit within the voice of what a UN would like to do, to make sure it spoke to a broad audience, an international, UN kind of audience. They didn't have many corrections, we already spoke that way. But that was the process for doing that. Then we proposed the organization of the images and how it would be laid out. They suggested space and then when it changed or when we were able to do things, we suggested how people would move through it, what the flow would be. I spent a lot of time thinking about how images would be juxtaposed next to one another, the color palette, the things that are iconic, such as sharks, to things that are texture based and more artistic, such as delicate movements of an anemone or a scallop. I really wanted to take people into a place where when they were there, they were almost lost within not knowing it was New York, except really thrown through sort of a reinforced language of always the location stating New York. I think we got a lot of really positive comments and reviews so that was nice. I think the number one comment I would get was, "wow, this is really right here in New York," and I don't think people could believe there is a seahorse here in New York, that we have these things. So that was amazing. Sometimes I would 
just listen to people as they walked through so that I could hear what they were saying without, you know, they wouldn't know me.

I think the captions are extremely important with the photos. I think that it provides a context for people and I think the image is probably what grabs people's attention at first and then people will become curious and I think it's critical to provide a little context of what things are and to sort of frame it in a way that is both understandable to the general public - here is great South Bay, which may not mean a lot to anyone, but to understand that here are oysters, this is an estuary, that this is where juvenile fish grow up and go out into, provides people a little context for what they're looking at and then an ability to be able to learn more without overwhelming them. So we really tried hard to contextualize things and to break it apart so that it showed the broad range of what New York had to offer in this instance. We wanted to show shallow water things that are inshore to way off shore to more abstract interpretations to more of the entire animal so that it brought in people's appeal within an area. So I think that the text is critical and certainly in an area where they're not familiar at all with it. So where it would be a coral reef for instance, it might be a little more self-evident that this is a coral reef, you would of course want text there to help frame someone's mind. But I think even more so in an area where they're just unfamiliar with it. Like everything else, when you give someone a point of view or you help guide what they're looking at, like when you go to a museum, you look at these things and there's some context. Then you both learn and understand and appreciate what to perhaps look for. I think that also helps frame people's experience at least looking at these images more than just walking by and going, oh, they're a pretty picture. Which of course, selfishly I would like, but really would like them to walk away with being impacted into wanting to understand more. So that was one of the other things. I think additionally, I spent a lot of time working on the prints and the scale of the prints, they were printed large, and really I work hard on the actual print and the color and that experience and how the light hit it so that the reaction really showed all the details that I spent a lot of time working on to capture that I thought would, maybe not overtly, but definitely impact people as they got closer and could examine these things. So from both far and close, there were experiences that I thought that they could grow into and absorb and that was also meaningful, and things that we thought about.

I think people's reactions are a couple of broad reactions. I think one, there's always a sense of amazement, like, "Wow, this is really under there?" And so it's hard to characterize in one way because with some people who are less familiar then it's more amazing. It's like, "My God, I've never seen these kinds of animals or I've never seen this perspective." I think for people who are more familiar, the key is how do you create that amazement or that intrigue in a photo in an interesting and unique way. I think that's the challenge of photography. So it makes things really fun. I do think keeping people's reaction interesting and interested in a subject is, you know, that's the joy of art. So hopefully they get engaged.

I think one big difference that's happened is the access to digital has changed people's ability to capture images and I think in a way, some of the craft of photography, the things that make photography so difficult are at the simplest level, much more easily accessible now and easily achievable with very little skill set. However, when looked in tandem, the art and the craft is still extraordinary, but the barrier is now much easier to be able to do. You know, when I first started you had film and you didn't know if it was right. You came back thinking every shot was fantastic and then all of a sudden you look at your film and you're like, "oy ay ay" not exactly what I was hoping for. If you had one good picture per ton, the learning was much slower. You had to keep meticulous notes. You would take the pictures and you didn't know. Now because 
you can learn instantly and see immediately, it's a quicker response and I think people's reactions are also quicker because they're bombarded much more frequently. So you have the two things that happened simultaneously. They see these things much more frequently, much more regularly, and people are able to achieve these things much more easily. So that doesn't mean that I don't think there's still amazement and interest all over. I think that the reaction of people is similar in the sense of it's a world that most people can't go to or see and I think that really sparks the interest of a lot of people. I think that the second part that's nice is the intersection of art with this and how do you make something beautiful or artistic or interpretive in your own way and that adds a different element than just an image. You know, as a photographer and artist some of it is process - this is how I take my pictures - this would be the process then you deal with it and then these results. 
Octavio Aburto is a scientist who fell into photography. He is based in San Diego as an Assistant Professor at Scripps Institution of Oceanography, but still finds time to be the director of the Gulf of California Marine Program, an associate with the International League of Conservation Photographers, and conduct his own research.

\section{Website: www.octavioaburto.com}

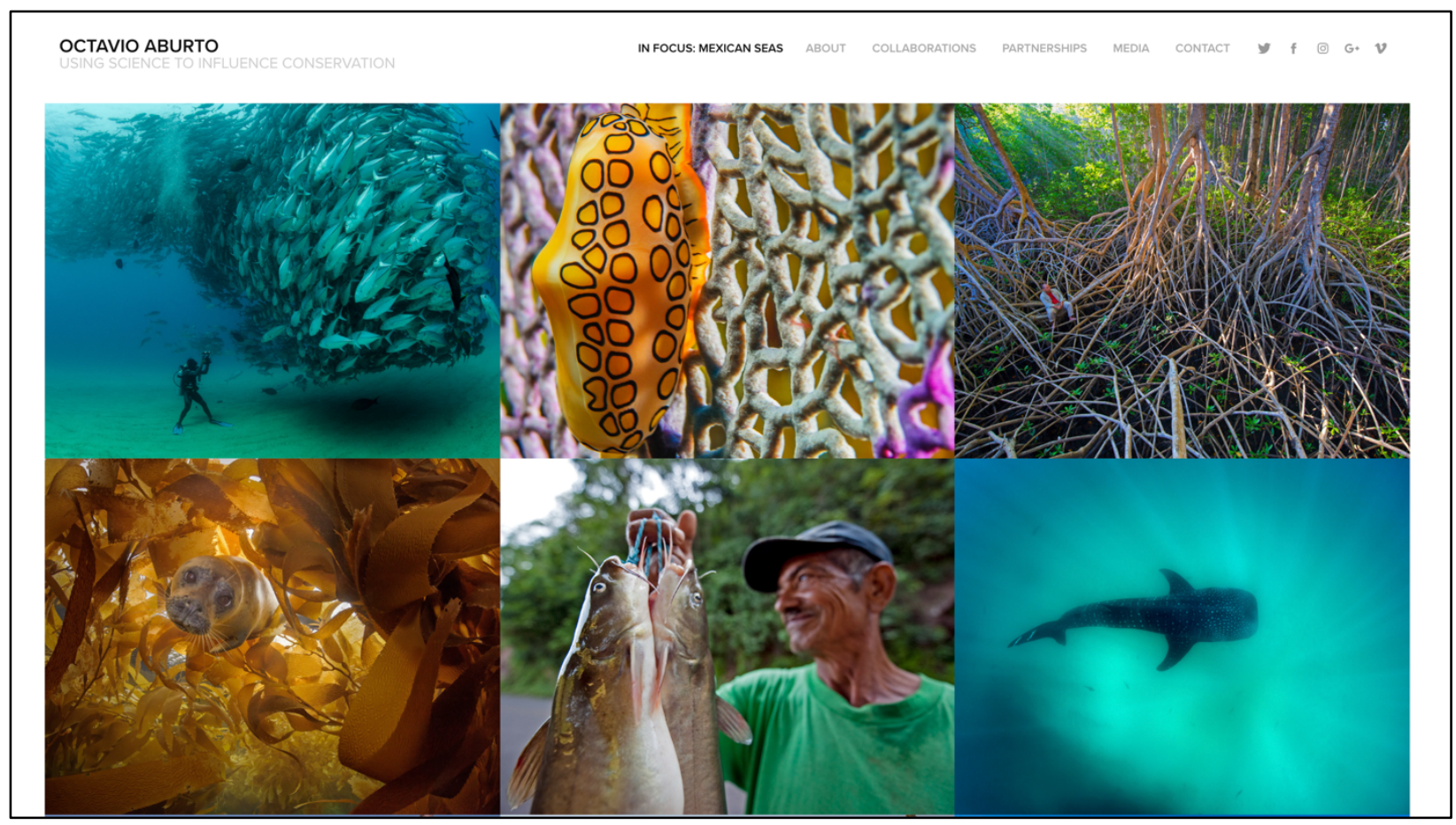

Silver, exposed metal pipes on the ceiling with one long fluorescent light give an industrial feel the space Octavio is in. Dressed casually in a jean shirt and vest, Octavio is busy fielding questions from students knocking on the door. When he speaks of conservation photography it is clear that he feels more purpose is needed and he implores people to create that space for change.

I am a scientist. I always say that I am not a photographer because my paycheck comes from the science, and I know how difficult it is to live from the photography. I'm very respectful about how photographers, especially conservation photographers that dedicate their lives to the wildlife photography all day, all the challenges that they need to face to get their check. So I am a scientist, I do science. I am a professional, I have a stable income, but at the same time I have 25 , 27 years doing photography and something that began as a hobby and now in the last maybe 10 years during the more with an angle of professional. Because not only improving my photography, also thinking about how my photography will really impact or compliment the science that I do. 
My story is very simple. I was a student, an undergraduate student, and the director of the lab that I was at, he said, "Somebody needs to use the video camera and the photography camera." In that time still film, to take samples. So basically photo quadrants and video transects and nobody raised their hands so I was the only one that said "Okay, I'm going to do it." At the beginning basically that was my job. To prepare the cameras every time that we'd go to the field, the batteries, and then do the photo quadrants, and the video transects and I don't know when, but wasn't too much later after I started doing that, that I started corrupting myself and taking pictures beyond the photo quadrants and the video transects.

This story is funny, but actually is true. My mom always asks me, "What are you doing? Because you didn't bring grades." I was born in Mexico City and when I was 17 years old, I moved to La Paz, and in Mexico its completely different from the states where young guys and parents once you are 16, okay go away, go away, leave the nest. But in Latin America it almost is, if you can buy a house that is beside the house of your parents that is the common thing that you see. So for a young guy at seventeen years, to move very far from his home, that was a big challenge. I only came back to home for holidays or between quarters, between semesters. My mom was asking, "What are you doing?" So after two years or after one year using the cameras. I brought video, I brought pictures and she started learning or understanding what I was doing. So that was the way I got involved with cameras, and at the beginning, probably in the first ten years, my knowledge of using the cameras was related with what I learned reading. There wasn't internet, there wasn't YouTube or Google. So you needed to read a lot. And also... no I think it was more reading and feeling. Just feeling about what I was doing in my research, especially in my research thesis. My bachelor's thesis was about the behavior of a fish and I was using video to record that behavior. In my master's thesis I was working with the fish community in different habitats. So I used the camera to show the different species that live associated with different habitats. So again in that time, I'm talking before 2005, my learning was directed to the feeling or the use of the cameras for certain purposes and what I read. And after 2005 I tried to collaborate with people that were doing wildlife photography and I think this is the second stage for me that I learned a lot, especially techniques about using the camera in another way to improve my skills, not only in the technology, but also in the composition or feeling about what I need to take or how I can take it.

From 2005 to maybe 2010 or 12 , I started collaborating with many photography groups, and this is when I decided to really match my science with photography that I wanted to do. And after 2012, everything has been storytelling, creative, and the science that I do and photography that I take and that is the next level that I'm trying to, actually I think I need to learn more about how to tell stories in a better way. This is now, my efforts, my concentration is about how to tell stories in a better way because I know that I can produce the images. I know I can produce the science, but if you don't tell the story in a better way, these two things don't match.

I am part of the International League of Conservation Photographers (iLCP). The International League of Conservation Photographers was a movement created by photographers that are or were linked with conservation efforts. One in particular is Cristina Mittermeier who used to be the wife, spouse of Russ Mittermeier from Conservation International, and she was very instrumental, a very important link to put together this organization. From my point of view, that organization started trying to mimic something that the Museum of Chicago started doing that basically in that time were called, I think, rapid assessment programs. Now are called Bioblitz. In that time, like 15 or 20 years ago, the Chicago Museum basically said, "OK, I'm going to bring these experts in to one area and assess that area in terms of what biodiversity that 
area has. They were called rapid assessment programs, biodiversity assessment programs. Nowadays they are called bioblitz. Basically you take experts to one area, experts from different fields and they assess the biodiversity in one area. So Cristina and other people they say, "OK, let's do something like that, but with photography." So they created this concept of rapid visual expeditions, RAVEs. And basically they convinced very top photographers in order to do RAVEs in areas that were very important and areas that were, or are, threatened by human activities. Then after they created that organization, they created an emerging photographer program and I was one of the first ones that joined. And in theory, that emerging league would be mentored by these photographers with great expertise. I had the opportunity to work with Phillip Nicklen, one of the best underwater photographers, and I learned a lot. And again, that happened between 2006 and 2012 .

Now for me, I think that the conservation photography is not necessarily that tool. The RAVEs, the rapid assessment visual expeditions is only a tool about what really conservation photography is. For me, conservation photography is the voice. The political voice that the photographers have in order to express what we think about problems in this planet, in the oceans, in the land and our photography, our photographs not only are representing our feelings, our point of view of the problem. Also, these photographer's photography represents a political statement to change these thing, what is happening with these things. Now in the organizations that I have collaborated with, like iLCP, I think we never have reached the point of using the photography to change what is happening in that photography. Yes. Because the photograph is only a visual statement, it's like Jane Goodall, imagine Jane Goodall just showing her research about chimpanzees and basically just doing that in order to do or to try to change something. She hasn't done only that. She has gone to the senate, she has gone to big presentations. She has gone to very, very influential conservation meetings. Not only to show her research also to show, or to give a statement about what shouldn't be done or shouldn't continue. So the picture, the photo, it's only one part of the conservation photography. You need to take that picture that you took with a lot of feelings, with a lot of knowledge, sometimes with a lot of risk, and take it to the arenas in order to match the image with the statements that you need to do. If you do it as an individual, that's OK, but probably you won't have the same impact that if you do it as a sector or as an organization like iLCP would. So when I joined iLCP and then I have been having these discussions with other fellows or colleagues, I'm still waiting that the organization will come to the main forums, use this amazing photography that many people have produced, many photographers have produced, and really give a statement, a declaration, an action. And I think that is what conservation photography is. It is not only about the photography, for conservation photography the photography is a visual representation of the statements that you need to put into the discussions.

I think there are many ways, and sometimes very random opportunities, for conservation photographers to bring these statements. But when you have the opportunity, for example the for Birch Aquarium I took the opportunity to tell the people, here are four communities and these are the pictures I took. But the four communities have one thing in common, these communities are thinking that having healthier ecosystems produces larger economic benefits and these four communities are demonstrating that this is true. If they preserve, or if they maintain the healthiness of the ecosystems they are receiving more economic benefits. So when I had the opportunity to have an exhibition at the Birch Aquarium, I thought about what will be the message that I wanted to put in that exhibition. It's not only pictures, it's about the statement and it's about the storytelling. So they told me that my exhibition will be nine months and its already 
been three and a half years that they have had the exhibition there. It will actually be removed this coming May. But I think that people enjoy it and enjoy not only the pictures, I hope that they enjoy the message about this community.

When you have a very nice story to tell, even not necessarily with very nice pictures, if the story is very good sometimes you don't need the image that's like "ohhh, look at this image." Just have a very nice story to tell and compliment it with pictures. For that reason I believe that many people could be conservation photographers because they don't need to be Brian Skerry, National Geographic Brian Skerry, or National Geographic Tom Peschak, you can be just Octavio Aburto and have a very nice story to tell with pictures. I mean I have dedicated a lot of time to take some pictures, but sometimes I don't have the same time or the budget that these guys have to produce their images, but I have told very nice stories without having super top-of-the class photography. So conservation photographers or conservation photography is beyond the photography and sometimes the storytelling is more powerful than the photography.

I have learned that if you disconnect the human perspective from these stories you won't impact in the same way that you can when you introduce the human side of the story. This is first, if you need to choose between what is the positive angle and what is the negative angle, or what is the human side in a positive way or a negative way, most of the time the stories that show the human side from a positive way are the ones that are receiving more attention. And I'm convinced, because also now I am collaborating or participating in other initiatives like Nancy Knowlton who used to be a professor here at Scripps Institution of Oceanography. Nancy Knowlton, now she moved again, she was in the Smithsonian, then came to Scripps and now is again in the Smithsonian, she is leading an initiative that is called Earth Optimism and last year she put together the first Earth Optimism symposium, or summit. I had the fortune to be part of this first cohort of the speakers, but the idea was to come and, rather than complain with all the things that we see in the media, to come and share positive stories about what is happening. Sometimes you realize that there are more positive stories than what we thought because the media basically is in charge or telling us every day that this is world is... I mean of course it's happening, but maybe we can change that if rather than just show the bad things we also show the good things and sometimes the good things are more than the bad things. So again, I think for conservation photography, the human side and the positive outcomes, or the positive side of the stories, in my opinion are the ones that have had more impact when I share these stories with the audience.

One challenge is to know when you are actually a conservation photographer. People that do wildlife photography, are they conservation photographers? People that document, or take pictures about pollution in the water, are they conservation photographers? So one challenge is to understand. A challenge for a conservation photographer is to understand if they are really doing conservation photography and again for me, many people can be conservation photographers, but it's beyond the photography in order to really become a conservation photographer. So yes, you need to take pictures about wildlife, maybe pictures about how pollution or other factors are affecting that wildlife and this planet, but also you need to be a responsible citizen in order to use that photography to change what is happening. So you cannot just document negative things. You need to incorporate that activity in a way to create these statements and do efforts to change things. When I studied in elementary school, I was taught kind of civil rights and citizen obligations. When you live in a society, you have rights but you also have obligations. The problem is that young guys are not receiving those kinds of classes anymore, nor in Mexico. And this is because individualism has been changing, or has been transforming, our societies. It's 
very funny because if we want to live in society, why do we behave as individuals? So when you do photography and when you do conservation photography, you need to be a good citizen in order to take this documentation, it's just a graphic documentation and use it to change what is happening in your society, in your community, in your neighborhood. So you cannot disconnect your responsibilities as a citizen from your inspiration as a photographer. So when you match these two things is when, for me, you have a conservation photographer.

I'm trying to solve problems with overfishing, I'm trying to solve problems with ocean pollution, and again, I'm not sure how good I am doing as a conservation photographer. For example, last year, for the last two years since 2016, I participate with National Geographic, I am a National Geographic explorer and also a member of the Pristine Seas Project with Enric Sala, I've been working with Enric Sala for 20 years and his initiative, Pristine Seas, and my initiative, Mares Mexicanos - Mexican Seas. We joined forces to inspire Mexican society and to help Mexican government to declare this archipelago that now is the largest marine reserve in North American. What we did, we went to that archipelago. We did science, we put together the science, we created a report with pictures. We created a social media campaign with the pictures and then we put together a video and this video was presented in different theaters in Mexico and we work as well with the minister of the environment, and we push, and we have a lot of discussions and fights with the fishing industry, now I am not necessarily the most... I don't have fans in the fishing sector in Mexico, especially in the tuna fishing sector right now. But this is all together finished in November last year when the Mexican president signed this declaration of this big reserve. And it wasn't only pictures, but the pictures were fundamental, especially when we wanted to say this is a very, very pristine area. This is a very, very natural area.

You cannot go with young guys and say, look at the graph, and look at the graph of the biomass of sharks. No! You show the sharks. My mom now understands why I went to that place and why I was very involved in asking the Mexican government to protect this area. So this is the way that you inspire people, but a conservation photographer cannot just say, "oh yes, I took the picture that inspired people." No, you need to go to a politician and show the picture and say, "You need to protect these!" You need to go to the fishing sector and say, "Here is the picture, you are fishing this and you are fishing this illegally." You need to take the picture to your mom and say, "Mom, you need to raise your voice because this is part of the Mexican heritage. Not only take the picture, you need to use the picture to create a statement and to convince people that we need to make changes in order to preserve these important natural resources. 
Chris Jordan is a Seattle resident whose recent work is focused on Midway Atoll, a remote island roughly midway between North America and Asia. There Chris Jordan's photo and video work swirls around ocean plastic pollution, Albatross, human consumption, love, and the beauty of our world.

\section{Website: www.chrisjordan.com}

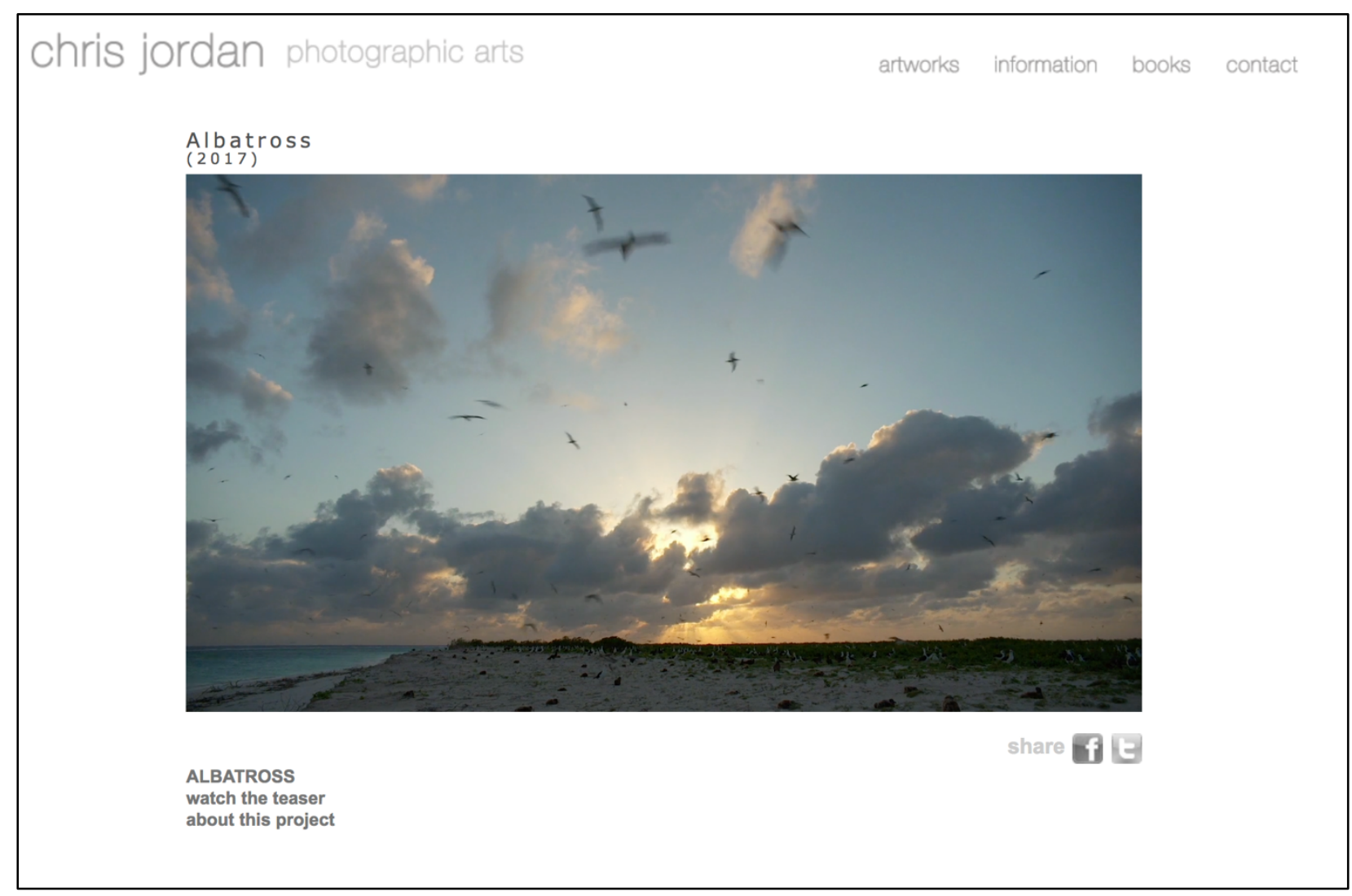

Upon entering the main part of Chris's garage studio the first thing my eye is drawn to is multiple gongs hanging on the wall, each at least five feet wide. The space is filled with materials and art can be seen everywhere, down to the paint splatters on the concrete floor. A deep couch sits in front of an iron worked coffee table that holds a Buddha statue and some hammer options for playing the gongs. The windows are blocked off with cloth and Tibetan prayer flags decorate near the ceiling. A long panoramic photo of a field of albatross hangs on the garage door. Chris is barefoot and has a big welcoming smile on his face.

My dad was a photographer, so I learned photography from him, and my mom was also a watercolor painter, so I've been immersed in art for a very long time. But I took a sort of side trail into the practice of law for a decade. I went to law school and became a lawyer and worked for a decade in Seattle as a lawyer and was terribly unhappy that whole time. I was just quietly 
dying of depression in the Seattle legal world and I was photographing all that time. That was my passion even before law school, I just didn't have the courage to do what I loved, to take the risk of failing, but when we don't take the risk of failing, we also don't allow ourselves to take the risk of living. Because to fully live you have to take the risk of failing and that's when life becomes an adventure. It took me until age 38 to find the courage to take the risk of failing and I finally left the law practice and can't even believe what's happened to me since then.

I left the law firm that I was working at and people kept telling me if the art thing doesn't work out, you can always go back to being a lawyer and I was really afraid I would make that come true. The little self-sabotaging devil on my shoulder was like, ah, that means we can fail as an artist and we still have a safety net. So I walked into the Washington State bar office and I said, I would like to resign my license to practice law. I remember the secretary there, she was really funny. She said, "Well, no one's ever done that. We don't even know how and you shouldn't do it anyway because for just like $\$ 5$ a year you can go into standby status and then if you ever want to come back to full status, you just start paying your normal dues again and you don't have to do anything." I was like, I know, that's exactly it. So it took her awhile, she's going through all these forms and finally found a form and I signed the form and I walked out of that office feeling like I was floating about three feet off the ground.

I was in therapy at the time, had a really good therapist that I worked with for many more years than I ever thought I would. He helped me see that in the law practice I had been motivated by fear all these years. I mean, I knew that. I was afraid to leave the law practice because I was afraid of failing and I had this horrible scenario that I imagined. It was that I would end up as a homeless drug addict and I gave myself a very high chance during all the years that I practiced law that I would fail as a photographer, run out of money and be too ashamed to tell anybody about it. I didn't have any real deeply supportive friends at the time, so I'd become lonely and alienated and turn to drugs and alcohol to medicate myself and lose all my stuff and get kicked out of my apartment and end up as a homeless drug addict. I was really afraid that would happen to me. That was a fear that wasn't a motivating fear, it was a stopping fear. It was like a wall in front of me for all the years that I was a lawyer and I couldn't figure out a way over or around or under that wall. It was just this massive thing.

Every time I got to the idea getting out of the law practice, every time I'd hit again that wall again. I'm going to be a homeless drug addict. My therapist helped me connect with another fear that's a thousand times scarier than that, because I thought the fear of failing, fear of becoming a homeless, drug addict was the scariest thing I could possibly think of. But there's another fear that's a thousand times scarier than that and that's the fear of not living my life, the fear of becoming old and realizing I didn't take the risk of living. That is a motivating fear, that fear felt to me like a giant cowboy boot kicking my ass all the way over the wall, and so that was the fear or a new kind of motivation to take risks. Ever since then it's been really easy for me to take what other people see as being super gnarly, courageous risks. Like right now, I just worked for eight years on my Albatross film, eight years and I've had almost no income. It's just trickled in, I've almost had to declare bankruptcy like four times in the last eight years and I could sell my film for a couple million bucks, but I'm giving it as a gift to the public just because it's the right thing to do, because I want to. It's a huge risk, but it's easy for me to do because I want to know what it's like to fully live, to like make a gesture toward integrity. I want to know what that feels like and send out Albatross into the world with a beautiful energy.

I gave up a decade of my life to learn how much I don't care about money and how much it costs in terms of spirit and energy and time when that's the focus. I just decided I don't care if I 
lose my apartment or lose my house and have to sleep on friend's couches or whatever. I don't care about money, I'm just going to do the work that I'm called to do. So, right from the beginning I've not done what all of my other professional photographer friends do, which is jealously guard their images and you only get to legally put a shitty quality, little jpeg version on your website with the huge watermark. So nobody could use it for anything without contacting you and paying you. I'm the other way I'm like, take it, if there's anything you want to do with it, no problem. And if you have some money to pay me, that'd be great. Otherwise whatever, publish it or use it on your website or put it in your publication or whatever.

Originally I wasn't particularly interested in anything marine. What I was focused on for a very long time before that was mass consumption and really the deeper interest there is collective consciousness. That's what I'm really interested in. If you trace the problem of our mass consumption upstream, whether it's the amount of minerals we're extracting from the earth or that our forests are being cut down or our oceans are being polluted or violence of all kinds around the world as well. Exploitation, all of those things. One way you can see those is as individual problems that all need to be solved and there are millions of activists working on all of those problems individually. In another way you can see all of those things as being symptoms in the physical world of a problem that lives literally in another dimension. If you go all the way upstream to any one of those problems, you finally arrive at our culture, which is something that lives in the dimension of our consciousness. So that's what I've been interested in for a really long time, sort of looking out at the horror, not to say we need to solve that problem, but as a mirror for what's going on inside our mind that gives rise to that problem.

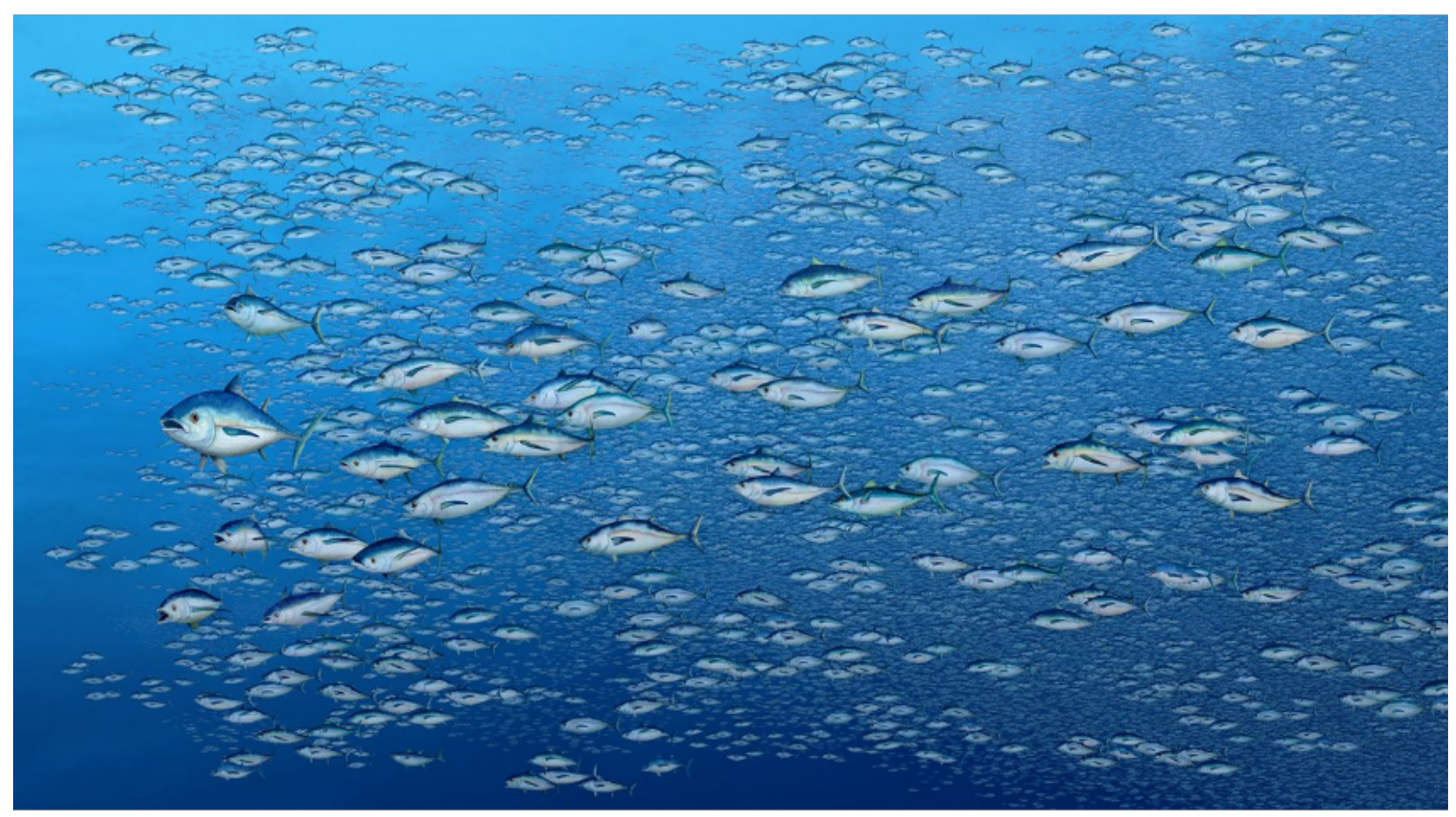

Title: Tuna, 2009; Caption: Depicts 20,500 tuna, the average number of tuna fished from the world's oceans every fifteen minutes; Details: $64 \times 115$ ", made from nineteen watercolor paintings by Sarah Waller; Credit: Chris Jordan 
I learned about ocean plastic pollution in 2008 and it arrived to me as another one of those massive global catastrophes that's invisible, that we read about. We read numbers in the hundreds of tons, or the millions of tons, or billions of tons, but you can't see it. It's spread out over the entire earth. And I've always had a concern about those issues and that's what the whole Running the Numbers series is about. That series is an attempt to visualize these statistics about our mass consumption that are otherwise invisible to us. If you can't see the thing, then it's really hard to comprehend it and hard to feel anything about it if the only information we have available to us is numbers that are far beyond our ability to comprehend. Reading a statistic about the number of plastic bottles that we use, which is 210 billion per year in the United States and that's an old statistic. For the number of plastic bags, it's like more than a million plastic bags per second in the world. I can't remember that number exactly. Some atrociously massive number. And a million pounds of carbon per second are being emitted into the atmosphere. Imagine if the way our world worked is every time you use a plastic bottle, there's one pile of plastic bottles where they all go and you had to personally go to that pile of plastic bottles, which would be many times larger than Mount Everest and throw your bottle onto the pile. You would stand in front of that thing and it would change your life in a moment. It would be absolutely mind-blowingly shocking. But the scenario that we have is that it all goes away. It all just disappears into waste streams that disappear into landfills. So the only information we've got to try and comprehend an issue like our plastic bottle consumption is these numbers that are far beyond our ability to comprehend. Ocean plastic pollution is like that.

There's no Pacific Garbage Patch. There's no place where it all swirls to the middle, where you could go and float your boat and look into the horizon and see only floating plastic garbage and go like, oh my God, now I get it. In 2008 I thought that's what it was like, I had just heard. That meme got released into the public consciousness by a Ted talk and I thought there's a floating island of garbage in the middle of the Pacific Ocean and I wanted to go there and float to the middle of it in a boat, climb to the top of the mast with my camera, and make a panoramic image of horizon to horizon floating plastic garbage that's going to blow everybody's minds. I quickly learned from the scientists I started talking to that there is no such thing. The plastic breaks down into smaller and smaller pieces all the time. It's down in the water column, a huge percentage of it sinks and then the vast majority of all of it that's floating is smaller than a millimeter. So you can't see it even if you're swimming in it, and it's spreading and spreading and spreading out over 60 million square miles of open sea in the Pacific.

These guys all said that plastic behaves in the water the same way smoke behaves in the atmosphere. It doesn't collect someplace except like on the side of a building or where it washes up at beaches. I was in a meeting of a bunch of scientists and somebody said that, they said you can't photograph the Pacific Garbage Patch. I slapped my knee in frustration and I said, "Damn, I'm a photographer, I want to go take a photograph of the Pacific Garbage Patch" and there was a young woman who was a scientist sitting next to me who turned to me and she said, if you want to take a photograph of the Pacific Garbage Patch, go to Midway Island and look inside the stomachs of dead baby albatrosses and I'll never forget that moment. Her name's Anna Cummins. She's a really amazing ocean plastic activist, one of the world's leading ocean plastic activists now. She had been to Midway and she had seen that phenomenon and I immediately just felt this magnetic pull to go to this place and experience that. 
At the time I wasn't interested in albatrosses. I wouldn't call myself a bird lover, but just a general nature lover. I'm into backpacking and I love nature, and I would have called myself an ocean lover just because I love oceans, I love mountains, I love forests, I love deserts, and I love nature, but I didn't have any particular thing that drew me to the oceans. I was interested in the plastic. That's why I went to Midway. It was only when I met the live birds, and this was on the second trip, on the first trip I was there at the time of year when all the birds were gone. So I never met a live albatross. It wasn't until I went there the second time and I met the birds and encountered these magnificent beings who have no fear of us and there's a million of them on this tiny island. Like you have to carefully walk not to step on them. They don't run away and fly away and they're as big as eagles, their wingspan is about a foot longer than mine. When I met them, I slowly just began to feel this reverence for these beings and started to fall in love with

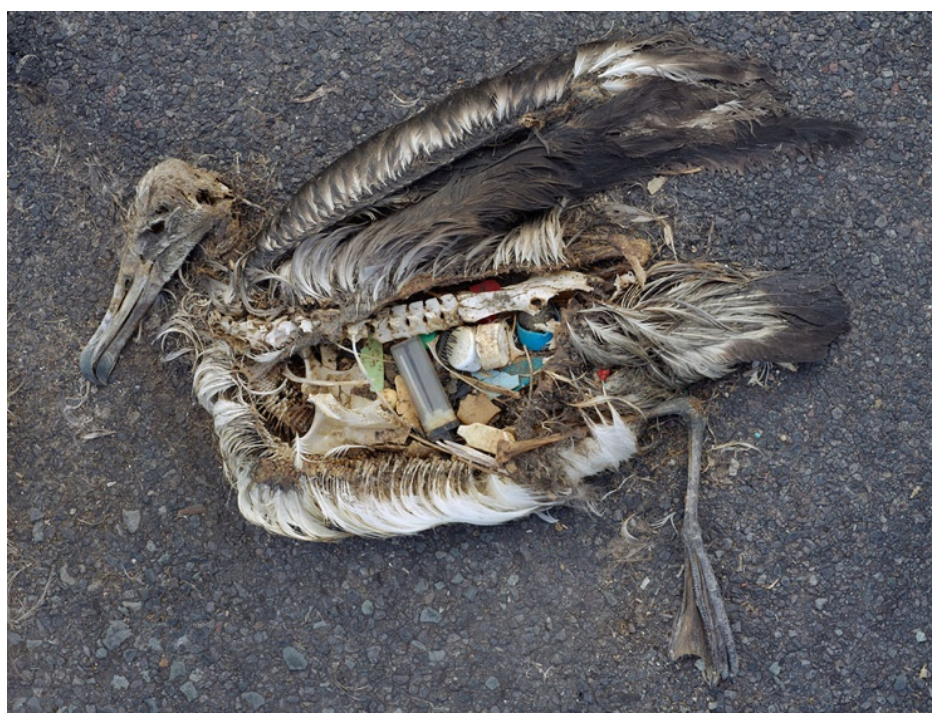

Credit: Chris Jordan them and then also the island they're on and the Pacific Ocean that they live in. It was a slow process, I went to Midway eight times total. Every time was very expensive and challenging.

When I think about conservation photography, I think about the complex relationship between the bad news and the good news, between horror and beauty, and on one hand it's easy to focus on the bad news and make images that look really bad and there are a lot of people doing that about plastic in the ocean and there are a lot of documentary films that are being made. I saw this on Midway Island, the first time we went to Midway, I fell into that same trap. We went and there's a little corner of the harbor when the wind blows at a certain angle, all the plastic that would otherwise wash up on the beach comes to the corner of the harbor. If that does that for a few days the corner of the harbor is a 20 foot by 20 -foot floating mass of plastic junk. If you go with just the right lens and film the corner of the harbor, without showing that there's miles and miles and miles of clear open sea and even the whole rest of the harbor looks okay, if you film with just the right lens you can make it look like the Pacific Garbage Patch is a real disaster. Then if you put on scuba gear and go underneath and film that one little corner of the harbor, just floating plastic garbage, it looks horrible. There's certain beaches on Midway that face a certain direction and when the wind is blowing there's a lot of plastic, and if you go up close so you can find a lot of plastic on the beach. As a conservation photographer, if I want to make the issue of ocean plastic pollution look really bad I can focus on that, leaving out all the good news and conversely you can do exactly the opposite. You can go to a city park and take a really beautiful picture of a cedar tree that carefully avoids the container facility that's right on the other side, or the power lines or whatever. Or you can go to a national park or go to a zoo and take a picture of a tiger that looks just like it was taken in the wild and conservation photographers do both of those things. My question is how to really authentically be a conservation photographer, how to not exaggerate in either direction. I have no idea what the 
answer to that is, but it feels to me like the medium of conservation photography is letting go of an old story and we're transitioning into a new story that's more relational and more authentic and its more sort of whole. It's less one-dimensional, less binary.

I think my previous work was also a little more one dimensional or I would say just a little more dimensionally narrow. Albatross is much broader than anything I've ever done. And with Albatross, the range of responses, like I was at the ocean film festival down in San Francisco just a couple of days ago, and there were maybe 20 emails that came in from people who saw it and it ranged from one guy who said just what I always dreamed that someone would say which is he didn't talk about plastic at all, didn't talk about oceans, he talked about beauty. He said something like, you helped remind me of the beauty of our world and love that we're all made of. Then on the very other end of the scale, somebody writes and says, thank you for raising awareness about our need to reduce plastic consumption and that's the thing that I'm least interested in, but everybody meets it where they're at and there's this sort of broad response from a very narrow interpretation, specifically around plastic. My least favorite response to my film is somebody comes up and says, I recycle, and a lot of people do that. As if I'm the plastic police and they just recycle then everything's okay.

I think the biggest challenge of conservation photography is helping people or getting people to really understand our interconnectedness. Our inter-being with each other and with the world because we've categorized the world in so many ways and divided everything up into individual problems as if racism and ocean conservation have absolutely nothing to do with each other. In fact, they're incredibly closely connected because they come from the same fear, the same fear which lives in collective consciousness. The destruction of our environment and the distraction of each other, the exploitation of each other, the fear and hatred of each other is the identical cause. Fear of scarcity, fear of the other, fear of the unknown, of a worldview that's based on a core belief that we have to each compete against each other and everything that I get is at your expense and everything that you get is at my expense. That our fundamental job is to take as much as we can for ourselves, for our own self-preservation.

One of my favorite lines in the film that nobody has made a comment on yet, but to me it's really goes to the heart of that is when you see the baby albatross sitting, waiting for its parent to come home and I say, "The parents serve as a living umbilical cord from the ocean to the stomachs of their babies. Every molecule of food, every bite of food they've ever eaten, every molecule their body is made of, came from the sea. In this way there is no boundary or separation between the Albatross and the ocean." I really hope that people get that we're exactly like that as well.

There is no boundary or separation between us and the ocean, or between us and the food that we eat, and between us and the atmosphere. It looks like there's a boundary or separation. We've convinced ourselves that there is. To really understand that our own health is dependent on the health of the oceans and dependent on the health of each other and the health of our world. Like to really get that, then there wouldn't be a category of people who are ocean conservationists and people who aren't, I really hate that there are people who don't think of themselves as environmentalists. It just breaks my heart that that's even a category.

Would I consider myself a marine conservation photographer? Well, that's really interesting because on one hand I would say yes. On another hand I even grate against the label of environmental photographer a little bit. Like eco artist, I hate that term because it sort of puts me in a category of a broken paradigm and I want to be one of the people that help break the paradigm. In the field of Eco Art there is so much hypocritical, finger wagging and binary, I'm a 
good guy, you're a bad guy, and you should all change. And I'm not the good guy, I'm in no position to, I mean my printer all by itself is the equivalent of buying like 200 new I-phones and I fly all around the world on jets. My personal carbon footprint is humongous and I don't beat myself up about it. We're all stuck in this paradigm, but I'm not in a position to wag my finger at anybody about their consumption and it's just not about that. It's not about telling other people that they're bad or that they should change their behavior. I don't think of myself as an Eco artist, I'm just a regular artist who's interested in consciousness and shifting consciousness and I believe on a kind of global level humanity is in between stories right now.

We're at a midway point, but like the old story of capitalism, militarism, our politics, our education, all those institutions are all in a state of collapse. None of them are working anymore. The whole exchange of money, none of it is working anymore and there's so much patching and band-aiding and like 'well if we just bring canvas bags to the supermarket then everything will be okay' and we can keep right on with the catastrophe. We're trying to hold on because we think that if we let go of the old paradigm it's going to be some horrible loss. We will all starve to death or there'll be violence or whatever. But I think there's a new story out there that I want to be a part of. I'm trying to make gestures toward it, like giving my film in the gift economy. It's a gift to the public under the new paradigm gift economy, completely outside of the whole world of capitalism. How could I make a film about birds whose bodies are filled with plastic knowing that the ultimate cause, the reason those birds are filled with plastic is because of, if you trace it all the way back upstream, it's capitalism.

You can't just say, all we have to do about those birds on Midway is go and take the plastic out of their bellies, but we can keep on buying, keep on doing everything else. Just go solve that one very specific local problem. That's ridiculous. Or all we have to do about ocean plastic pollution is go to take it out of the ocean. Keep pouring it in, keep all the rest of the catastrophe going, we'll just take it out. That to me is like, imagine if you had a stab wound. Someone just came and stabbed you and it went through to the lung and blood is gushing out of your body onto the ground and your only response is we have to clean up the blood on the ground. Here, I got a sponge no problem. Not looking at the cause, just only cleaning up the symptom. So I can't subscribe to the paradigm of capitalism at the same time as knowing that that's what filled my beloved birds with plastic. To me, to have integrity, I have to step into that new story. Even at huge personal financial risk. 
Bethany is a biologist and photographer with a passion for science communication and a degree qualifying her to do it. She spends a lot of her time underwater with dolphins in the Bahamas, but her focus is on storytelling about any marine wildlife and the scientists who study them.

\section{Website: www.bethanyaugliere.com}

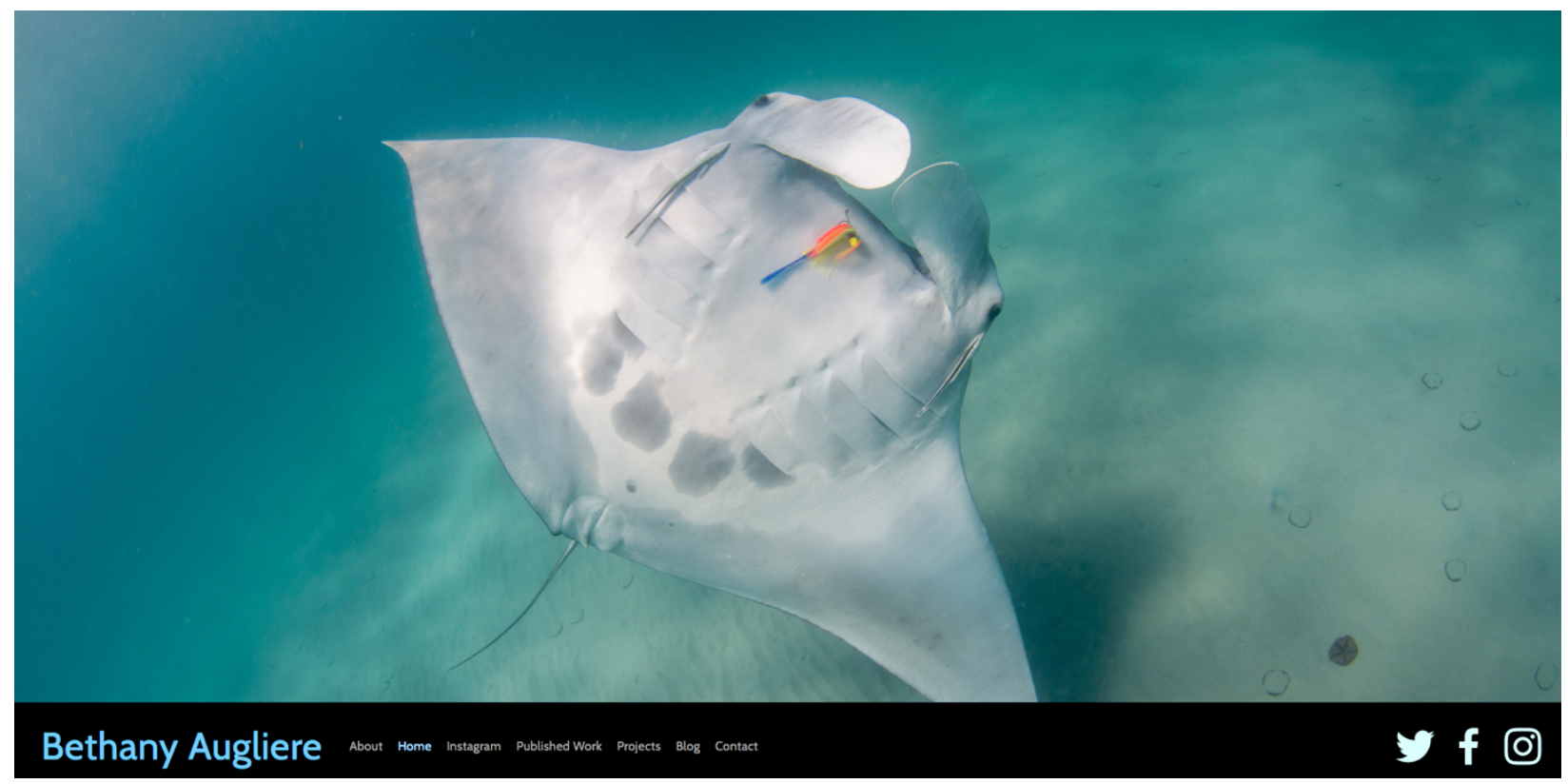

Bethany has just come from an interview she was conducting and is excited to be the interviewee for a change. She has a blue hammerhead necklace on and a cloth wall hanging with bright toucans on it can be seen in the background. It is obvious she is in the tropics.

My background is actually as a biologist and I did my undergraduate at Virginia Tech in wildlife science, but always loved the ocean, so did as many internships as I could during the summer in marine related fields. Then graduated and got a normal job with NOAA as a biological technician. That whole time I loved photography as a hobby and I traveled a lot. So I just took pictures of the animals I saw and my skills as a photographer grew in that sense. I went from just being like, "I'm going to document this bird I'm seeing," to, "I'm going to try and get a nice shot of it or wait for it flying or doing something cool." So then I went to grad school in 2009 with Denise Herzing of the Wild Dolphin Project and did a master's thesis looking at movement patterns and habitat use of spotted dolphins in the Bahamas. So I lived on a boat for 10 days at a time all summer long and my job as the graduate student research assistant was to take underwater pictures of the dolphins for photo ID. I had a GoPro, so I had done a little bit of underwater photography myself but didn't have the gear or the equipment to really do it well, but spent a lot of time taking pictures of dolphins with little point and shoot cameras for research so 
that we can identify them. Denise has been studying these animals for over 30 years, she started in 1985, and there's only about a hundred of them at a time, so we know them all by individual spot pattern and we know who their moms were, who their grandmothers were, who's been bit by a shark, who likes to play with seaweed. So we have all these really cool stories of their individuality and I was sitting here thinking there's all this great information on these animals and it just kind of stays within the scientific community and how cool would it be to inspire others to love the ocean through getting to know these dolphins and their lives, the stories of these dolphins. So I talked to my boss about that and she let me start blogging for the project. So doing stories on certain individuals and sharing photos on social media. This whole time I'm exploring the fact that I really love storytelling in addition to science. I'm becoming obsessed with other National Geographic photographers, I'm watching documentaries and flipping through the pages of magazines and sort of discovering the field of what it means to be a photographer. Then I left my job in 2015 to pursue this more seriously and I actually did a graduate program in science communication at UC Santa Cruz.

So I knew that I loved photography. I knew that I wanted to get into this storytelling, but I had no idea what that meant or how to do it. I had just been taking pretty pictures of dolphins for the past however many years, six years, and other animals. So I applied and got into the UC Santa Cruz Science Communication Graduate Program, which taught me how to write. It taught me what journalism was. It taught me what science communication was and opened up my eyes to this whole new world. Even though it kind of focused on writing it introduced me to the editorial world. Once I graduated that program, I just started asking scientists to go out and document their work and pitching stories. I was a biologist first and decided that I wanted to have a greater impact by sharing stories as well as doing the research.

Conservation photography makes me think about taking images that have a meaning, that inspire people to take action, positive action for the environment, or show people the plight of wildlife and ecosystems. So I think its images that have an impact on conservation and inspire people to take action or tell a story about the environment that's going on, but I don't think it always has to be negative. Like I think we can get wrapped up in, they are important photos, but the shocking photos of the rhino without the horn. I think there's something to be said for images that are also just really stunning that make

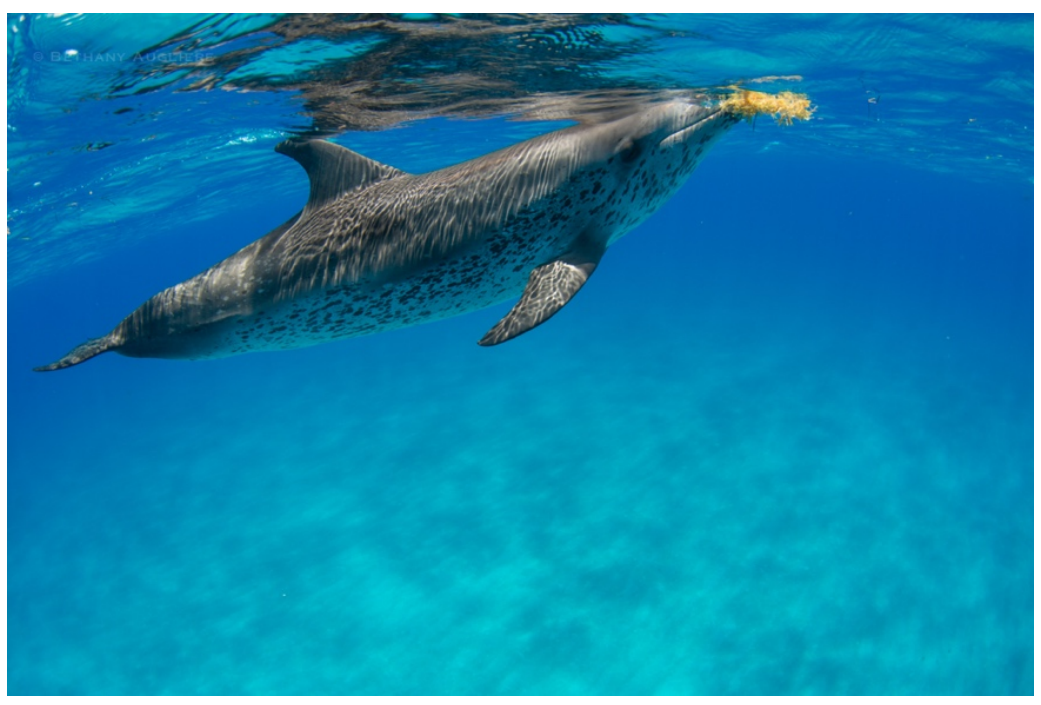

Credit: Bethany Augliere people interested in an animal, right? So like the dolphins that I was working with weren't necessarily endangered, although they face threats from boats and climate change and all that. But if I could get someone interested in the ocean by just sharing a cool photo of a dolphin, that to me is also conservation photography. 
Most of the response is really positive. I don't have a huge following on social media, but I do a lot of posts and I'll share images of the scientists working with the animals and I use my social media professionally and so I try and use it as another platform to share conservation photography. So my captions are like little mini snippets of journalism and science writing and I get lots of feedback there that people love the work I'm doing. They love learning, they love sharing these stories. I know the scientists that I work with are always really appreciative usually if the story is getting out there and it just seems positive like people like learning and like hearing about this kind of work. I think people, well maybe because it's my circle of people that I interact with, but the people that are coming to my talks or to the exhibits or reading my stories, they generally value this work and think it's important, which I'm sure not everybody does.

Since I'm a freelancer, I try and think of species in my backyard because that's what I have the resources to shoot. I'm not traveling around the world right now, maybe one day. I reach out to them and say I'm a freelancer and that I want to do stuff on Florida's endangered species and so they bring me out to the field. Then I try and get a portfolio of images that can tell a story. In that case, like I am working on a story right now which I'm excited about for National Geographic and I pitched the story based on the photos I have. So one way is just pitching, right? So I go out, I build a portfolio of images and from that I can pitch a story. Because I have a lot of journalist friends that are science writers

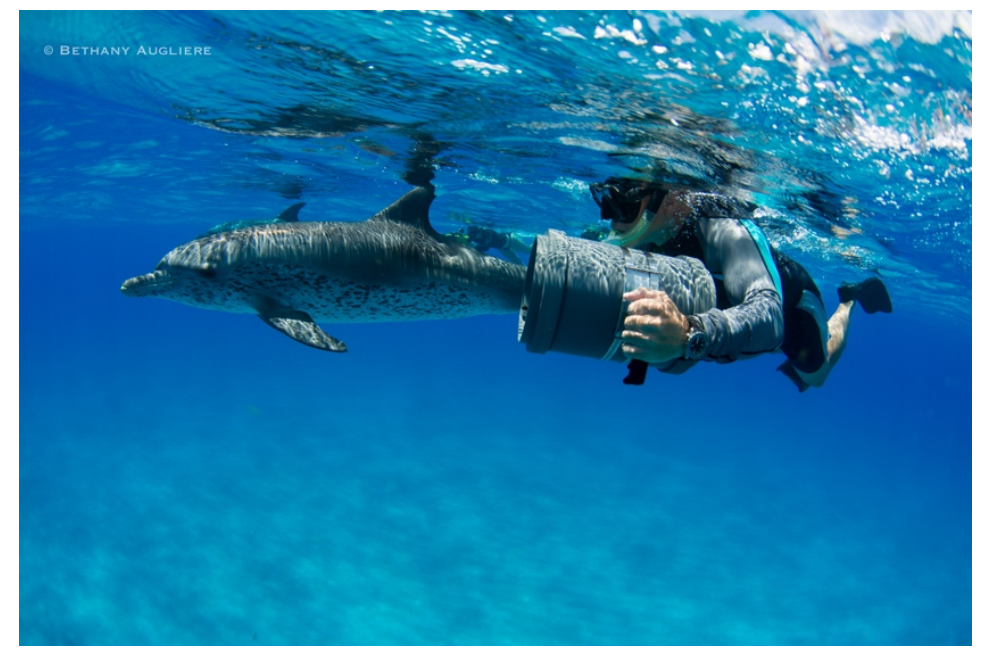

Credit: Bethany Augliere that need art sometimes they come to me. So for Mongabay for example, I knew the writers and they needed images and they're like, can we use yours? Or, you know, can we license these? There was one assignment where I was working with a biologist and she knew that a magazine was covering her work and so she told the editor that she had a photographer working and the editor of the magazine reached out to me and was like, we would like these images, can you shoot this for us? So I'm not really, you know, I'm not established enough where places like Nat Geo are calling me up and being like, "Yo, go shoot a story on manta rays for me." But one day hopefully. So most of it is me putting in the time getting images and then pitching to editors.

A lot of marine field work takes place out on boats, so for the scientists there's limited space even if they want to bring you on. If you're on staff for a magazine, they'll often pay for your spot on a boat to like fund your spot. So for me as a little freelancer, convincing people that I'm serious enough, that I'm worth their time to invest in me coming on their boat and giving me time and space on their boats can be challenging. Although for the most part so far people seem to be pretty appreciative of interest in their work unless they're already getting a lot of big attention. So finding connections. So what I've done so far, which has worked out, is I reached out to graduate students or scientists that don't have a long-established project. They haven't been featured in Nat Geo or BBC, so they're willing to give me the time because they know it's good for them to also get exposure. So that has been challenging but good. Getting space and then just like the shooting can be really hard. Like you're dealing with rough seas and animals underwater 
that you really need to get close to. It's not like I can put a telephoto on and shoot an elephant really far away. I have to be really close to my subjects. I also get sea sick which sucks as a marine biologist and as a photographer. I just have kinda learned to deal with it. It can just be difficult shooting conditions and like anything, finding things that are easily accessible. Like when I do, you know, one of the projects I'm working on is also the dolphins of the Bahamas, and that's because I have access to it because I go on the boat and have a relationship with the project because I was a graduate student. So if not, I would have no way of being able to afford that.

I don't only and haven't only done marine stuff, but that is sort of the field that I'm trying to most identify with because I think trying to do everything is hard. So if I can sort of find that niche and kind of own it and claim it and get to know the other people that are working in that world as well, that's probably better. I haven't yet like labeled myself a marine conservation photographer. Like in my social media or anything like that. But that's most of what I do so far.

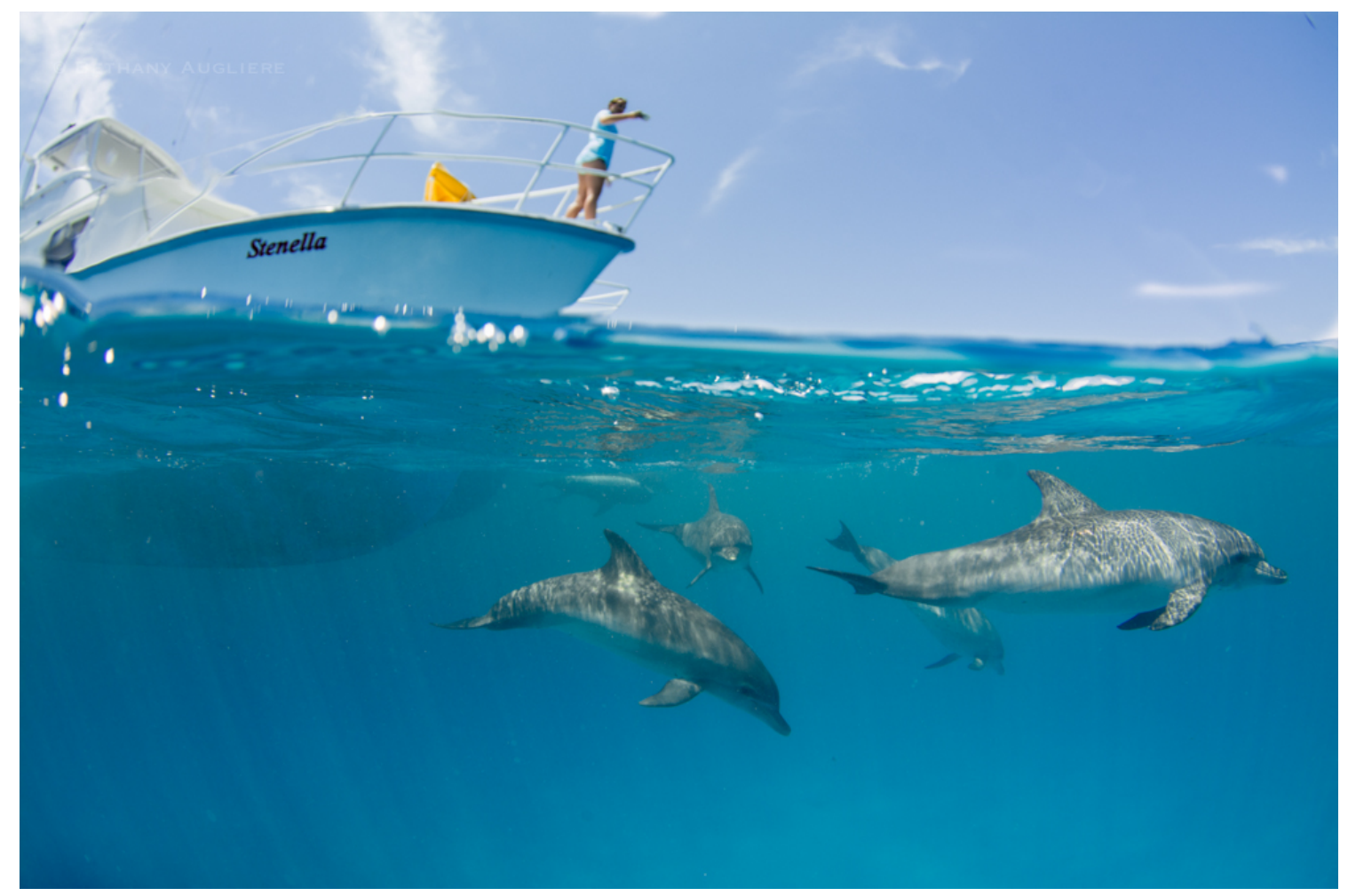

Credit: Bethany Augliere

Marine conservation photography would be raising awareness I think, for the threats that the oceans and ocean related ecosystems, so like the coastal ecosystems, face, and then what we can do. What's important work being done to either study that or see it in some cases. Yeah. So I would say marine would include like if you're working on ecosystems that are land based but related to the ocean that would still be marine. It's like anything related to the ocean and it doesn't have, that doesn't mean it has to be under water, right. Like if you're shooting a story on the shark finning trade, I still think that's marine because sharks are apex predators in a marine ecosystem and valuable. So, by telling the threats there, you know, by sharing the threats that 
they're facing and how that is impacting the whole ecosystem. That to me is still marine conservation photography. 
Tanya Houppermans is a Virginia-based mathematician-turned-photographer who travels the world on assignment. Her subject focus is on sharks with a goal to educate and inspire others towards their conservation.

\section{Website: www.blueelementsimaging.com}

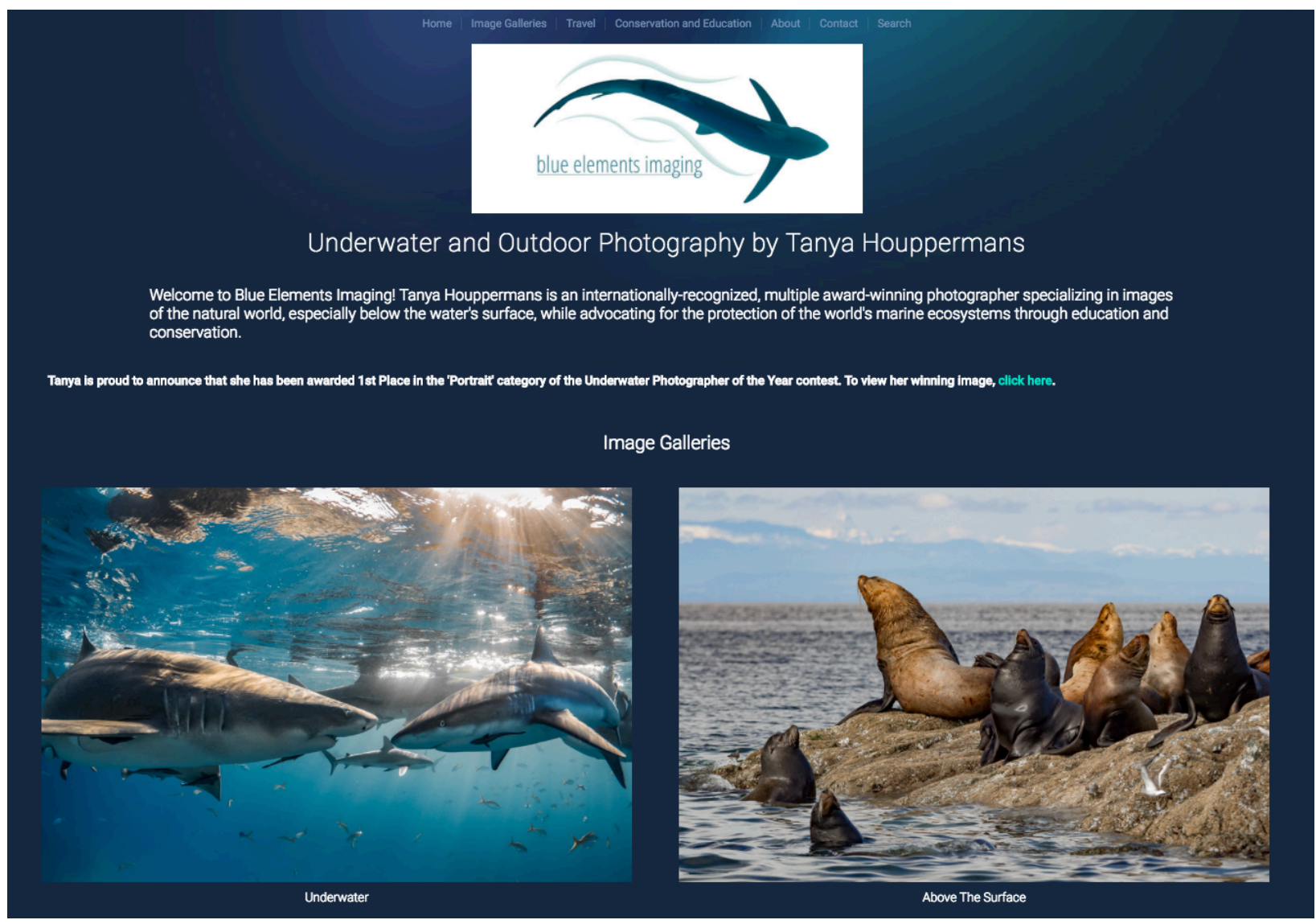

A bright blue shirt with a shark silhouette on it indicates clearly the animals Tanya loves the most. A dive flag as part of a painting in the background shows how she gets close to those animals. She speaks clearly and passionately about sharks and her journey into her newfound career.

I'm actually kind of still in the process of defining my career because this wasn't something I said, "oh, I want to do this when I grow up." Actually, growing up in the late 1970s in the age of Jaws and growing up in southern California, this was the last thing I ever thought I would be known for around the world. Being a shark photographer. So there are all sorts of things I wanted to be growing up. I wanted to be an astronaut. I wanted to be a doctor. Science was definitely the common denominator, if you will forgive the pun because I ended up with a degree in mathematics. I studied math and physics in college and I got my degree in math and I 
went to work, I was a mathematician for the Department of Defense and then I moved over to the corporate side and I absolutely was miserable sitting in an office.

I was a diver and so the more that I was around sharks, especially the sand tiger sharks at North Carolina, which is convenient for me. I live in Virginia, so it's about a five-hour drive for me to get down to North Carolina. I really fell in love with those animals and so I started around 2012, started to just kinda do some research about sharks and shark populations and was absolutely shocked to find out about shark finning and the decimation of shark populations worldwide. Because I realized that I had been mistaken about these animals. So everything that I saw from Jaws or everything that the media portrayed and actually a lot of things that I saw on Shark Week, which is ironic because I work with a lot of those guys now. So once I found out the dire situation sharks were in, I wanted to do something to help and it still did not occur to me to pick up a camera. I ran a marathon and raised a thousand dollars for Shark Savers and did that, but I still felt like there was more I could do. I knew a couple of photographers and so basically in 2014 I bought my camera and my knowledge of photography consisted of knowing what a camera looks like. I just quickly started to teach myself and going on as many trips as I could to hone my skills and it was one of those things that came naturally to me. I know a lot of people don't want to hear that because you know, they struggle for years and years, which is what I expected to do. I mean, there are other things in life that I will never be good at no matter how hard I try, but photography was just one of those things that came naturally to me.

So in 2015 I was able to make the break from the corporate world and move from sitting in a desk all day to doing what I do now. But the main purpose, the purpose of the photography was never to have images hanging in a fancy gallery somewhere, it was always going back to making people care about these animals. There was also another reason that I picked up a camera and that was also to document my son's journey as a scuba diver with autism. And so the way I saw it was kind of a win-win. I could use my images to dispel misconceptions about sharks and also dispel misconceptions about what people with disabilities are capable of. So how I got here certainly wasn't a just straight and narrow path.

Today I'm sitting here working on a presentation and next week I'll be flying out to Singapore for ADEX, which is the Asia dive expo, and this year's ADEX is dedicated to everything sharks. So I'm giving two presentations and one is actually titled Making a Connection: Using the Power of Imagery to Inspire People to Care About Sharks. So how do we use these images to not only change minds, but then take it a step further to get people to actually do something about it? So for my presentation, I broke it down into a few things and we can get into more detail if you'd like, but the basic topics are first and foremost, we want to educate. We fear what we don't understand. So you can't feel this connection. You can't feel the need to help or to do something if you have fear, it's just not going to work. So first and foremost is just educate on the importance of sharks to the ecosystem. You know, a little bit about shark anatomy and physiology, just understanding them. The next step would be dispelling misconceptions. What you see on so much of the media is not true. You know, people think if you get in the water and there is a shark within 10 miles, it's going to come over and eat you. The truth is the complete opposite because I've been in the water where there are big tiger sharks and hammerheads and we can't get them to come close enough to even take a picture of them because they're as scared of us as we are, as some people are of them. So I want to dispel those misconceptions.

Presentations are a big one. To the general public, to the dive community, to basically anybody who will listen. Another way to disseminate is through magazines, through publications 
both online and in print. A lot of online nowadays because print publications are becoming fewer and far between with digital media. Speaking of media, the general media, for instance I worked with a news agency that picked up a series of images taken in North Carolina last summer. A sand tiger surrounded by this massive bait ball of fish. Those were picked up by a news agency that I worked out with and those images were seen in newspapers and online publications all over the world. So having that sort of platform really helps a lot for the general public, because the dive community, sometimes you're preaching to the choir sort of thing, although there are still a lot of divers who don't dive with sharks and may not understand. Speaking to little kids, I'll go and talk to schools and little kids and get them interested while they're young and that definitely helps too. So there are a lot of different platforms to use. There's no real one way, there's a lot of little ways that I do this and, you know, juggling a lot of balls in the air. But that's what you have to do. That's what you have to do. Just disseminate as much as possible.

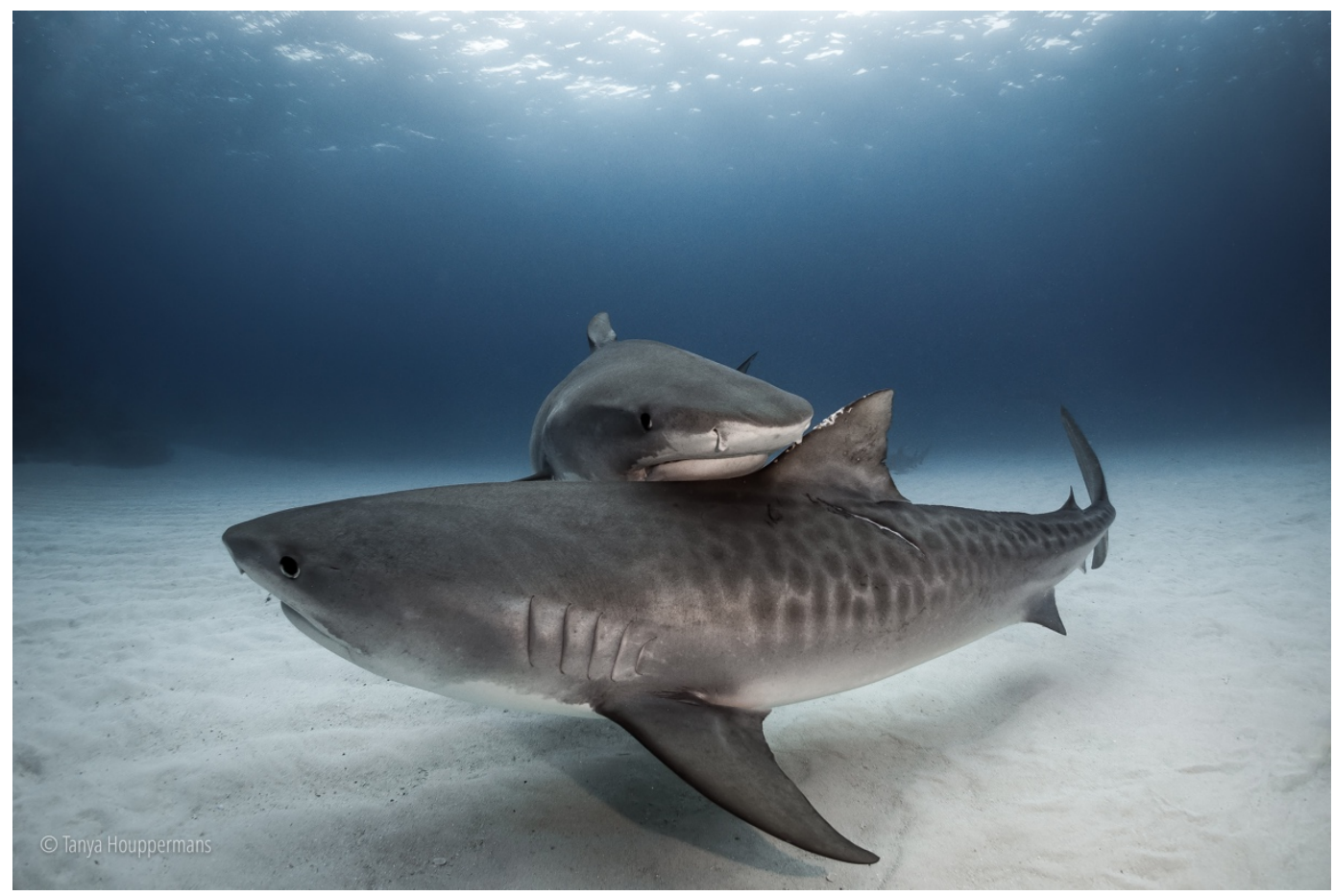

Credit: Tanya Houppermans

I think one of the big changes is how images are disseminated. Again, we're seeing less and less print publications and more and more digital media and a lot of the problem with that is that digital media doesn't pay as much or as often as print does. So for those of us going out there and doing this, we need to earn money somehow. This is still a job. You know, I still have to pay my bills, I still have to maintain and upgrade my SCUBA equipment, my photography equipment. I think it's only going to get tougher and I don't see a lot of people being able to do this. Maybe on a part time basis, but full time not so much for specifically those of us who are videographers or photographers. Now conservation as a whole, I think there might be more opportunities, but if you're just talking about making the images and making the films, it's going to get tougher. Which is a shame because we're the ones bringing these images of these animals 
to people in their homes and so you need people like us out there doing that. But we need to be able to buy food and pay our bills too. So it's just a sad fact that that's just how it is.

Because I've only been a professional in this for, well, since about 2015. I started taking pictures in 2014. I guess that it's only anecdotal as far as the bigger picture, but we do see more and more people being informed about the plight of sharks, about the ocean and a lot of that has to do with environmental movements, they're getting bigger these days. There's more interest in them and you have a lot of celebrities spearheading that which certainly helps. So I think that attitudes are being changed. I think as a society we are becoming more environmentally conscious, more conservation minded, realizing we really need to take care of this planet we live on and all the creatures in it. On a personal level, I know many people who have emailed me later after seeing a picture or hearing a talk or something and it affected them personally such as they would go into an establishment that was serving sharks or shark fin soup and they would explain to the owner of the restaurant why that's not such a great idea whereas they would never have known that before. Or maybe they stopped using one of their brands of cosmetics, finding out it has shark liver oil in it. So things like that on an individual basis I do know about. So I think we are making changes in the positive direction. There will always be people out there who no matter what you tell them, are still going to think that sharks are monsters and you put effort towards changing hearts and minds. But then you just have to accept that some people just aren't and so you move on to those who do.

My favorite part of my job is actually being in the water with the animals. Being in the water at that moment in time, knowing that you are seeing something that very few people will ever get to see. And there have been many times when I'm in the water and I'm taking pictures and I think to myself, I can't believe I am right here, right now, seeing this. You know, I am swimming with tiger sharks at night or here I am above this shipwreck, surrounded by hundreds of sand tigers in this massive bait ball or big southern Stingray going by. So being in the water, it's the tiniest part of my job, but it's the best part of my job. A lot of people think my job is a permanent vacation. You travel around the world and you get to go dive. OK, but they don't see all the days I'm sitting right here at my desk editing photos, or writing articles, or answering emails or, you know, everything that goes on behind the scenes, you know, they don't see the times that I've been rocking back and forth on a boat, I do have a propensity to sea sickness. Horrible, horrible trait to have as an underwater photographer. Thank goodness for the patch or I could not do my job. They don't see me lugging 50 pounds of scuba gear, 50 pounds of photography gear, plus the rest of my luggage by myself through airports trying to get from point A to point B. It's stressful. It can be really, really stressful. So I guess there's a lot that goes on behind the scenes, but when you're in the water with the animals, you kind of forget about all that. 
In most of my images of sharks, I like to show them in a way that's disarming. You're not gonna find a lot of those gaping mouth because they're all over. You can see those anywhere you look. Google, "Shark," probably the first image that's going to come up is a gaping mouth. So I'm showing sharks in a way that's disarming, I'm showing the beauty of them. Even some humor, I have actually some really funny pictures of sharks, believe it or not. Something else that I like to do in my images is show eye contact, the eyes of the shark with the viewer. Again, that whole,

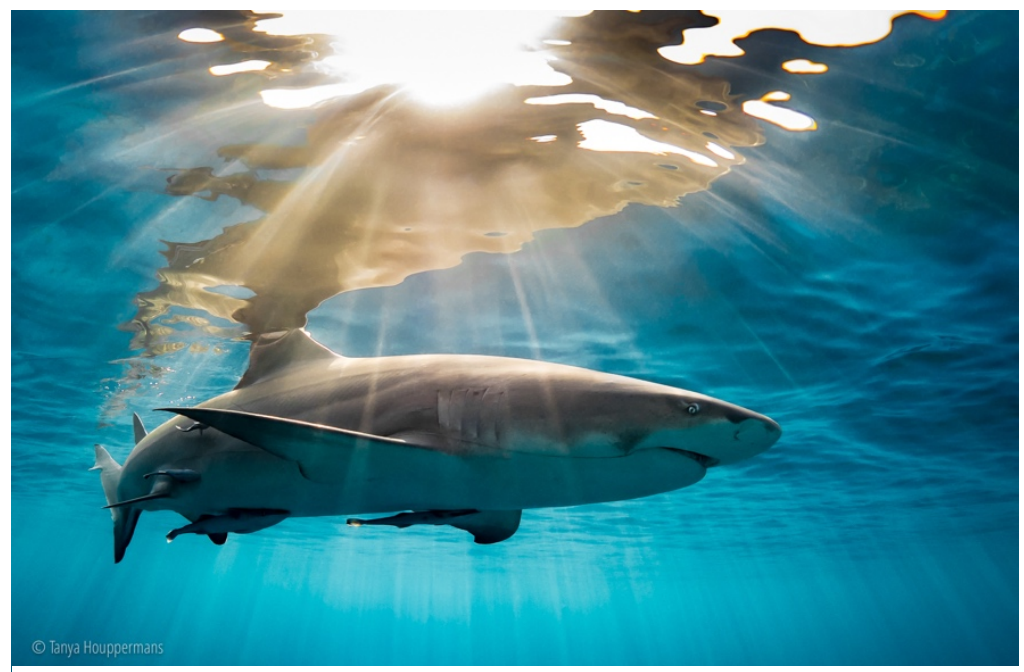

Credit: Tanya Houppermans you know, the eyes being the window to the soul sort of thing. We can't relate to a lot of animals in the water. We don't have fins, we don't have a tail, we don't have gills, but we have eyes. So just that connection with eyes, something we can relate to I think can be very powerful in images. Another thing is just to show images of the plight of sharks. You can tell people over $70,000,000$ sharks are killed every year. But that's so abstract. Just like if you hear on the news there's a natural disaster somewhere and 10,000 people died, and of course you think, oh, that's really sad and it's horrible, but your brain can't really wrap itself around it until you see a picture coming back from that disaster area and that's what I do with the sharks, show. I've come upon sharks that have been stabbed and people see the suffering of these animals and realize, oh my gosh, they can suffer too. They are not these mindless monsters. So I think that showing the plight of sharks and showing sharks in ways that people rarely see them, for instance, I dive with sharks at night. Not a lot of people see sharks at night and I think that's something that's inherent in all of these images, is that in the back of their minds, the viewers thinking, wait a minute, this lady was in the water with these animals. She still has all of her limbs. She wasn't in a cage. So maybe they're not as bad as we think. Some of the images have a lot of those different concepts. And never underestimate the power of beauty, showing the beauty of these animals to, again, getting to those emotions to make that connection, for somebody to have that emotional investment in these animals. And all other animals, I mean sharks are my specialty. I also photograph a lot of other animals, but this could very well go for a lot of animals in the ocean.

Whenever anybody asks what I do, I tell them I'm a marine conservationist and a professional underwater photographer because that is the ultimate goal of my photography. It's nice for people to have the prints to hang on the wall and everything, but ultimately it's to get them to care about these animals. That's the purpose and why I do what I do. 
